\title{
USING STUDY CIRCLES IN THE WORKPLACE AS AN \\ EDUCATIONAL METHOD OF FACILITATING READJUSTMENT AFTER A TRAUMATIC LIFE EXPERIENCE
}

\author{
by \\ BARBARA BARSKI-CARROW \\ Dissertation submitted to the Graduate Faculty of the \\ Virginia Polytechnic Institute and State University \\ in partial fulfillment of the requirements for the degree of \\ DOCTOR OF PHILOSOPHY \\ In \\ Adult and Continuing Education
}

APPROVED:

Harold W. Stubblefield, Chairperson

M. J. Cline

Marcie Boucouvalas
Ronald L. McKeen

Phyllis O'Callaghan

April, 1998

Blacksburg, Virginia

Keywords: Education, Workplace, Study Circles, Trauma

Copyright (C) by Barbara Barski-Carrow, April 30, 1998 


\title{
USING STUDY CIRCLES IN THE WORKPLACE AS AN EDUCATIONAL METHOD OF FACILITATING READJUSTMENT AFTER A TRAUMATIC LIFE EXPERIENCE \\ by
}

\section{Barbara Barski-Carrow}

\section{Committee Chairperson: Harold W. Stubblefield Adult Education and Human Resources}

\begin{abstract}
(ABSTRACT)
Employees who have had a traumatic life experience (TLE) and are returning to the workplace face a difficult road to recovery. The workplace as it exists today is not well equipped to handle such individuals. Managers and co-workers lack knowledge of a recovery framework to facilitate and support the survivor-employee's re-entry.

This research addressed the development of a cost-free short-term adult educational intervention called Study Circles to assist both managers and co-workers in understanding the dynamics of recovery for individuals after a traumatic life experience (TLE). Herman's (1992) three stage recovery process is used as a model for the Study Circle intervention: (1) Establishing a safety net, (2) Telling the trauma story and (3) Reconnecting the individual back to the work community. As an educational intervention, this Study Circle is designed to complement any individual or psychotherapeutic intervention for TLE survivors.

This research considered these questions: (1) How can Study Circles be designed and used to engage managers in a discussion of the problems of returning TLEs? (2) How can Study Circles be designed for and used by managers and co-workers to facilitate the TLEs re-entry? (3) Does a manager having previous experience with a TLE in the workplace engage more easily and intensively in a dialogue with a TLE than managers without such experience? (4) What examples of group-participation dynamics are likely to occur during such a Study Circle? (5) How open are managers to dialogue with a TLE in the workplace? (6) Does the environment and setting of a government agency have relevance for Study Circles in assisting managers to help returning TLEs?
\end{abstract}

The research clearly showed that Study Circles can and do work successfully in the workplace especially in a government agency. Two groups of Study Circles (Group A and Group 
B), conducted during the lunch hour, attracted both managers and employees. The lunch hour served as an excellent time for Study Circle sessions since it did not interrupt the work schedule of the participants.

Each Study Circle program consisted of three sessions where participants, managers and returning TLEs, engaged in open dialogue and discussed questions pertaining to creating a "safety net", "telling the trauma story" and "reconnecting the employee to the workplace." Each session provided insights to the participants on the issues and concerns managers may have in "welcoming" a returning TLE to the workplace, along with feedback from returning TLEs on the expectations they have of managers and the organization. These sessions provided an opportunity to explore uncharted territory in the organization, that of bringing a sensitive topic to the workplace and openly talking about its effect on management and its employees.

Both Study Circle groups were different. Group A was homogeneous and shared more feelings and suggested that the organization needed "guidelines to assist managers" in their task. On the other hand, group B managers did not share their stories or experiences with the group, but encouraged the organization to focus on training its managers to "communicate" better and learn "active listening skills." Although Group B managers were not as open as group A managers, the employees in both groups were equally open and eager to share their stories with the other participants.

Both groups created their own group culture engaging not only in the session's topic but other pertinent issues relative to manager/employee concerns such as acknowledging differences (each TLE will be different), communicating more openly, and recognizing performance issues when the TLE returns to the workplace.

It was concluded that to appropriately welcome a returning TLE employee, managers did not need to have previous experience in dealing with a returning TLE. Their success in this depended on the individual and his/her career experience, how comfortable they felt in engaging the returning TLE, and the managers own personal experience with trauma.

Although the Study Circle format has been extensively used in community meetings, church groups and home study groups, it has only rarely been tried in workplace settings. These Study Circles proved that this adult educational process applied in business and corporate 
settings with business and corporate settings with excellent results. 


\section{ACKNOWLEDGMENTS}

Throughout this research project from its inception and germination to the final product many people have contributed to its success. I would like to recognize especially the following:

First and foremost, my advisor, Dr. Harold W. Stubblefield, who encouraged and supported my idea and kept me focused along with assisting me in its accomplishment to him goes my heartfelt thanks and gratitude.

To the members of the committee: Dr. Jerry Cline, for his research guidance; Dr. Ronald McKeen, Dr. Phyllis O'Callaghan and Dr. Marcie Boucouvalas for their support and friendship.

A person cannot experience or live life to the fullest without the friendship of people one meets along life's path and the relationships one builds. Through this process, I have been blessed with the gift of friendship and support from the finest friends and mentors. They include: Dr. Louis M. Savary, who served as a mentor, guided my writing and gave me inspiration, Dr. Patricia H. Berne, Dr. Constance Condrell, Dr. Elizabeth M. James, Dr. Elizabeth Johns, Dr. Mary M. Bender, Mary C. McDonnell, J.D., Mary Krauser and Dr. Gabriella Belli.

To my colleagues at Virginia Tech who supported and encouraged my work. They include Dr. Brenda Lewis-Holmes, Dr. Faith Skordinski Williamson, Dr. Becky Domokos-Bays, Jacqueline Magness and Elizabeth Roslewicz. A special thank you to Dr. Martha RedstromPlourd for her friendship. She was a sounding board for ideas and a supportive companion through this journey with me.

From the Department of Health and Human Services (HHS) I thank all of the managers and employees from the Study Circles Group A and B who volunteered their time for my research project. I appreciate their interest and support in wanting to create a more compassionate and enlightened workplace environment for traumatized workers.

To my friends at the Study Circle Resource Center in Pomfret, Connecticut, especially Francine Nichols, Project Director, and Matt Leighninger, Program Director, for their time and phone conversations, researching and faxing the materials I needed for my research, I thank them.

My supervisor, Barbara B. Aulenbach for her encouragement and support in pursuing this project to its completion. My transcriber, Mary Drake, who transcribed all my interviews with accuracy many times with a short turnaround, I thank her for her time and patience. My 
videographer, Robin Noonan-Price, who meticulously worked with me on every detail of the videotaping and final product, my appreciation and thanks.

To my parents, Michael and Catherine Barski for their love and support of my educational goals, especially my mother who wanted this for me and walked the path with me. My brother Michael and sister-in-law Bernadette for their words of interest and encouragement. To my niece, Lydia who always ignited the "child" in me when she was in my presence, which helped keep my prospective.

To my husband, Milton M. Carrow, J.D., I am grateful for his loving support and for maintaining a "balance" in my life through this whole process.

Lastly, I dedicate my dissertation to the memory of my uncle, Dr. Walter M. Novelli, who played the most significant role in my education during my formative years and continued supporting me through college and graduate school. From him I received the gift of a love of learning and a love for life. 


\section{TABLE OF CONTENTS}

\section{ABSTRACT}

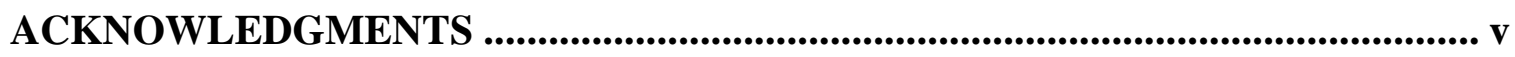

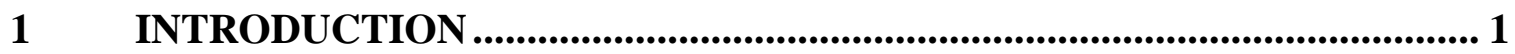

Background of the Problem.............................................................................. 1

Employee Workplace Violence.......................................................... 2

Organizational Support is Scarce ................................................... 3

The Challenge Ahead ...................................................................... 5

Interventions Presently Being Used in Organizations................. 6

Statement of the Problem ........................................................................ 7

Organizational Dilemma....................................................................... 7

Managers Resistance is a Contributing Problem ....................... 7

Survivors Assistance........................................................................... 8

Purpose of the Study ...................................................................................... 9

Research Questions............................................................................................ 9

Significance of the Study................................................................................. 10

2 REVIEW OF RELATED LITERATURE.................................................. 12

Introduction ................................................................................................ 12

The Classification of Views on Trauma and its Effect.......................... 12

Early Findings of Trauma............................................................. 12

Trauma and Psychic Wounds....................................................... 13

Trauma and the Attachment Process ........................................ 13

Trauma and Bereavement....................................................... 15

Trauma and Health ........................................................................... 17

Trauma and Children ...................................................................... 18

Trauma and Life's Journey.............................................................. 18

Trauma and its Effect on a Person's Career............................... 20

Trauma Intervention Techniques .............................................. 27

Individual Psychotherapy and Group Therapy ..................................... 27

Psychotherapy …................................................................................... 27

Group Therapy ................................................................................ 27

Short-Term Group Therapy ........................................................ 28

Grief Counseling Intervention ........................................................ 29

Open Grief Group Intervention....................................................... 30

Self Help Therapies........................................................................................ 31

Self Help as an Intervention............................................................. 31

Helping and Interviewing Models of Intervention.................... 33

Other Suggested Types of Interventions For Traumatized

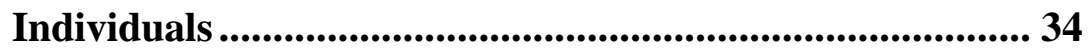

Critical Incident Stress Debriefing Intervention (CISD)....................... 34 
Four Level Intervention Model...................................................... 35

Survivor Recovery Intervention..................................................... 37

Insights on Gender Intervention.................................................... 38

Summary of Psychological Interventions ................................... 38

Study Circles ................................................................................................... 39

Introduction ................................................................................................... 39

Historical Background of Study Circles................................................... 39

Study Circles in the United States since 1970 ........................... 41

Study Circles and Group Participation...................................... 43

Study Circles as a Adult Learning Process.................................. 44

Summary................................................................................................ 46

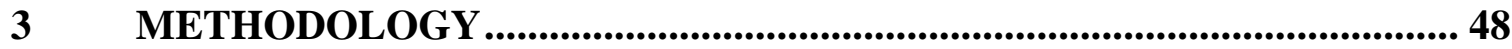

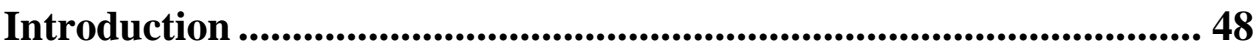

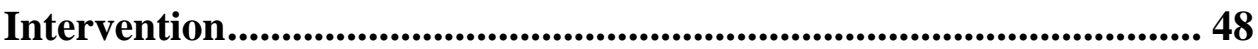

Selecting Sample …………....................................................................... 49

Procedures................................................................................................... 51

Spontaneous Adjustment............................................................................... 51

Data Information Collection and Processing .......................................... 53

Observation and Audio Tape Interviews ................................................ 53

Videography ................................................................................................ 53

Evaluation Form ...................................................................................54

Pilot Case Study ............................................................................................... 54

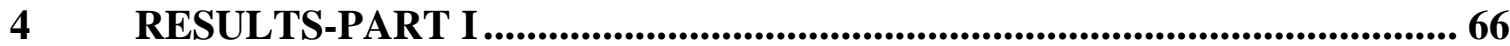

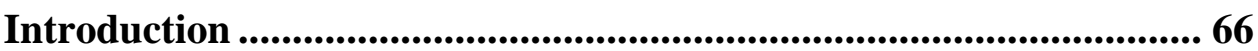

The Study Circle Model and Its Components......................................... 66

Profile of Participants...................................................................... 66

Study Circle Format........................................................................... 66

Pre-Study Circle Interviews ............................................................ 67

Facilitator ............................................................................................ 69

Evaluations ........................................................................................ 70

Assessment of the Study Circle as an Educational Model

In the Workplace........................................................ 71

Affective Learning ...................................................................... 72

Behavioral Learning................................................................ 73

Cognitive Learning.................................................................. 73

Case Studies (preview) ................................................................... 74

Case Study I......................................................................................... 75

Case Study II ......................................................................................... 82

Identification of Critical Elements for Discussion .............................. 85

The First Session.................................................................................... 86

The Second Session................................................................................. 87 
The Third Session.................................................................................. 89

Group Participation in the Study Circles ............................................... 90

Videography, Group Dialogue and Interaction ........................ 90

Communication and Group Climate ............................................ 90

Summary of Group A Study Circle Sessions.............................. 92

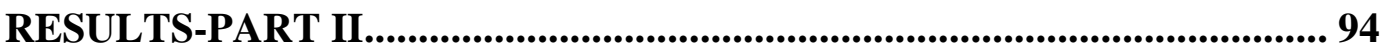

Introduction .................................................................................................... 94

Profile of Group B Study Circle Participants ....................................... 94

Pre-Study Circle Interviews with Group B Participants..................... 95

Composition, Dialogue, Observations and Dual Role of the

Researcher in the Study Circle Sessions ...................................... 96

Dual Role of the Researcher ....................................................................100

Identification/Discussion of Critical Elements for Groups A/B .........101

The First Session.................................................................................101

The Second Session.....................................................................103

The Third Session....................................................................105

Videography ..................................................................................................107

Evaluations...............................................................................................108

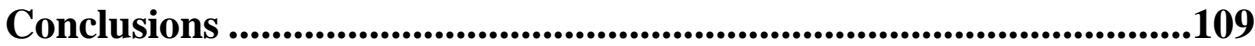

Behavioral and Interaction Observations.................................109

Administrative Observations ...................................................111

5 SUMMARY, LEARNING EXPERIENCES AND RECOMMENDATIONS Introduction ..........................................................................................112

Achieving the Educational Learning Experience ..................................112

The Lessons of This Research Project......................................................113

The Study Circle: An Educational Format............................................114

The Study Circle: A Psychological Process ..............................................115

Recommendations for Future Research ..................................................117

6 MANUAL FOR FACILITATORS .............................................................118

Manual for Facilitators: Study Circles

in the Workplace.....................................................................................119

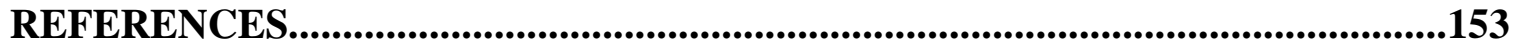

\section{APPENDICES}

A Model of Learning Process (Jarvis) ......................................................................160

B Principles/Approaches for Study Circles ............................................................161

C Letter of Invitation for Participants ...................................................................162

D Confidentiality Agreement ...................................................................................164

E Pre-Study Circle Interview Questions .................................................................165 
F Study Circle Handouts ........................................................................................166

G Evaluation Form of Group A Study Circle Sessions ..........................................172

H Evaluation Form of Pilot Study ............................................................................174

I The Role of the Participant .................................................................................176

J Evaluations of Group A Study Circle Sessions..................................................178

K Evaluation Notes from Group B .................................................................188

L Study Circle Discussion Notes................................................................................189

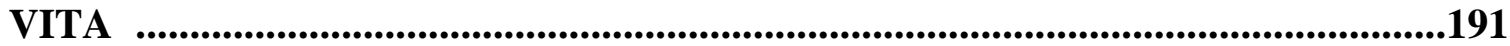




\section{CHAPTER 1 \\ INTRODUCTION}

Trauma in one form or another has always been and will always be with us. Authors, philosophers, musicians, poets and playwrights have used some form of trauma as fodder for their creativity. From their art form and from our own experience we know that individuals who survive and overcome trauma achieve a transcending perspective of themselves. For those who allow trauma to defeat them, life is a complicated and endless struggle. Willy Loman in Arthur ller's "Death of a Salesman" was plagued by anger, rejection, and depression caused by a trauma in the workplace from which he could not recover, and he withdrew into isolation. Audiences around the world have identified with his plight. Yet, according to Judith Lewis Herman (1992), it is possible for individuals to recover from trauma. Her thesis centers on trauma victims reestablishing connection with their public and private worlds.

The study will focus only on providing a vehicle for managers who supervise re-entry employees. Even more specifically, this study will center on employees returning to the workplace after experiencing a "traumatic life experience" (TLE), a term the researcher coined after a number of years observing people trying to cope with traumas in their life. This study will not distinguish between the various types of trauma experienced; for the purposes of this research study the common denominator is that in some cases, the trauma has removed the employee from the workplace for a period of time. The study will introduce Study Circles as an adult-educational intervention to the workplace.

\section{BACKGROUND OF THE PROBLEM}

Traumatic life-experienced (TLE) individuals are entitled to return to a full and productive life. They should be able to eventually re-enter the workforce easily and go forward with as little resistance as possible. However, their's is a difficult road to recovery and an even more difficult road to productivity as employees. According to Noer (1993), traumatic experiences have caused employees to lose their sense of self, their sense of competence, and their ability to function as before. He writes of the experience of survivors of the NASA space shuttle disaster:

After the space shuttle Challenger disaster, the thousands of people who had worked in the shuttle program felt like disaster survivors. 
Descriptions of the symptoms experienced by these survivors... provide an example of survivor symptom similarity.

Shortly after the disaster, observers said that the shuttle survivors experienced guilt, anxiety, and fear with the full intensity of these feelings yet to be dealt with because of the denial (p. 39).

Herman (1992) notes that it is critical for survivors who have experienced trauma to renew connections with their co-workers and those people who compose their work world, thus re-establishing the personal elements that were damaged or deformed by the traumatic experience, i.e., such basic capabilities as trust, autonomy, initiative, competence, identity and intimacy. Just as these capabilities were formed in earlier relationships with people, depending on the type and intensity of the trauma, they may need to be reformed/recreated when an individual returns to the workplace.

\section{Employee Workplace Violence}

Likewise, government agencies and the private sector "suffer" when any of their employees are traumatized within the organization by workplace violence or outside the organization by a personal trauma. The suffering can easily be observed and measured in overall morale problems and lower productivity, caused not only by the traumatized employee but also by the inability of managers and co-workers to effectively deal with a traumatized employee. Organizations suffer the cost of interruption of business, increased absences, low morale and low productivity. The business community is concerned as to how to prevent these kinds of incidents from continually happening (Mantell, 1994).

An increasing number of traumatic life experiences are caused by violence in the workplace. Employees may suffer a trauma at work from violent actions such as co-worker threats and intimidation, sexual harassment, physical assaults and continued disruptive behavior. In a recent article in the LRP Publications Federal Human Resources Week Magazine it is stated that the National Safe Workplace Institute estimates that the cost of violence in the workplace to businesses in the United States is $\$ 4.2$ billion annually.

Trauma and violence are on the rise within corporate America, a recurring nightmare to companies, schools and government buildings in the last few years. Statistics show that suicide in the workplace is often the fastest growing form of homicide in the United States. 
No organization is immune. Barski (1993) points out the many forms of workplace violence by providing a hierarchy of the types of behaviors that describe the kinds of violence caused by employees.

At the first level of employee violence Baron (1993) identifies the following: refusing to cooperate with an immediate supervisor, spreading rumors to harm others, consistently arguing with prospective customers, acting in an unkind or belligerent manner toward clients and using profanity.

At a second level, showing a slight escalation of emotion, he lists: continuing to argue with customer and vendors, refusing to obey customer policy and procedures, sabotaging and stealing of equipment, seeing the self as constantly victimized by management.

At a third level, manifesting an intense anger on the part of an individual, Baron (1993) identifies the following: suicidal threats, physical fights, destruction of property, utilization of weapons and, most serious, murder, rape and arson.

\section{Organizational Support is Scarce}

The question is where do organizations begin? How does the workplace help managers recognize warning signs that signal these incidents? Do managers know what to do and how to deal with them?

Much is written on how to observe and report warning signs of potential outbursts, but what is not available is how managers deal with returning employees who have experienced a traumatic life experience (TLE) whether in the workplace or elsewhere (Mantell, 1994). Strauss (1997) states that within organizations, baby boomers whose parents are dying are returning to work and are unable to concentrate and cope with the demands of their work. The emotional toll on these employees in trying to grieve and take care of themselves is resulting in absenteeism, people leaving work early, and projects not being completed. This is creating a new kind of problem for corporations.

In 1995, the nation suffered a most devastating trauma when innocent children, visitors and government workers were killed by a bomb that destroyed a federal building in Oklahoma City. Smith (1996), a senior management official from the Division of Personnel at HHS who visited the Oklahoma bombing site and interviewed federal government survivors, reported that 
managers were unable to deal with the aftermath of this tragedy. Supervisors were trying to go on as if nothing had happened--trying to go back to a "business as usual" mode, thereby failing to attend to the needs of the employees who were recovering from this trauma. The result has been disruption, loss of productivity, and decreased morale (Smith, 1996).

Barski's (1993) study found that managers are seemingly in a quandary when they are required to deal with a returning TLE employee. They are confronted with a number of questions: What to do when a TLE employee does not want to do his work? What are the correct words of comfort to express? How do you deal with co-workers who may resent the TLE employee's need for additional attention? Most managers feel impotent in these situations. Their management training has not prepared them for the extraordinary demands of a returning TLE employee. The TLE employee most likely places an inordinate burden on the manager's time, energy and patience; this imposition can develop into resentment by the manager and coworkers, if the manager is not properly able to deal with the intricate and complex aspects of this management dilemma.

In the workplace primary responsibility for relationships rests with managers, i.e., the person perceived to have greater authority. However, managers sometimes are conflicted in their functional roles. Powell (1988) noted that managers are responsible for two types of behaviors: (1) initiating structure, or how the manager initiates activity in his group, organizes and defines the way in which work is to be accomplished; and (2) consideration, or the extent to which a manager is concerned with the welfare of the group, i.e., the human resources role. These behaviors are not polar opposites, nor are they mutually exclusive. However, they do compete for a manager's time and attention. To the extent, then, that managers are pressured to call upon their initiating structure behavior to meet management objectives, their consideration behavior is diminished. This results in many human resource issues not being addressed; employees and managers suffer the loss of a vital communication link which could assist to resolve problems and create a healthy work environment. The impact of this loss is even more significant for TLE employees.

Unfortunately, many TLE employees are not given the attention they require to readapt to their work environment. Some managers reveal considerable ambivalence in dealing with TLEs 
some admit to having little or no idea how to make re-entry easier for the TLE. Similarly, the TLE employee's co-workers are unable to understand the dimensions of the emotional toll experienced by the TLE employee and are also unsure how to behave (Barski, 1993).

As reported by Kleinfield (1996), companies have also changed their attitude toward employees. Employees who once considered the company "their family" have lost that sense of belonging. For example, as reported in the New York Times (Kleinfield, 1996), Chase Manhattan no longer wants to be a parent to its employees, it wants to be their best friend. Companies are replacing their paternalistic attitude toward their employees by trying to assist them in being responsible for themselves. By offering courses and career counseling the company assists them in sharpening their skills (Kleinfield, 1996). Survivors from a major layoff that occurred in the Chase Manhattan Corporation which was being taken over by the Chemical Banking Corporation were bitter because they looked to management to take care of them until they retired. This no longer is happening (Kleinfield, 1996). Those employees who survived may face each day with trepidation and wonder about their future. People who are left stranded in situations like this are left many times to cope on their own.

\section{The Challenge Ahead}

Organizations today are just beginning to acclimate to dealing with workplace issues such as child care for working women. Strauss (1997) states AT\&T permits alternative working schedules (flex-time), telework/ telecommuting and job sharing for their employees. It also provides workers three days a year for family needs, such as parental care and bereavement. However, a major challenge for corporations is the approach that will be used to assist managers in dealing with the re-entry of TLE employees.

Several researchers have explored the TLE employee experience. The essence of what a TLE employee experiences in the workplace is disempowerment and disconnection, both from individuals (including co-workers) and their community (including the workplace) (Herman, 1992). Perlman (1983) emphasizes that healing occurs in relationships, especially when another

person touches an emotional response cord that closely matches the person experiencing the pain or joy. She says, they are "akin" to each (p.28). Thus, the TLE survivor must renew connections with his co-workers and his broader work world, thereby re-establishing the interpersonal 
elements that were damaged or destroyed by the traumatic experience.

Herman (1992) offers a process of recovery that unfolds in three stages. She claims that the stages are imposed to create simplicity and order to a process that is painful and inherently turbulent. Usually these stages are "worked through" with a therapist and the process can be described as "spiral," where issues that may have been discussed and processed with the therapist are revisited from time to time.

Herman (1992) claims the stages include establishing a safety net for the traumatized person. By safety net Herman (1992) means focusing control on the body, and gradually moving outward toward control of the environment. The safety net can only be developed through a support system. The second stage includes allowing the victim to reconstruct the trauma story. Telling the trauma story helps the survivor integrate both the trauma memory and circumstances that led to the trauma. This process assists the survivor review the important people of their life and deal with the trauma in a more realistic way. The third stage includes restoring the connection between the survivor and his community. Here the survivor must deal with creating a future and the development of a new self and new relationships. Emerging from an environment of uncertainty, survivors then reach out to other people to reclaim their new world.

\section{Interventions Presently Being Used in Organizations}

Returning TLEs exist in all organizations, but most organizations do not have a method which organizations can be used to effectively deal with the issues that confront returning TLEs.

The Postal Service has initiated a nation-wide intervention entitled Critical Incident DeBriefing (CISD) Group. A cadre of trained psychologists and support staff are sent to each site where a trauma has occurred. Their purpose is to offer support to the employees for the short term and assist them to getting back to work. This training has been used throughout the country with the Postal Service and it has proved very successful.

This study will introduce Study Circles. The Study Circle format is a well-developed format with its main educational thrust designed for people who have an innate desire to learn. Study Circles are conducted in an atmosphere of cooperation, and participants help each other in the process. The Study Circle that the researcher is proposing will be one in which participants will assist each other (managers and TLEs) to understand and address each other's concerns 
relative to the subject matter.

\section{Statement of the Problem}

Today the workplace manager needs assistance and guidance in recognizing and understanding the traumatic life experienced (TLE) person. Many questions for managers arise such as: What do you do when a traumatized person returns to the workplace and does not want to do his/her work? What do you say to a person to comfort them on their work assignments? How do you know if the traumatized person understands that he/she must go through a process of grief and mourning following the trauma? How do you help your employee deal with his/her self-esteem after a trauma?

The three components that affect individuals who are returning to the workplace after experiencing a trauma are the organizational dilemma, the manager's resistance, and the survivor's apprehension of re-entry. Barski (1993) uncovered a wide range of responses from interviews conducted with managers, survivors and therapists on the subject of employees who re-entered the workplace after having experienced a trauma. A brief description follows with some of the highlights from these interviews.

\section{Organizational Dilemma}

With the rise in violent incidents in organizations, more assistance is required in organizations on how to manage traumatized employees and how to educate supervisors and managers to work with returning traumatized employees. Mantell (1994) has written about how to look for and report warning signs of potential outbursts of employees in the workplace, but what is not available is guidance on how managers should deal with such an employee in general.

\section{Manager's Resistance is a Contributing Factor}

The manager also faces organizational setbacks dealing with the loss of resources, such as when budgets are slashed, divisions are deleted, responsibilities are added and productivity goals are doubled and tripled. These are the squeaky wheels which get the attention of managers. Managers then must prioritize their time and staff, and a returning TLE may not get the attention that he/she should receive upon re-entry to the workplace. 


\section{Survivors Assistance}

Survivors who return to the workplace after having experienced a trauma are not given the attention they require to readapt to their work environment. Barski's (1993) study revealed that when survivors returned to the workplace, they received no support from the organization, and their managers did not know what to say to them. They felt they wanted to talk about their trauma, but had difficulty reconnecting with the work community.

Today the only way an individual who is returning to the workplace after experiencing a trauma can address the after-effects of this experience in the workplace is through the Employee Assistance Program (EAP) and individual grief counseling which is usually administered by a therapist or social worker. Every government agency has an EAP Office which specializes in individual therapy or can direct a person to an outside support group where they can share his/her experiences and get assistance (Tyler, 1996). A model being used by the Office of Personnel Management (OPM), Washington, DC in dealing with traumatic events is offered to managers by Dr. Mary Tyler, a psychologist. The lecture course includes information on workplace violence, domestic violence and helping an employee through the recovery process of a trauma. In an interview with Dr. Tyler (April 29, 1997) she states that managers are very concerned with dealing with traumatic incidents, and there is a need to continue to develop new approaches in the workplace.

It was apparent that what is lacking in government organizations is a short-term educational intervention that can be conducted on site and individuals who may have had therapy or counseling, employees who have experienced a trauma, and include managers who supervise re-entry employees. Currently there is no non-therapeutic intervention designed to create this type of ambience in organizations.

One of the resources that an organization can explore to assist managers and employees in learning how to assess the needs of returning TLEs is through Study Circles. According to Osborne and Shevat (1982), the Study Circle is a collaborative effort with all participants, including the facilitator, having equal status. It serves as a venue where employee and managers can come together to try to understand each other's needs in a forum of conversation and learning. However, there is little understanding about the Study Circle as a resource for an 
organizational intervention with managers interfacing with individuals returning to the workplace after having experienced a trauma.

If Study Circles were perceived as a new and unique educational format for organizations to adopt, then this adult educational intervention can hopefully bring managers and employees together for the first time to examine and discuss opportunities for open dialogue. The Human Resource area would herald a new approach to welcome the 21st Century. Both government and organizations would welcome an opportunity to participate in a forum that would offer a cost free learning environment that could be conducted at their work site where managers and employees could dialogue with each other.

\section{Purpose of the Study}

The purpose of this study was to examine the effectiveness of Study Circles as an adult educational intervention for re-entry employees and those who manage re-entry employees who have experienced a traumatic life experience (TLE).

1. Gain an understanding of the process, content and characteristics of this unique type of Study Circle.

2. Determine the effectiveness of the Study Circle as a dialogue/learning approach for managers and returning TLEs.

3. Identify conditions, interactions, relationships, and other factors that may facilitate or impede the Study Circle process as an adult educational intervention.

Information and data collected by the researcher was expected to provide greater knowledge, insight and awareness for government agencies and organizations and provide factfinding research which will be growth enhancing to the Study Circle community.

\section{Research Questions}

1. How can Study Circles be designed and used to engage managers in a discussion of the problems of returning TLEs?

2. How can Study Circles be designed and used to facilitate TLEs to tell their re-entry stories.

3. How much of the re-entry process must the researcher/facilitator know in advance of the Study Circle in order to make the telling of the re-entry story a stimulus to dialogue? 
4. Does a manager with some experience with a TLE in the workplace engage more (quickly, easily, intensively) in a dialogue with a TLE in the Study Circle than managers without such experience.

5. What examples of group participation emerge in the Study Circle with TLEs?

6. What is the nature of discourse? Are managers open to dialogue with returning TLEs?

7. Does the environment and setting of a government agency have relevance for Study Circles in assisting managers work with returning TLEs? 


\section{Significance of the Study}

It must be recognized that current economic condition have resulted in pressures of crisis proportion in many organizations which are trying to create or maintain their position in a highly competitive global economy, keep up with rapid technological changes, and cope with routine management issues. TLE employees are thus aberrations who more easily and often are avoided, disregarded or simply tolerated. Yet, as Herman (1992) stressed, re-establishing relationships and connections is critical to the well-being of the TLE.

Organizations must try to be creative in developing ways to complement the efforts of Human Resources departments. More new and cost effective methods could be designed to assist managers, supervisors and employees to facilitate the re-entry of TLEs into the workplace.

One of the most significant results of this research is recognizing the unique application of the Study Circle as an adult educational tone in the workplace. In other words, the Study Circle provided a well-structured format for managers and employees, as equals, to explore a very sensitive personal and organizational issue in an atmosphere of mutual respect and dialogue. No other educational process currently available in the business world can make this claim.

Also, new ground will be broken in the Study Circle community and human resource area. Lumsden and Lumsden (1993) state that "organizations develop norms, expectations, and responses that become part of their culture; these guide the way people act and what they do." (p. 81). The group will be creating an identity of its own in the Study Circle community and in organizational culture.

Currently this particular approach has not been tried in the Study Circle community although Study Circles on race relations, spousal abuse political and community social issues have been addressed with much success.

The significance of this study is that it will add to the knowledge of the Study Circle community and will hopefully improve relationships among the managers, supervisors and employees who are re-entering the workplace after having experienced a trauma. It is expected that the recommendations that emerge will have value to TLEs, the organization and the Study Circle community. 


\section{CHAPTER II \\ REVIEW OF RELATED LITERATURE \\ INTRODUCTION}

Chapter II contains a review of the literature related to (a) a classification of views on trauma and its effects, (b) trauma intervention techniques and (c) Study Circles.

\section{The Classification of Views on Trauma and Its Effects}

While researchers have found that the range of emotional and physical reactions to trauma vary from individual to individual, there are numerous symptoms that trauma victims have in common. This section discusses the many theories that explain the consequences of trauma, effects of trauma in our lives and relationships and the effect a trauma can have on our career.

\section{Early Findings of Trauma}

Although the term trauma was first used in medicine to describe physical symptoms, trauma was also used in psychology to describe mental symptoms.

Freud (1940) was the first theorist to discuss trauma as a psychological process. For example, he talked about the death of a loved one as a traumatic loss in relationship and the effect it has on people, as well as the importance of "working through" the trauma. Freud (1940) wrote an article on grief entitled 'Trauer and Melancholi.' It is here that he introduced two important concepts for understanding grief: object love and ambivalence. He states that object love is a bond formed with someone or something to whom one is attached. The goal and purpose of grief is to break the bond which exists between the griever (subject) and deceased (object). Freud stressed that the mourner must work very hard and he called the process "grief work"(p. 9). Freud believed the person must "work through" their loss, or else grief cannot be overcome. Freud (1940) claimed the main cause of pathological grief is ambivalence in relationship with the lost object. "Depression occurs when an individual is unable to transfer the libido from the lost person to the new object"(p. 7).

Understanding trauma lies in recognizing the psychological experience in all its forms in trauma survivors (Janoff-Bulman, 1993). The definition of trauma that will guide this study is found in the work of Slaby (1989). "A trauma is a turning point in the course of anything that life offers, from good news to bad, from personal injury to upward mobility. After a trauma, things 
are not the same, nor will they ever be again" (p. 15).

\section{Trauma and Psychic Wounds}

Sobel (1994) explored the emotional impact and psychic wounds that a trauma can have on our lives. He maintains that survivors of a traumatic experience lose their sense of control and their connection to others, and their life meaning is brought into question when they are dealing with the aftermath of a trauma. At the moment of trauma, most victims are rendered powerless; trust in others is lost and they feel abandoned.

Engel (1961) is an English psychiatrist whose theory on trauma and grief centers around the wounds of the psyche. He states that many times it is difficult to distinguish between a person's emotional wounds and bodily wounds. We often, hear terms such as "it was a hard blow for her" and "he was knocked out of it"(p. 12 cited in Leik and Davidsen-Nielsen 1993).

Engel (1961) was the first person to compare emotional loss with a physical wound. In both cases the wound must heal, which takes time. When a wound heals first a scar is formed. Engel sees grief and trauma work as a healthy process which slowly heals the wounds of the psyche. He wrote an article entitled 'Is Grief a Disease?' "No, grief is not a disease, but it can develop into one." He states, "It is possible to die of a 'broken heart'"(p. 13 cited in Leik and Davidsen-Nielsen 1993).

\section{Trauma and the Attachment Process}

A traumatic life experience may occur because of the loss or deprivation of physical closeness. Bowlby $(1969,1973,1980)$, a psychoanalyst who introduced the theory of attachment, emphasizes the biological rather than the psychological function of grieving. The biological purpose of grief is to regain proximity to the attachment figure, separation from which has caused the anxiety. Bowlby maintains that individuals can attach to many things such as money, homes, vacations, possessions, work, as well as persons. Generally, we take our physical appearance for granted, but if a parent loses an arm or a leg we begin to understand the importance the attachment to the body and how one feels about it. The attachment process is most profound. Usually when we lose someone very close to us, it is then we feel the deepest trauma and our grieving for the loss begins.

Bowlby $(1969,1973,1980)$, who has done the most research on attachment and loss, 
regards close attachments as essential as food and water. He developed his theory of "optimum distance" by monitoring the behavior patterns of newborn infants. A new baby is born with the ability to develop behavior patterns that will evoke a response from the mother. The child learns to smile in order to get positive attention. Gradually he/she ventures further by walking, holding objects and following the mother around. The goal of this contact behavior is to ensure security. As the child gets older, the contact may involve sitting on the mother's lap or viewing her, as long as she is within sight of the child. Later, the "optimum distance" will be extended. The age of the child continually changes the "appropriate security." As adolescence comes, the "optimum distance" may be uncertain. Bowlby stresses that the need for close attachment is a flexible optimum distance and will vary throughout life.

Erikson (1968), in an approach similar to Bowlby, sees a person's lifelong growth as a long series of developmental crises. In each of these stages there is an emotional dilemma to be solved. Erikson's (1968) first two stages of development correspond with Bowlby's attachment period, namely the child's development up to 3 years. Erikson sees a child's first crisis as how to achieve basic trust and overcome the feeling of distrust. Success in resolving this crisis gives the child hope, through trust the child develops the needed closeness with the mother. The attachment is created if the child can securely expect his mother to return when she goes away, that she will be there if the child needs or wants her, and the child will be able to summon her.

The next stage of Erikson is achieving independence. Here the child's (from 18 months to 3 years) autonomy is encouraged. During this stage the child once again realizes that he/she is in control of his/her own behavior and begins to develop a sense of independence. Conflicts arise for the child when he/she tries both to assert his/her independence and to maintain his/her dependence. Here the child wants to eat, dress, open and close things by himself/herself. It is here where parents play a crucial role. How much liberty will the parent allow the child and how does the parent set limits for the child so that the child develops self-confidence? If the child is over-inhibited or given too much freedom, he/she may develop a gradual feeling of doubt about himself and his abilities. The experience the child has had in these two areas determines how he /she will attach himself to people and how flexible he/she will be in finding an "optimum distance." This is an issue people work on all of their lives. If individuals have difficulty in finding the 
"optimum distance" they may also have difficulty in making effective use of a network. This in turn, can have consequences in the way they handle a traumatic event in their lives, not only among family but also at work. Erikson (1968) also points out if an adult has unresolved issues and the above stages continue to be unresolved, the person suffers the loss of psychological health. Unresolved psychological development issues can affect a worker's ability to readjust after a traumatic experience.

The work of both Bowlby $(1969,1973.1980)$ and Erikson (1968) is important in understanding attachment to others. It is understandable that people who may have had difficulties in their attachment process may also have difficulty in dealing with grief and trauma, because their basic trust has been undermined. Bowlby \& Erikson (1971) state that for such people it is hard for them to say goodbye to a dear one and welcome new contacts. Their difficulty is in finding "optimum distance." Problems with their network may appear along with working through their grief and trauma.

Both Erikson and Bowlby give us a framework for understanding human attachment and the potential problems that can occur during the healing stage of the grief process. They both offer insight to the many factors that can influence or aggravate the psychological effects of a traumatic experience in an adult life.

\section{Trauma and Bereavement}

Lindeman, (1993) an American psychiatrist, pioneered trauma research in a study of the reactions of the bereaved after a serious fire disaster in which 500 people perished in the 1942 Coconut Grove night club fire in Boston. He is credited with defining the symptomatology of acute grief and with identifying people's patterns in reacting to grief and crisis situations, which he found were remarkably uniform. His theory notes three phases: (1) deliverance from the past by recognizing the loss, (2) re-building the present, and (3) creating a future with possibilities and new pathways. His work is considered a milestone in the development of understanding grief and bereavement.

Lindemann claims that working through grief and trauma is a long and painful process that creates turbulence and frightening feelings for people. "It is called a state of crisis when someone is so much 'out of their wits' because of the traumatic event that for a while they cannot use their 
ordinary problem solving ability"(p.10). Because they are emotionally overwhelmed and confused, Lindemann feels, they need the help and support of people and a network. Lindemann (1993) views the grieving process as work. The tasks that he outlined assist the bereaved person in undoing emotional and psychological attachment to the deceased and in adjusting to a life without the deceased, and in creating new relationships. Since work is a significant part of one's life and relationships, working through grief and trauma also needs to be integrated at the workplace.

Kubler-Ross (1969) made a landmark contribution to the study of death, loss and grief by unlocking the doors to open communication on the subject. She centered on the grieving process that a person experiences in dealing with a loss. Her five stages of grieving include: (1) denial and isolation, when a person has difficulty accepting what has happened; (2) anger, when the reality of the situation is resisted; (3) bargaining, when the individual who has been traumatized promises something to a higher power, e.g., to Buddha or their God, provided their loved one is not taken from them; (4) depression, when the person begins to accept the reality; and (5) acceptance when the person no longer denies the reality of the loss.

Parkes (1972) investigated widows' grief reactions. He collaborated with Bowlby who inspired him to take as his starting point the attachment theory between the mourner and the deceased. Parkes (1972) concluded that individuals who have lost a loved one should use their healing forces to work through the grief; if they do not, the grief could affect their mental health.

The survivor of trauma (from death of a loved one) tries to make contact with or hold onto the loved one in an unconscious way. He says, "weeping is one way of summoning the deceased, just as a baby cries to summon his mother"(p. 10).

Weeping has two levels: (1) calling weeping and (2) letting go weeping. Calling weeping is a shallow form of weeping, whereas letting-go weeping is the deeper form and brings more relief when the individual is letting go of the deceased.

Zunin (1991), a psychiatric consultant and an authority on attachment and loss, notes that bereavement trauma is associated with changes in behavior that encompass relationships with others in their day-to-day activities. For grieving persons, the simplest activities, such as paying the bills or doing housekeeping chores, may feel like major burdens. Zunin (1991) points out that 
traumatized person commonly feel as though he is "falling apart."

Zunin (1991) also made several observations from his work with military wives in a group program called Operation Second Life. He reported that women who were able to discuss with their husbands the possibility of death prior to their departure for active duty were able to deal more effectively with their bereavement and they made a faster adjustment.

\section{Trauma and Health}

The effects of traumatic life experiences may be more pronounced in a person with poor mental or physical health. Viorst (1986) states that loss through death is a major life stressor and if a person endures additional stressors in his/her life, the risk of mental health and vulnerability to illness increases. She claims those with a poor history of mental or physical health are at greater risk.

Viorst (1986) states that there are eight million Americans ever year who experience death in their immediate family. There are 800,000 new widowers and widows, and 400,00 children die every year before they reach the age of twenty-five. According to the Institute of Medicine, "those who experience loss without the support of a social network tend to find the trauma more intense" (p. 252).

Simonton (1978), the cancer researcher, states that there is a clear link between stress and illness, "A link so strong that it is possible to predict illness based on the amount of stress a person experiences"(p. 43).

Dr. Hans Seyle (1956), an endocrinologist, father of stress research and Director of the Institute of Experimental Medicine and Surgery at the University of Montreal, states that chronic stress on the body can produce hormonal imbalances which can do harm to our kidneys and cause high blood pressure. Seyle (1956) discovered that "chronic stress suppresses the immune system which is responsible for engulfing and destroying cancerous cells or alien micro-organisms"(p. 49).

Dr. Seyle's research is confirmed by two Dr. R.W. Bathrop at the University of New South Wales, Australia, and Dr. J. H. Humphrey at the British Medical Research Council. Dr. Bathrop (1977) has conducted studies which show that bereavement lowers the body's immune response. He studied twenty-six recently bereaved persons (ages twenty-five to sixty-five) at two 
weeks and six weeks after the death of their spouses. A control group comprised of twenty-six hospital employees who had not experienced any bereavement in the past two years. Their findings showed that the lymphocyte function, a critical measure of the body's immune system, was significantly depressed in the individuals who had lost a spouse.

Dr. J.H. Humphrey's (1975) research demonstrated that the body's response to tuberculosis is reflected in the mental and emotional stress it puts on the body's defenses.

\section{Trauma and Children}

Miller (1986) concluded from her research on trauma and grief with children that "it is not the traumatic occurrence itself that leaves its traces, but the way the parents accommodate the child's emotional reaction to the loss or trauma"(p. 15). Miller states that a child needs to express his feelings clearly and plainly, and adults must be able to accommodate those feelings. She states that many parents are not capable of accommodating their children's emotions around a trauma, because they are usually provoked by them. Consciously or unconsciously, the parents expect their children to meet their needs.

\section{Trauma and Life's Journey}

Many TLEs occur naturally as people go through life. For example, Slaby (1989) points out that there are six basic life situations that constitute a trauma. Each one signals a crisis and after shock: (1) The Element of Expected Versus the Unexpected in our lives: an aging grandmother outlives a young child who unexpectantly dies in a family, (2) A Sudden Shock in a Family; the sudden death of a loved one who has shown no signs of illness, (3) A Disruption in Family History: the loss of a business venture may cause an individual to be hesitant to take future risks in business, (4) The Element of Unfairness: the unfairness of life when a family plans a vacation and the airplane is hijacked and innocent people may be physically or emotionally injured, (5) The Loss of Control: events in our lives that we cannot control such as the downsizing of a corporation which may leave individuals suffering from stress related illnesses, (6) The Element of Blame: people blame themselves for events that occur in their lives, such as a lost career or a broken marriage.

During life individuals develop a set of basic beliefs about the world and people, such as "the world is a caring place" or "the world is a meaningful place" or "people are worthy" or 
"people can't be trusted." Janoff-Bulman (1987), a researcher who has done extensive work on basic beliefs which she calls "fundamental assumptions," focuses on the coping mechanisms that are needed to deal with the effects of trauma. These "assumptions" are the "bedrock of our conceptual system; they are the assumptions that we are least aware of and least likely to challenge"(p. 5).

According to Janoff-Bulman (1987), it is not always something negative that induces trauma. "There is something unique about traumatic events that assaults our most fundamental assumptions about the world and ourselves"(p. 56). These events are extremely powerful and their potency is not fully accounted for by their out-of-the ordinary, directly-experienced nature, they involve the most basic of threats, that to our very survival"(p. 56).

Janoff-Bulman (1987) states that traumatic events call basic human relations into question. Traumatic events can breach the attachments of family, friendship, love and community. They can shatter the construction of the self that is formed and sustained in relation to others. After people undergo a traumatic experience, their sense of control, connections to others and life meaning fall apart.

Herman (1992) has done extensive research with victims of sexual and domestic violence, and other traumatized people, particularly combat veterans and victims of political terror. Her analysis of individuals who have been traumatized reveals that commonalities of recovery occur, and traumatic syndromes follow certain pathways. Herman (1992) points out that traumatic reactions occur particularly when action is of no avail. "When neither resistance nor escape is possible, the human system of self-defense becomes overwhelmed and disorganized"(p. 34). Each component of the ordinary human response to danger--fight or flight--having lost its usefulness, tends to persist in an altered and exaggerated state long after the actual danger is over. For this reason, traumatic events may produce profound and lasting changes in sensory arousal, emotions, cognition and memory. Traumatic symptoms may become disconnected from their source and take on a life of their own.

Schneider (1984), a noted clinical psychologist, counseled clients who were terminally ill and depressed. During a single week in his life, three of his clients died, one attempted suicide, he then witnessed a young woman killed by a train outside his office. After these incidents, he was 
unable to be effective with his clients because of his own grief. Shortly after, another client committed suicide and this led him to question the type of intervention he was attempting. According to Schneider (1984), some of the common denominators of trauma include intense fear, helplessness, loss of control and loss of memory. He concludes that when we are traumatized our usual problem-solving capacities can malfunction. We may be able to do routine activities, but we will not be able to respond to new circumstances. The behavior of traumatized persons changes; they become fixed on well-controlled tasks, things they know they can do well. Traumatized people isolate themselves. Their reality and perceptions are blurred--often seeing and reacting to situations that are not there.

Barski (1993) found that the physical health symptoms are generally the most obvious symptoms displayed by returning TLE employees and are also likely to be the most disruptive in terms of the workplace. If an employee must take time off due to trauma-induced health problems, which frequently linger after he/she returned to work, this will most certainly affect his/her level of productivity. Managers, therefore, cannot rely on the TLE employee's performance and productivity levels, and they will likely be required to adjust the TLE employee's (and perhaps his co-workers's) assignments. Such disruption and its impact on productivity could result in additional time-and-expense costs, and would ultimately affect profitability.

\section{Trauma and its Effect on a Person's Career}

Much trauma is generated in the workplace when people lose jobs and organizations are restructured. For example, when AT\&T employees lost their jobs they went through an "identity crisis" as described by Bridges (1980).

Immediately after the divestiture experience there was a kind of identity crisis for AT\&T people. A safe, collective voice almost could be heard saying: I knew the Old Bell System, its mission, its operation, its people, its culture. And I knew my niche in it. In that knowledge, I had identity and confidence about my company and myself. Now I work for a new company, one fourth its size with only a partial history and no track record. With the loss of our mission-universal service--and the fragmentation of the very business of providing telephone service, I find myself asking, Who are we? Who am I (p. 39)? 
A new corporate strategy was being defined and these people did not know where they belonged. Although it is well known that termination and transition are painful and even traumatic to individuals who have lost their jobs, been fired, or have gone through an organization redefinition, organizations typically offer no psychological help to terminated employees. During an organizational seminar with Bridges (1988) one of the participants spoke about his own personal resistance to change and how difficult it was to accept being in a "transitional state." $\mathrm{He}$ wondered if individuals in organizations shared the same feelings.

Bridges (1988), an organizational consultant who visited the Department of Health and Human Services (HHS) in 1996, stressed the milieu that is created in organizations when they are going through change, especially during a downsizing. He talked about the "neutral zone" that seems to captivate employee. The "neutral zone" as he describes it is essentially a sense of emptiness in which the old reality looks insubstantial and transparent and nothing feels solid. In such an environment, managers become conflicted when faced with individuals who, whether they know it or not, are dealing with a trauma. These managers don't know what to do; they do not know how to advise or deal with their healthy employees, let alone the TLE employees. Bridges (1988) states,

When an organization is going through continued significant change, these confused and empty feelings can pervade the corridors and offices...People go about their tasks mechanically, and an outsider might think that things are going smoothly. But they are not. People's minds and hearts are elsewhere. In spite of the fact that there is more to do than ever, the employees move like people in a dream or waste their days in endless bickering. People talk but do not communicate; they listen but they do not hear. The days pass with little getting done (p. 60).

Newman, (1988), an anthropologist at Columbia University, studied unemployed managers who were once secure in a job. In her book, Falling From Grace, she describes managers who were unable to cope after losing their jobs. They became depressed, embittered, stopped taking care of themselves, started drinking, lost contact with their families and friends and some committed suicide. She called these people the "downward mobility" of their organization. She claims social scientists are labeling the destruction of a person's career as "intra generational 
downward mobility"(p. 20). This occurs when people attain a certain level of occupational success in their careers and then see it evaporate. They find themselves sliding down the socioeconomic ladder--their "fall from grace"(p. 20). In a survey conducted by the National Opinion Research Center (NORC), about one-fourth of the respondents reported that their financial situation had been poorer than in previous years. This number rises and falls from year to year, and NORC data shows that financial deterioration affects people in good and bad years in the economy. Government statistics show that the median income has declined 14 percent between 1972 and 1982, and has not recovered.

Newman (1988) asserts that people in this type of position often inappropriately blame themselves for what happened. Such managers buy into the cultural belief that "a manager succeeds because of his/her own hard work"(p. 38). Whenever successful managers fall from grace, that traditional ideology boomerangs. This produces a psychological trauma that Glassner (1994) called a "career crash." If individuals are responsible for their own destinies, there is no one else to blame in case of a failure.

DeCarlo and Gruefeld (1989) studied aspects of "merger mania," which began in 1982 when companies who decided to buy-then-build began responding to global competition. A study of mergers conducted by McKinley and Co. involved 200 of the largest corporations. DeCarlo and Gruefeld (1989), found that employees have a tough time adjusting to new policies, bosses and administrative change. "It is a given when a company restructures that employee stress will shoot up and job satisfaction will drop"(p. 67).

When organizations arbitrarily decide to cut their staffs and functional responsibilities through reorganizations and downsizing, their employees are psychologically affected. They see their achievements and goals become meaningless, they are unable to figure out what has happened.

Doss (1993) believes that during times of termination and transition employees who are going through "workplace depression." He claims that those employees who do survive distrust the company and become more cautious; as a result, innovation and creativity are stifled. Based on available research, it is fair to conclude that organizations have yet to understand, let alone deal with, the underpinnings of trauma. 
According to Glassner (1994), there are many routes to a career crash, the fastest and surest one is to be fired. "In the 1990's, with downsizing a routine part of American life, it may also be the most common"(p. 34). Glassner's (1994) research includes a survey of 250 managers who had been seeking a new job from six months to two years revealed that people in their midthirties to mid-fifties have the hardest time finding employment. He states only 55 percent of those surveyed had succeeded, compared to 67 percent of managers who were either younger or older. Glassner (1994) also personally interviewed people who lost their jobs. These interviews revealed fear of looking for another position, sheer shock of being out of work, embarrassment to tell their parents, children and spouses and hurt and anger at the company to which they had committed their loyalty. An employee whom Glassner interviewed shared the following with him:

I'd never been involved in anything where I could be called a failure or less than extremely successful,... I was raised to believe that if you keep your nose clean and do a good job, you'll be rewarded. On some level, of course, I knew that wasn't true anymore. In fact, I'd laid off people myself during an earlier cutback. But knowing about it and going through it yourself are two different things (p. 35).

Organizations such as AT\&T, Eastman Kodak, Xerox and IBM have all undergone cutbacks in their workforce. It seems America's obsession with cost cutting is no temporary trend. David Hornestay who writes for the Government Executive and focuses on the employees plight of turbulence that is caused by downsizing says some of the government decisions are hasty and irrational.

The word downsize came into the American language in the early 1970's. According to Uchitelle and Kleinfield (1996), it "was coined by the auto industry to refer to the shrinking of cars"(p. 11). It was in 1982 when it was applied to humans and appeared in the American Heritage Dictionary.

Across the country new terms are being invented for downsizing. Where once the word layoff was used, today we hear terms such as reengineering, reshaping, revamping, streamlining, severed, separated, and unassigned. What has emerged is a "New Reality", i.e., a new environment with a new value system where companies are replacing their paternalistic attitudes 
toward their employees with near total concentration on business profitability.

Meyer (1995), an executive with McDonnell Douglas and a former reporter with the St. Louis Dispatch, tells his story of being "let go" by corporate America. He gives his personal account of being unemployed and the day-to-day degradation and despair of searching for a new job in this culture of shrinking organizations. His own descriptions are haunting--bitter sounds of the jobless blues--a frightening and enlightening window of what happens to a person in a corporation.

Meyer (1995) describes the vulnerability of all employees in today's economy where corporate loyalty seems like a lost ideal.

Resentment isn't a strong enough word for what I feel when I think about all this. ...I'm ashamed in two ways. ... I'm ashamed of myself for being out of work, for getting my family into such a fix, for allowing myself to become an executive in the first place and then letting the whole thing go so wrong. I'm ashamed of myself for losing. When I hear the guy next door start his car in the morning and drive away, I'm ashamed I am still in bed.

The other shame is deeper, more important. It has nothing to do with how people see me, but everything to do with who I am. In some ways this second shame comes perilously close to selfloathing ( p. 9/11).

When such career trauma victims eventually return to work, the negative symptoms they display are similar (although perhaps not in degree) to TLE employees who have experienced a more "traditional trauma." These individuals, whom Glassner (1993) calls the "working wounded," also need to re-establish relationships, regain their self-esteem, and be re-integrated into their work environment in order to fully heal.

Braverman (1994), a pioneer in the field of traumatic stress in the workplace, says corporate downsizing and restructuring heighten the risk of workplace violence as more employees face the humiliation of fear and rage associated with job loss.

Braverman (1994) states that employees who have been fired, demoted or passed over for a promotion may return to the workplace wanting revenge. Because of the employee's despair he/she becomes a threat to other employees. He illustrates this by citing incidents in 1991 of murders from the U.S. Postal Service in Royal Oak, Michigan, and the 1993 shooting of eight 
people at the San Francisco law firm of Pettit and Martin. Braverman stresses the need to look at today's workplace issues as health problems by citing that people at work, according to figures obtained from the Occupational Safety and Health (NIOSH) and Bureau Statistics, are exposed to lethal violence. Homicide accounts for $17 \%$ of all deaths in the workplace.

Braverman's research claims that human resources staff play the most significant role, especially in advising management in understanding today's organizational problems. He claims that human resource management needs to reassess and look closely at how they are communicating and managing. Organizations tend to deny or ignore human issues. Mangers who simply try to deal with violent acts treat them as problems of supervision. This is not so.

Braverman encourages organizations to deal with workplace violence incidents as "systems problems," he believes violence occurs because of a combination of events and conditions. He says they fall into the following three categories: (1) individual characteristics, such as paranoid personalities or a style of thinking in the workplace, drug or alcohol abuse, life stressors (divorce/separation and illness) and experiences of helplessness and isolation; (2) precipitating events or conditions that might include terminations, job change, and harassment by superiors or fellow employees; (3) systems characteristics, or the way an organization responds to stresses, change and crisis. Do they deny or ignore human issues such as individual differences and the needs of employees, manage unusual situations (such as downsizing), punish or expel deviant behavior in employees, instead of recognizing the need for specialized focused solutions to these dangerous situations? Is there adequate communication between management officials? If not, this could signal problems that information is not shared. How does "top management" respond to problems? Do they delegate down or are they involved?

Braverman (1994) criticizes the way in which management delegates problems and says that management needs to develop a new approach to deal with violence and trauma issues. He claims more work needs to be done on the practices of human resource staff, management styles and company-wide work cultures. Braverman decries today's practices, especially the way employees are handled after a downsizing or the way an employee is handled after a disruptive situation, e.g., termination. He wants management to recognize the need for specialized focused solutions; his hopes are to try to create a workplace environment where issues are dealt with more 
openly.

Mackay (1997) points out that although organizations are re-shifting their priorities, they are no longer employing "generalists," people who are capable of carrying out many organizational functions. His prediction for the 21st Century is the "specialist" employee who has a specific skill and a talent for a particular job will know how to survive in today's workplace. He urges today's workforce to reach out to other people inside the organization and create crossfunctional teams and networks with individuals inside and outside of the organization. His concerns focus on the traditional employee who is looking to the boss to help him. Mackay says the boss may no longer be able to help the displaced employee because he may be next to lose his job.

Bridges (1994), a consultant and lecturer, states "that our jobs are disappearing," and that many organizations are headed down the path of "dejobbing." He elaborates by stressing that most people get their identity through their jobs, but they must learn to get it in other ways. Traditionally, a job provided a person with connection to the community, a sense of purpose, and to many people, self-esteem.

Both psychologically and mentally the shift that Bridges is predicting is hard to make since our jobs have been so much a part of our way of life. It will prove impossible and traumatic to some.

Historically the concept of "job" appeared in the early 19th Century to describe the work that needed to be done in factories and bureaucracies. Then technology enabled companies to automate production lines. Bridges (1994) wants us to forget about "jobs" and look only for the work that needs to be accomplished. One's career in the 21st Century, according to Bridges (1994), depends on the following: (1) employability: security in employment will come from having the abilities and attitudes that an employer needs; (2) vendor-mindedness: a loyal employer is no longer an asset; start thinking like a outside vendor who is hired to do a specific task. (3) resiliency: today's organizations will be using a different modus operandi, what the new employee will need as well as the organization will be the ability to be flexible, to get rid of the outdated ideas and learn new ones and implement them, bounce back quickly from disappointment, live with ambivalence and uncertainty, and find security from within rather than from the outside. 
Trauma and its affect covers every facet of our lives from childhood to adulthood. Understanding it will help many cope on the road to recovery from a traumatic event.

The next phase for individuals and organizations is to address how to intervene helpfully with a TLE employee by defining effective techniques for reintegrating trauma survivors.

\section{Trauma Intervention Techniques}

The intervention techniques available to returning people who have suffered a TLE are many and varied, and their relative applicability and effectiveness will depend on a number of factors, e.g., the traumatic event which was experienced, the level of medical and psychological therapy the TLE employee has had following the traumatic life event and before returning to work, and the help the TLE employee has sought and received from support groups, family members, friends and associates.

This section will present a variety of psychological interventions that may already be available to individuals who are returning to work after experiencing a trauma. They are grouped into three sections: Individual Psychotherapy and Group Therapy, Self-help Interventions and Other Suggested Types of Interventions for Traumatized Individuals.

\section{Individual Psychotheraphy and Group Therapy}

\section{Psychotherapy}

According to Viscott (1992), an invaluable support for a trauma victim is psychotherapy, which is the unique experience of relating to a caring, supportive person who assists the survivor and who is detached enough to allow the victim to grieve without interference. Viscott (1992) calls the process of coming to terms with a loss "working through." "Working through involves not forgetting the pain but feeling the pain, testing your ability to live with it, and, finally, allowing the pain to subside" (p. 134). This is the main concern of psychotherapy, in which the unmourned loss is identified, its effects defined, and its pain liberated from the defenses that bind it, so it can be felt and accepted.

\section{Group Therapy}

Corey and Corey (1997) point out that group therapy originated during World War II in response to a shortage of personnel trained to provide individual therapy. The "Therapy Group" is another intervention that is highly effective as an approach for helping individuals working 
through their problems. Yalom (1995) has observed in his work with clients that "...the therapeutic goals of patients, somewhere between the third and sixth months of group therapy, often undergo a shift. Their initial goal, relief of suffering, is modified and eventually replaced by new goals, usually interpersonal in nature"(p. 20/21) Corey and Corey (1997) also find that, "groups provide a natural laboratory that demonstrates to people that they are not alone and that there is hope for creating a different life"(p. 5). Bradshaw (1992) notes that "group therapy has more power to demystify than one-to-one therapy because groups provide more faces to give monitoring feedback and groups provide more ways to restore the interpersonal bridge"(p. 139). Yalom (1995) asserts that, "despite the complexity of human problems, certain common denominators are clearly evident, and the members of a therapy group soon perceive their similarities"(p. 6). Yalom claims that "therapy is an emotional and corrective experience"(p. 26). For the therapy group to be effective it must focus on the here-and-now..

Yalom (1995), points to two components which are necessary for the effectiveness of group therapy: (1) Experiencing. Members of the group must experience an authenticity and spontaneity with the other participants. Here, strong feelings are generated among members toward each other and the therapist. These here-and-now feelings become the major discourse of the group. Such focus facilitates the development and emergence of each person's social microcosm which encompasses feedback, meaningful self-disclosure and learning of new social techniques. (2) Illumination of process. If the powerful therapeutic factor of interpersonal learning is to take place, members of a group must examine the process. A reflective loop must be set in motion where the group reflects upon what it has experienced as a group. This step is crucial if the emotional experience is to be transformed into a therapeutic one (Yalom, 1995).

\section{Short-Term Group Therapy}

In 1960, encounter groups and personal growth groups were ways in which people could make a connection for personal growth. Today, there are short term groups for specific problems designed to assist individuals. According to an article published in the American Psychological Association Monitor, Scott Sleek (1995) as cited in Corey and Corey (1997) describes an affordable range of group techniques that can be used for both psychological and medical problems. Because groups can now be designed to fit into managed care they serve multiple 
purposes. On a timely basis individuals can address personal growth problems and on a cost basis it is affordable. Sleek (1995) summarized studies giving evidence that group therapy is as effective as individual therapy in bringing about change.

The 1990's has witnessed a resurgence of interest and work in short-term, specific issue groups. Such groups provide a sense of community and shared striving; they are time-limited and have fairly narrow goals. Many of these types of groups are aimed at symptomatic relief, such as teaching participants problem-solving skills that can assist in personal change.

Another type of intervention that deserves to be mentioned is the project launched in 1986 by Piper, McCallum and Azin at the University of Alberta Hospital, Edmondton, Alberta, Canada, entitled a "Short Term Therapy for Loss Patients Group." Its general orientation is psychotherapeutic with an emphasis on the group as a system. It is a time-limited, short-term treatment and participants enter the group after having experienced a loss during the past year. The group's time period is twelve weeks and the group's structure is homogeneous. Piper, McCallum and Azin (1992) agree that "short term therapy group approaches are among the most cost effective forms of treatment"(p. 5). The format has been so successful that the short-term therapy format has been extended to other areas, such as conflict resolution and problem solving.

\section{Grief Counseling Intervention}

Corey and Corey (1997) state that grief counseling differs from a therapy group in that it deals with conscious problems. It is not aimed at major personality changes but is oriented toward the resolution of specific and short-term issues; furthermore, it is not concerned with treatment of more severe psychological and behavioral disorders.

Grief counseling intervention is one short-term group approach which therapists can use to provide a smooth re-entry transition for traumatized employees returning to work. Bass and Davis (1988) believe "grief waits for expression and when you do not allow yourself to honor grief, it festers"(p. 120). Tatelbaum (1980) says, "grief unexpressed is like a powder keg waiting to be ignited"(p. 8). Ward (1995) concurs: "If we do not mourn losses at the time they happen, more problems can occur, for example, severe depression can be triggered off when another loss may occur"(p. 53). "Grief needs space and time to express itself, and you need to give yourself the time, security and permission to grieve"(p. 120). Fitzgerald (1994) adds that grieving is a 
process, and grieving people can help themselves if they understand what is happening to them (p. 37).

\section{Open Grief Group Intervention}

Ron Ramsay (1993), a Dutch professor, introduced another type of grief intervention called "the open grief group." Survivors who choose this type of intervention may use it to complement individual therapy. This group process is challenging for the survivor. In its setting a "confrontational approach" is used. The purpose behind this group process is reducing the fear people have regarding their emotions. Ramsay noted that, "clients would become less afraid of their emotions if they see other people living through their pain and finding relief by letting go of their pain"(p. 91).

Ramsay (1979) tested his thesis by bringing three people together who were experiencing the trauma of loss. They expressed relief at being able to share their losses with other people. A decade later, after success with over 900 clients, Ramsay (1979) asserts that the "open group approach" supports healthy grief work after having experienced a trauma.

Bradshaw (1992) disagrees with the "confrontational approach" which Ramsay supports. Bradshaw (1992), in his work with families resolving a loss, stresses the process of working through the trauma or grieving by internalizing the source (figure) relationships. Bradshaw defines source figures as biological parents, stepparents, adopted parents, and surrogate parents, such as guardians, relatives, or anyone else who is significant in teaching and relating to the person in a loving way. He claims our source figures often represent early childhood negative interactions we may have had with them. He suggests that each person re-imagine their original relationships with their source figures and, hopefully, transform this relationship into a growthful experience.

Bradshaw (1992) promotes the theory of having a support person work with the traumatized individual. He claims that when a loss occurs (e.g., death of a spouse or parent) the grieved person is vulnerable and wounded. The role of the support person is essential in this

process. That person enters a partnership with the grieved person and tries to interpret the grieved person's way of seeing the world and mirrors it back to them so they can see themselves more clearly. Bradshaw states, "The process that he is assisting his clients achieve does not 
involve 'confrontation' although some therapist encourage their clients towards this technique claiming this assists in their recovery effort." However, Bradshaw (1992) is emphatic about his process, only because he is assisting his clients with separating from their source figures by utilizing the images that represent these people and their relationship to the grieved person in this relationship.

\section{Self Help Therapies}

\section{Self Help as an Intervention}

There is also much assistance to be gained by the TLE employee from the abundance of books, magazines and other publications written to provide guidance and support to individuals who have experienced a range of traumas. All book stores now have a "self-help" section where a person can select from a menu of general and specific publications.

A person can also join a self-help group. Kennedy and Charles (1990) state that since the 1970's these groups have witnessed an expansion of resources and people. The self-help groups focus on peer support and education and do not provide treatment. These groups are available at low or no cost to large numbers of group members who are coping with developmental disabilities, chronic emotional problems, or a specific life event such as a divorce or death of a family member. Counselors and therapists often suggest that their clients participate in these groups in order to cope more effectively with their specific problems. The resources usually consist of individuals who share a common experience and who serve as helpers to assist other people, providing and disseminating information about the common issue, often engaging in constructive actions related to an experience that the group shares.

Some self-help publications which have applicability to a broad range of symptoms exhibited by trauma victims are: Feeling Good; The New Mood Therapy by David D. Burns, M.D.; Timeless Healing: The Power and Biology of Belief by Herbert Benson, MD.; and Putting It All Together by Dr. Irene Kassorala. Each of these three authors discussed in the following paragraphs provide insights applicable to TLE's.

First, Burns (1980) proposed cognitive therapy as a self-help tool. By "cognitive" he means how you are thinking and feeling about things at a particular moment. Beck's (1972), one of the world's foremost authorities on mood disorders points out: (1) If you are feeling depressed 
and anxious, you are thinking in an illogical, negative manner and you behave in a self-defeating manner. (2) With some effort you can train yourself to straighten your thinking patterns. (3) As your painful symptoms are eliminated, you will become more productive and happy again, and you will respect yourself. (4) These aims can be accomplished in a relatively short period of time (p. 3).

According to Burns, our moods are created by our own cognition or thoughts--the way one looks at things and the way a person interprets things. Burn's (1980) calls this approach "fast acting." Once a person eliminates their symptoms he/she can alter any mood.

Benson (1996), an associate professor of medicine at Harvard Medical School, introduced a self-healing approach based on the innate human impulse to turn to the "visceral nature of human beliefs" and faith in times of illness and need.

Dr. Benson stresses the power of self-care that healthy people can do for themselves. Benson in his 30 years of practicing medicine claims, "I've found no healing force more impressive or more universally accessible than the power of the individual to care for and cure him or herself. I believe the ideal model for medicine is that of the three-legged stool. "The stool is balanced by the appropriate application of self-care, medication, and ethical procedures"(p. 23). One leg, represents the patient and what he/she can do for themselves, is the most discredited and ignored aspects of health care today. The second legs refers to the health care professionals, and the third leg is self-care which includes not only nutrition and physical exercise, but the inner development of beliefs that promote healing.

Benson postulates that invoking beliefs is not only emotionally and spiritually soothing, but vitally important to physical well-being. By tapping into your beliefs, which may include, "soul searching", "mulling it over." "listening to ones ear," "going inside oneself," "praying," "sleeping on it," using your intuition and know something "feels right," people tune into their internal wisdom that calls out to them (p. 297). Benson's challenges and encourages the reader, when faced with a medical decision, to ask the following question: "What feels like the right thing to do? What would I do if the choice were entirely up to me?"(p. 297). He stresses letting 'belief' play a part by honoring your convictions and perceptions and not over relying on the medical system to give all of the answers." Benson's approach is particularly useful for TLE employees 
because it enables them to access their intrinsic ability to heal themselves.

An acknowledged leader in group work, Dr. Kassorla (1986) offers practical analysis, suggestions and exercises which can assist a TLE individual to focus and deal with the interpersonal problems they have as a result of a traumatic experience. Dr. Kassorla's focus on dealing with negative emotions within ongoing relationships is important because, as Herman notes, the TLE employee re-entry to the workplace involves re-establishing his relationships with his supervisors and co-workers.

\section{Helping and Interviewing Models of Intervention}

Carkhuff (1993) introduced helping models of intervention, which some have used in dealing with the aftermath of crisis and trauma. This model involves the training of a helper and a helpee to assist each other through an interview technique. Helpers ask questions, offer feedback and try to mirror what the other person is saying. Interpersonal and communicative skills exercises are taught to assist them in developing rapport with another person. "...helping is simply a learning or relearning process leading to change or gain in the behavior of the helpee"(p. 240).

Bergin (1971) and Carkhuff (1969) state that comparative research on the lasting effects of counseling, rehabilitation and psychotherapeutic techniques has shown that within three-to-five years of treatment 65 to 75 percent of the ex-psychiatric patients would again be patients. The conclusion that psychotherapy and counseling were effective about 20 percent of the time.

Carkhuff (1993) also stresses the importance of feedback in any helping model. Taking a historic perspective Carkhuff (1993) states that psychoanalytic, neo-analytic, client-centered, existential and other treatments originated by Freud followed an insight approach. They believed that, with insight, people would function better. In contrast, came Watson and the behaviorist school of thought, neo-behavioristic, and other treatment approaches that favored action. They felt that with conditioning of new and more effective behavioral responses, and/or the counterconditioning of old and ineffective responses, people would function more effectively. To the proponents of these theories, action and insight were unrelated and one did not require the other.

With the evolution of the social learning theory and human resource approaches, Carkhuff noted that practitioners found that feedback was essential in moving the person from one level of 
functioning to another.

Carkhuff's model, which includes feedback, has had much success in helping communities work more effectively with each other. This approach has been used in community based justice settings and has yielded data indicating reduced recidivism and increased employability.

Gerald Egan (1990) in The Skilled Worker describes an interview approach that stresses empathy and probing. He has designed exercises to help helpers develop a more empathetic voice and ask appropriate non-offensive probing questions. Egan claims probing is very effective because it invites a person to discuss an issue more fully, and in using this approach relevant details are often evoked that the trauma survivor may not believe are important. Probing helps to clarify the issue, search for missing information, and expand on details. The main purpose of probing is to gather data that deepens understanding of the problem and creates more opportunities for dialogue.

\section{Other Suggested Types of Interventions For Traumatized Individuals}

\section{Critical Incident Stress Debriefing Intervention (CISD)}

An intervention that has been used nationally for trauma and crisis events is called the Critical Incident Stress Debriefing (CISD) Group. The U.S. Postal Service has used this type of debriefing very effectively with their managers and employees after the many postal killings. Mitchell (1988) points out that the Debriefing Team is a psychological and educational support group that uses a specialized combination of mental-health professional combined with peer support personnel. Their main objective is to "mitigate the impact of a critical incident and accelerate the return of personnel to routine functions after an incident." This team is primarily used for events that overwhelm the coping methods of in-house emergency personnel. Trained professionals provide important stress-reduction information. Participants are encouraged to speak out on the various aspects of the incident that has distressed them. The goal of the debriefing sessions is to foster discussion so that recovery for the participants is as rapid as possible. 


\section{Four Level Intervention Model}

Noer (1993) brings "layoff survivor sickness" to our attention. This is what survivors experience after going through a downsizing. He claims the root cause of layoff survivor sickness is a "profound shift in the psychological employment contract that binds industry and organization" (p. 3). These symptoms are found in pockets of the organization, and Noer (1993) states that both the individual and the organization must work together to eliminate them. He points out that people in organizations should strive to become less dependent on the organization for their survival. He claims it is only through interventions that the pathology of layoff survivor sickness can be addressed. Noer (1993) believes that individuals are responsible for their own recovery, and survivors must let go of the familiar and venture out into untested new areas. Healing survivor sickness requires great personal courage. Downs (1995), an executive consultant, and the author of Executive Executions states that the survivor syndrome is a real problem in an organizations. Downs (1995) agrees with Noer that "managing the survivors"(p. 52) is a tedious task.

Noer (1995) conducted a study which included interviews of small groups of layoff survivors and individual interviews of human resource professionals. An analysis of the interviews uncovered 15 categories of concern: insecurity, unfairness, depression/stress, risk taking/motivation, distrust/betrayal, optimism, commitment, lack of communication, anger, strategic direction, credibility, profit orientation, change unexpected findings. Five years later he returned to the same organizations to note that "time does not heal all wounds."(p. 71). Noer (1993) found very little change--employees were "ground down by five years of job insecurity and flux"(p. 83). Although the interviews showed they have reduced their dependency on the organization they remain an angry group still hoping for open communication from their organization. The study showed that survivor symptoms do not go away, but remain and may frequently over the years intensify.

In his research and findings Noer (1993) determined the survivors of downsizing and reorganizations experience the following: 


\begin{tabular}{|l|l|l|}
\hline Feeling Clusters & Coping Methods & Symptoms Over Time \\
\hline Fear/insecurity \& uncertainty & Reduced Risk-Taking & Fatigue/Depression \\
\hline Frustration/anger \& resentment & Lower Productivity & Loss of Control \\
\hline Sadness/depression \& guilt & Thirst for Information & $\begin{array}{l}\text { Heightened/Focused } \\
\text { Anger }\end{array}$ \\
\hline Unfairness/betrayal \& distrust & Survivor Blaming & \\
\hline & Justification/Explanation & \\
\hline & Denial & \\
\hline
\end{tabular}

Noer (1993) identifies four levels of intervention needed to deal with this pathology successfully and illustrates this gradual healing in the pyramid effect.

Level I is designed to assist employees to keep themselves from sinking into survivor symptoms. Here Noer (1993) suggests that the burden of managing the layoff process is crucial for employee. Layoff planners and managers need to understand how important it is to communicate to survivors what to expect and what resources are available to them such as severance pay, benefits, outplacement services and the maintenance of their work space. Level II deals with the actual grieving by employees who are losing their jobs. Managers and human resource staff should be trained to interact with employees who are losing their jobs and deal with the emotions and feelings that a situation like this may evoke. Level III is more complex because employees, who were once dependent on the organization, now have to learn to survive by themselves. Noer (1993) suggests people need to detach themselves from the organization and not depend on the organization to nurture and save their lives. This can be done by employees taking more control of their lives, keeping their personal power and approving of themselves even without additional affirmation of the organization. Lastly, Level IV encourages the organization's role in developing a new employee contracts with their employees; such processes might include self-directed teams, a flexible benefit plan, non-hierarchial performance reward system, diversity recruitment and non-traditional career paths.

Noer's "system approach" is very similar to Braverman's "systems problems" diagnosis of an organization. Both consultants focus on an intervention where the employees are the main 
focus. They differ in that Braverman takes an "internal look," mainly because his work has evolved around violence in an organization, whereas Noer takes a "global look" and makes recommendation to the overall operations of the organization.

\section{Survivor Recovery Intervention}

Herman (1992) introduces a recovery process that has three stages. These three stages include (1) establishing a safety net, (2) telling the trauma story and (3) reconnecting the individual back into the work community.

Establishing a safety net is necessary since survivors feel unsafe and their emotions and feelings appear out of control. The survivor needs a safe refuge. That safe refuge can be found in a compassionate friend or visiting a counselor willing to talk about these feelings. After a trauma, a survivor may want to go into seclusion and perhaps avoid going home. It may take days and weeks before he/she may feel comfortable in resuming simple activities such as driving, shopping or even visiting friends.

The second stage of recovery is the "remembering and mourning stage." It is here that the survivor may want to tell the trauma story and reconstruct it to include a review of the meaning of the event. It is only by working through this mourning stage that survivors find their inner life.

The final stage is reconnection. Having come to terms with the traumatic event, survivors must now venture out to reconnect themselves with the larger world. Herman (1992) states that survivors usually find a "survivor mission," such as, social action. Fulfillment of the mission can take many forms, from speaking out on the trauma, to getting involved in an organization and being an advocate for the trauma cause.

Greenstone and Leviton (1993) in his book The Elements of Crisis Intervention agrees with Judith Lewis Herman (1992) that individuals who have experienced a trauma must deal overtly with their thoughts, feelings and behavior. Greenstone \& Leviton (1993) elaborates by stressing the importance of communicating with a person in a traumatized state on three levels; (1) content, which provides him with the information he needs; (2) feeling, which conveys the sender's emotions and (3) meaning, which mirrors the behavior or situation that has generated the feelings being communicated. 


\section{Intervention Insights on Gender}

In his work as a psychotherapist and counselor, Golden (1996) reports some very interesting research on gender differences in group work with trauma participants. Golden says men and women grieve differently. Men tend not to share their feelings in a group. They grieve in private and do not want to burden anyone with their grief, they want to maintain their independence and they want to use their strength of action in dealing with their grief. For example, a male in a group lost his son in a car accident. After the son's death, the man started to put together a book about his son, something he could work at and hold in his hands. On the other hand, Golden states that women have a larger support network and will share their grief and connect with other people, therefore, the working through process becomes more interpersonal for the woman. Men are used to a hierarchy. They see grief as a personal burden and would not lay it on someone else. In a hierarchy you do not place burden on someone who has no responsibility for it.

This contradicts what Herman (1992) asserts, that it is important for the person--male or female--to tell the trauma story, male resistance to doing so aligns with the research compiled by Barski (1993), who interviewed ten survivors two of whom were men who had lost a wife and a son to death. They stated that upon their return to the workplace, they told no one of their grief or what had happened. They did not feel comfortable talking about it.

\section{Summary of Psychological Interventions}

As is evident, there are numerous types of therapies and psychological interventions available to individuals who have experienced a traumatic life experience or who are grieving the loss of a significant other. These psychological interventions share three qualities: (1) they all use a psychotherapeutic model whether it involves individual or group sessions; (2) the survivor of the trauma is the recipient of the therapy; (3) and the sessions take place outside the work setting. The intervention studied in this research, the Study Circle, is introduced as a complement to psychological interventions and differs from the latter in three ways: (1) The Study Circle is an educational format, not a therapeutic one; (2) the participants of the Study Circle group may or may not be TLE survivors but their managers may be and, indirectly, their co-workers; (3) the sessions are held in the work setting and are focused on workplace activities. 
While one purpose of the psychological interventions is to facilitate the TLE's return to the workplace, with a focus on the survivor's thoughts, feelings and behavior, the Study Circle's purpose is also to facilitate the TLE's return to the workplace, with a focus on the thoughts, feelings and behavior of the survivor's manager and co-workers in the workplace setting.

Whereas in the psychological interventions, the therapist or the group members act as the agents of change for the TLE survivor, the Study Circle promotes the survivor's manager and coworker's as agents of change on the job.

The Study Circle intervention is no way meant to replace or substitute for therapeutic interventions, which should be an essential part of the survivor's recovery process. Nothing can replace effective psychological healing. On the other hand, none of the psychological interventions currently available are designed to create a workplace setting--manager and coworkers--conducive to the successful re-entry of the TLE employee. Unprepared managers and co-workers can easily hinder or delay a survivor's successful re-entry, not through maliciousness but through a lack of knowledge of the psychological process which the survivor must go through.

\section{Study Circles}

The intervention to be used in this research study, The Study Circle, is primarily an educational intervention. According to Corey and Corey (1997) this type of educational intervention strives to educate members who are relatively well-functioning, but who may have an information deficit about a certain area. The specialist or facilitator uses the group medium to educate the group participants in a life transition or in trying to cope with an immediate life crisis.

\section{Introduction}

This section of the research project will discuss (1) the historical background of Study Circles, (2) Study Circles in the United States since 1970, (3) Study Circles and group participation and (4) Study Circles as an adult learning process.

\section{Historical Background of Study Circles}

Study Circles as a distinct form of education emerged in the United States around 1878 as one element of the Chautauqua Movement, a name derived from Lake Chautauqua, a campsite where Sunday School meetings were held. Bishop John H. Vincent created Study Circle groups 
from the individuals who attended the Chautauqua Literary and Scientific Circle (CISC). The CISC developed printed study circle materials for use by small groups to study subjects such as history, art, languages and literature. This reflected a fresh collaborative and interactive approach to adult learning and education different from the traditional classroom format. By 1878, 15,000 "home study circles" could be found across America using the Caduca approach as their form of education and discussion. Study Circles were utilized mostly in public affairs organizations, bible study groups, literary groups, and art groups.

According to Oliver (1987) what history has shown us is that in the United States organizers of adult civic educational programs seemed more comfortable with educational formats involving large public lecture halls and school auditoriums (i.e., Lyceum Movement, university extension, The Studebaker Public Forum Movement) than with small groups where people come together to discuss issues and exchange ideas. One of the few exceptions, as mentioned above, was the Caduca Literary and Scientific Circle (CISC) which developed a four-year correspondence study based on "home study circles." The Study Circle content responded to the needs of the industrialized urban population for college credits and knowledge.

Oscar Olson of the Swedish temperance movement visited the United States in 1898 and took the Study Circle idea back to Sweden. Oliver (1987) states Olson became known as the "father of the study circle" in Sweden around 1902 (p.2). Study Circles proved to be the mechanism to providing a means for effectively recruiting and educating the members of the movements.

During the 19th century Sweden was a bleak nation. Its social discontent created a demand for social change. Popular movements began to emerge, including the temperance movement, the free church movement, and the blue collar industrial union. These movements gave the people a framework and a taste for self-government as they fought for basic rights within their society. The leaders of these movements realized that the education of their undereducated members would help bring about a major change in Swedish society. Not only did the Study Circle serve as a vehicle for many popular movements to advance their causes and create opportunities for the education of their people, more importantly it brought all types of people together. Oliver (1987) stated "following World War II the Study Circle was the most important 
form of adult civic education in Sweden"(p. 5).

After the war, Study Circle activities became more extensive and larger in their scope, involving members of political and religious parties and intramural departments. Oliver (1987) states, "The Swedish government recognized and formalized the practice and organizational structure of Study Circles in 1947 by introducing government grants to subsidize the cost of leader salaries and materials"(p. 5). With the approval of these grants came a redefinition of Study Circles as "an informal group which meets for the common pursuit of well-planned studies of a subject or problem area which has previously been decided upon"(p. 6).

In Sweden the use of Study Circles is focused on a simple goal, to promote empowered citizens. For the Swedes, a citizen is empowered by taking part in a dialogue about complex issues, where each citizen has a voice and is heard. In Sweden, Study Circles became a way of life, where meetings were held in homes, churches and meeting halls.

\section{Study Circles in the United States since 1970}

Kurland (1982) Executive Director of Adult Learning Services of the New York State Education Department, undertook a study parallel to the study of Oliver (1987) of Study Circles in Sweden and Denmark. He described his findings in his article "The Scandinavian Study Circle: An Idea for the United States." Based upon his study, with support from the Rockefeller Brothers Fund and the New York State Education Department, he sought to extend the Study Circle concept to the United States. This took root in New York where the New York State Study Circle Consortium was established consisting of eight public and private institutions of higher education which, in 1980, ran 400 Study Circle programs across the state in various institutions. Although this particular approach has not been followed by other state agencies, the Study Circle movement has grown extensively in recent years. For example, the National Issues Forums supported by the Kettering Foundation has, during the past ten years, sponsored up to 5,000 Study Circles a year throughout the United States under the auspices of educational institutions, non-profit organizations and the like.

The Study Circle Resource Center in Pomfret, Connecticut, is a clearinghouse of information of Study Circle activities all over the country and provides substantive training materials to groups interested in conducting such programs. A newsletter is also published with 
information about the Study Circle community and substantive issues related to topics covered in Study Circles.

Aicher (1990), founder of the Study Circle Resource Center in Pomfret, Connecticut, visited Finland and Sweden and did extensive interviews with educators engaged in Study Circle work. He was interested in how the Swedish Study Circle experience differed from that of the United States. He concluded ..."in the United States, the pedagogy is seen as a tool to effect change. Swedes, on the other hand, approach the pedagogy as a tool for enrichment; while it may influence change, that is not the driving motivation"(p. 19).

One way that has been used to promote the Study Circle is to show that it has elements similar to the "rap group" process. This process was introduced in 1970 by Jay Lifton and Chaim Shatan, psychiatrists who invited Viet Nam veterans to retell their stories of the war trauma. Egendorf (1981) reported that those who were "hurting" felt comfortable in this setting. It provided a safe context in which to retell and reconstruct their trauma story outside of a traditional psychiatric setting. It was here that psychological trauma became a "real diagnosis," and eventually recognized and identified formally by the American Psychological Association (Slaby, 1989).

Although many Study Circles are community-based, there are a few examples of Study Circles that are organization-based. These indicate that the Study Circle is slowly making its way into the organizational life of the United States. In 1986, the International Union of Bricklayers and Allied Craftsman, a 100,000-member craft union, adopted Study Circles for its member education. In its first year, it trained several Study Circle leaders, published Study Circle materials and formed 27 Study Circles. The results were overwhelming. Attendance grew and surveys that were taken showed strong interest in union issues and membership. Eighty-eight percent of the participants recommended continuation and further discussion of the Study Circles. The Bricklayer Study Circle Association now has a full-time staff, a newsletter and strong support from union membership. It has trained over 200 local Study Circle leaders and developed a new Study Circle curriculum that covers topics such as union organizing and health care issues.

In the United States, Study Circle topics are many and varied. They are used not only in civic groups, but much more widely by church societies and other socially concerned groups. 
Study Circles are not seen as a necessary adult replacement of our formal educational system. In fact, people perceive the Study Circle as one more variety of a "discussion group." Unlike Sweden, the United States federal government is not--as yet--a major supporter of Study Circles.

\section{Study Circles and Group Participation}

When we are asked to participate in a group setting, two factors can inhibit communication according to Napier/Gershenfield (1987): (1) "previous experience of members with groups and (2) group disillusionment that success in a group is even possible"(p. 26). For example, individuals can readily recall family settings where interactions with parents and siblings led to futile attempts to be "understood." School groups and cliques are often selective in who may join, leaving people feeling alienated from their friends and colleagues.

Napier/Gershenfield (1987) state that false assumptions can also inhibit group communication, such as "We know what others mean, we know what we mean"(p. 26). In any group, it is likely that each person receives a message differently and interprets that same message in a different way. In a Study Circle, Levine (1994) claims each participant contributes in relation to his/her perceived objective. She states, "The most silent or least obvious contributor may be the individual who is the most self-developing. The most vocal or most active participant may be the one who, personally, has gained the least, even if he/she contributed the most"(p. 27).

At times individuals may gather in a Study Circle group to discuss very sensitive issues such as race relations and spousal abuse giving rise to unexpected outbursts of emotion on volatile issues. In a conversation with the Study Circle Resource Center in Pomfret, Connecticut, the researcher spoke with Matt Leighninger, Program Director about how Study Circle leaders cope in such situations. He reported that there is no documented research of violent incidents, but that they should be dealt with simply and directly. Individual feelings are processed during the Study Circle; therefore, if an outburst occurs, each person in the Study Circle shares his/her point of view including the person who may have caused the disruption. After all the participants have had an opportunity to talk about what occurred, the Study Circle continues. Mr. Leighninger states this is the process that is used and it works. 


\section{Study Circles as an Adult Learning Process}

Stubblefield (1981) says "the Study Circle offers a new format for engaging learners in studying and discussing public issues" (p. 120). Built on the experience and knowledge of the group members, it expands horizons by ensuring that everyone's views are considered during the discussion (Oliver, 1992).

Osborne (1981) states that "Study Circles represent an advance in the democratization of learning and an opportunity for local problem solving of community and public issues"(p. 73). Osborne (1981) an advocate for informal learning and public policy issues, believes ..."a study circle is a democratic form of group learning"(p. 73). Five to twenty people with a common interest gather to investigate a particular topic. Working together, they learn from each other, from prepared materials and from outside sources. No instructor teaches or controls the circle. "Led by a facilitator trained in group dynamics and the study circle concept, the participants make all the decisions"(p. 73).

The Study Circle learning format requires a leader who can give the members focus, foster group discussion, and encourage ownership of the topic. The leader does not teach and need not be an expert in the subject under discussion, but must be familiar enough with the subject matter to raise questions for the group. The leader must create a collaborative learning atmosphere where each participant feels free to express ideas, relate personal experiences, and discuss points of view on the subject (Osborne, 1981).

Osborne and Shevat (1982) reported on DeRidder-Thurston Inc. in Rochester, New York who reported having concerns with employee motivation and raising the level of productivity with their employees. After examining various techniques available, they chose to introduce Study Circles in their organization because the concept covered the employee's educational and social needs as well as the employer's needs. The goal was "getting people to work together"(p. 37). The Study Circles proved to be very effective in getting people to talk together which led to more cooperative efforts at work.

Oliver (1987) agrees with Osborne and states the following:

...adult education in this sense is conceived as a link between learning and life, based on the individual's innate desire to learn and grow (p.xvii). 
Oliver (1992) shows people that they can have voice in their civic community and the policies that are being made. The uniqueness about the Study Circle is that it encourages people to formulate their own ideas and share them with others, something seldom done in large meeting halls or public hearings. Oliver (1987) continues:

...Study Circle is a tool for study and discussion for democratic participation, for equality among members, and for encouraging members to become their own experts. It is a powerful vehicle for involving people at a fundamental level in the life of their community or organization. It is a proven and powerful means for adult civic education (p. 147).

Since Study Circles are driven primarily by the participants' needs, it is appropriate that the subject matter should drive the Study Circle. Christensen (1983) states "The process is perceived as important to this method as the content."(p. 212). Individuals meet and share their experiences, but the actual learning in a Study Circle occurs collectively when each person hears and relates their personal experience to that of the group.

Merriam and Caffarella (1993) describe a model of self-directed learning by Jarvis whose interactive dynamics are reflected in a Study Circle (See Appendix A). Jarvis (1987), a theorist in adult learning, defines adult learning as "the transformation of experience into knowledge, skills and attitudes" and further concludes that for adults "all learning has an experiential basis"(p.164). His interactive model of learning is analogous to his theory of learning--learning is accomplished by doing and participating, thus producing a person who is changed and more experienced. The model is strong because it deals with a variety of responses one can have from an interactive learning experience. Learning can occur in many different ways, with outcomes personalized to each participant. Jarvis' model describes well the results that occur in a Study Circle experience, where people learn in a participatory environment, reflecting on and integrating new information received about the topic being discussed.

Blid (1990) a Study Circle leader and an adult educator, has written extensively on Study Circles. He states that "adult education is a living, activist process that relates knowledge to action and social change, to development and creativity, and to social intercourse and collective 
development"(p. 23). The learning process extends from people understanding information in a way that influences their circumstances. Blid (1990) outlines different types of Study Circles that could be formed in (Appendix B).

Blid (1980) offers insight into the process of choosing a Study Circle leader. He states that leaders must be familiar with the subject matter and comfortable with the aims of education. A leader's main goal is to "guide but not direct the circle"(p. 29). The leader must be sensitive to the circle's progress by promoting a positive, cooperative atmosphere, being a good listener, getting to know the members, encouraging member initiative and participation and gaining membership confidence. Leaders do not act as experts or subject matter specialists.

Blid (1990) does not believe that pre-packaged materials should be prepared for Study Circles. He claims it detracts from the freedom of the members to control the course of the study group activities. Other proponents dispute Blid on this and say pre-packaged materials serve as a tool to be used, which can be adapted over and over again. Because of the flexibility built into the Study Circle plan, each Study Circle may adapt the materials to its unique membership and theme.

Kurland in his article referred to a 1977 report entitled "The Study Circle: A Brief

Introduction" published by Brevskolan, a Stockholm Study Circle publisher, which provided what excellent statement of the basic philosophy of the Study Circle. It states the following:

One of the fundamental educational ideas of the Study Circle is that people have an innate desire to learn. ...Experience of the growth of one's knowledge and of one's improving ability to understand and interact with the surrounding world is sufficient reward in itself. Life and learning belong together. The aim of the Study Circle can be defined as 'greater understanding or insight. Through their studies the members must be enabled to put their lives into perspective and to view their own subject in a wider social context (p. 25).

\section{Summary}

This literature review began by tracing the effects that trauma can have on an individual's life, and it examines different types of interventions. It examined not only the psychic wounds that a person must endure after a trauma, but also the underlying structures that may affect its healing process. After a long review of various psychotherapeutic interventions, it concludes with 
a discussion of Study Circles, the educational model of intervention that will be introduced in this research study.

The intervention section challenges the organization to explore some of the various types of interventions available to assist individuals in coping with a traumatic event in their lives. These creative models range from a small support group to individual psychotherapy and helping models.

Presently, there are few resources and almost no published research that discuss the research questions and topic of this research study. However, the researcher was fortunate in uncovering two theorists--Braverman and Noer (researcher met Dr. Noer at a seminar) who are presently doing work with organizations trying to affect change after a traumatic event has occurred.

Study Circles, an educational adult learning intervention, adds a non-therapeutic model that can be used in the workplace. This model will take Braverman's and Noer's "systems approach" a step further by providing an on-site, non-therapeutic approach to the traumatic recovery process. This model also integrates as its educational content the three stages of recovery from trauma developed by Herman (1992). 


\section{Chapter 3}

\section{METHODOLOGY}

\section{Introduction}

This chapter introduces the following: the intervention, Study Circles the adult learning technique which will be used in this study; methods of sample selection of participants; procedures for conducting the study; and data/information collection and processing. Specific research methods include the long interview, case studies, participant observations, audiotape interviews and videography. In addition, the pilot study and related insights are included.

This research project was conducted at the Department of Health and Human Services (HHS) in Washington, DC for two reasons. First, the researcher is employed in the department in the Office of Equal Employment Opportunity, and had access to the participants available for the study. Second, the researcher focused on senior managers in HHS (SES and GS-15 personnel) and returning TLE (traumatic life experienced) employees. After discussing the topic with the researcher's supervisor, it was determined feasible to conduct this study at the Department of Health and Human Services. Thus, the researcher was able to conduct this research as part of her functional responsibilities. It was agreed that this study and the related research findings would be treated as a contribution to the Department to assist managers in better supervising a returning TLE.

\section{Intervention}

The intervention that the researcher used for the current study follows an educational format called "Study Circles." The researcher selected the Study Circle method of intervention because it is an adult learning technique that allows managers and employees to come together to share their views on a specific topic. Study Circles promote both group interaction and collective sharing of ideas and information among participants. In a Study Circle, all individual views are considered, and participants have an opportunity to listen, dialogue and disagree.

As indicated earlier, Herman (1992) described three stages that are required for the successful recovery and re-entry of the traumatized person into the workplace. Accordingly, these three stages were selected as the themes underlying the three Study Circle sessions. 
Session 1. Establishing a safety net for the returning TLE.

Session 2. Allowing the person to reconstruct the trauma story.

Session 3. Reconnecting the TLE to the work community.

A safety net is defined as a safe haven, a place where someone can go for comfort in their recovery process. This, in turn, extends to a person's environment and includes a safe living situation, financial security, mobility and a plan for self-protection. It includes the survivor's body and related basic health needs, sleep, eating and exercise. This process usually encompasses a social support system that needs to be established by the survivor.

Establishing a safety net is important because when a trauma occurs, survivors are likely to feel powerless and robbed of control over themselves. They may feel unsafe in relation to other people, especially if they are returning to work after a long absence. Because of the time taken by the trauma experience, TLEs may not know if and when they will get paid and if they can have additional time off if they need it. The first session focused on what a safety net may mean to the survivor and how management can establish a safety net for the returning TLE.

The second session discussed the usefulness of having the TLE telling the trauma story. Research has shown that story telling is particularly important to a TLE when he or she returns to work. Sharing this with colleagues is likely to be beneficial. The discussion within the Study Circle focused on whether the trauma story should be reconstructed by the TLEs upon returning to the workplace.

The theme of the third session was reconnecting the TLE to the work community. This theme is important because the returning TLE employee may need to reclaim their "lost world," re-establish relationships with managers and co-workers, and build a new life. The manager plays a key role here. The discussion revolved around the manager's role and how the manager can assist the TLE reconnect with the work world which they may have lost because of the trauma.

\section{Selecting Sample}

Seventeen managers and five employees participated in two Study Circle groups (Group A and Group B) providing an overall sample of 25 participants. An invitation (Appendix C) along with the confidential agreement (Appendix D) were given to each participant. The invitation confirmed the participant's role in the Study Circle and the confidential agreement protects any 
participant disclosure during the Study Circle sessions..

The participants in the Study Circles, both managers and employees, discussed what it is like to re-enter the workplace after having experienced their trauma. The managers observed the employees in this sharing dialogue. Both employees and managers were selected in order that they could gain awareness from each other on how to address the returning TLE re-entering the workplace.

Pre-Study Circle interviews were conducted prior to each Study Circle. In Group A eight managers and three employees were selected. In Group A all but two managers were interviewed, and all the employees (3) were interviewed. In group B, all nine managers were interviewed, but the five (5) employees were not interviewed. The pre-Study Circle interviews (Interview Questions-Appendix E) served as an overview of the scope and purpose of the research, and the introduction of the themes provided background information to better familiarize the potential participants with each theme and its significance in the recovery process.

Because many of the researcher's colleagues were aware of this project and the need to recruit participants, various people in different divisions of the agency made referrals. From among these, the researcher selected individuals based upon the employees' and the managers' interest and whether they were willing to "sign on" for the research by making a personal commitment of time and energy. The researcher was also able to determine whether participants had a familiarity with this type of problem.

The researcher varied the mix in Groups A and B. In Group A participants were selected on a volunteer basis. All managers were either in the SES Executive Service or GS-15, and ranged in grade and pay scale. Group A consisted of eight Caucasian employees and three AfroAmerican employees. Group B was more and diverse included Caucasian, Afro- American, American Indian and Hispanic participants.

The final list of Study Circle participants included the four categories: (1) senior level managers who have not had a traumatic life experience nor supervised a TLE employee; (2) senior level managers who have had a traumatic experience and have supervised a TLE employee; (3) senior level managers who have not had a traumatic experience and who have supervised a TLE employee; (4) TLE employees who have made a successful re-entry to their workplace 
environment.

\section{Procedures}

Prior to beginning each Study Circle, participants received printed materials to read. This literature assisted participants in understanding the process of a Study Circle and the roles of participants and facilitator.

Each participant also received handout materials designed by the researcher (see Appendix F). These handouts served as reference material to acquaint managers and employees with additional information on trauma, managerial responsibility, and Study Circles. It served as a supplemental guide for individuals in the Study Circle.

Participants also signed a confidentiality form prior to engaging in the Study Circle to ensure privacy of all comments and stories (see Appendix D).

Two sets of Study Circles (Groups A and B) were conducted, each Study Circle consisting of three two-hour sessions, as described above under Intervention.

All sessions ran from 11:30 a.m. to 1:30 p.m. This proved to be an excellent time, convenient for both senior managers and other employees. A boxed lunch was provided by the researcher; sharing lunch together served as a social-warmup for all participants. The lunch period provided an incentive for the participants to share their experiences in the group.

The location for the sessions, a seminar room in HHS, was chosen based on availability within HHS, accessibility to all participants, and lack of noise distractions.

The researcher served as the facilitator, leader and observer in the Study Circle sessions. The researcher posed probing questions to the participants to begin the discussion and continued this throughout each session to keep the discussion focused on the theme of the session.

\section{Spontaneous Adjustment}

During the Study Circle sessions the researcher had an opportunity to observe the behavior of returning TLEs and managers. Behaviors such as inappropriate remarks caused slight disruptions in the Study Circle sessions. Some of these behaviors should be expected, as group interactions become intense with different personalities and diverse opinions surfacing on sensitive topics. The following situations may occur during the Study Circles and may need to be addressed by the leader. 
1. If a TLE cries in a Study Circle (as can be expected in the second study circle if the TLE reconstructs the trauma story), what does the leader do? Allow the participant to cry. Try to comfort the participant and assure him or her that it is okay to cry/weep. Continue to go on with the Study Circle.

2. If an employee or manager who is participating in the Study Circle does not want to share their experiences, what does the leader do?

The leader should move on with the subject or ask another participant to share their experience. A non-judgmental approach is the best in this situation, since either the TLE or the manager may have a good reason why they do not feel comfortable discussing certain points.

3. If one person in the Study Circle consistently interrupts and monopolizes the Study Circle with their experiences, what does the leader do?

Sometimes in groups we do encounter individuals who have an overwhelming need to talk, thus preventing other people from getting their share of group time. As time goes on, a group will become less tolerant of such an individual. A person who exhibits this type of behavior needs to be gently challenged to look at the effects of the behavior.

The leader can confront the participant by saying the following:

"Sally, you appear to share easily. I notice you typically identify with most of the problems that have been raised in the group. Is there anything special that you want us to know about you?"

This intervention will give Sally an opportunity to talk out her feelings. If she continues to monopolize the session, the leader can talk with her privately.

4. If one participant in the Study Circle wants to give advice to another participant, e.g, a manager or a returning TLE, what does the leader do?

Participants will be advised by the researcher at the beginning of the Study Circle not to give advice to other participants.

5. If someone in the Study Circle asks the researcher a question and the researcher does not have the answer, what does the leader do?

The leader should tell the participant that she will research the question and will get back to them with an answer, and at a specific time (e.g., an hour, next session). 
6. Many times a session which is really planned well does not turn out that way.

Sometimes there are time constraints that inhibit us from fulfilling what we have set out to do, what does the leader do?

The leader adjusts by deleting certain portions, watching the clock to include an appropriate amount of time for processing, bringing the issue of time to the group's attention and the content they need to cover.

\section{Data Information Collection and Processing}

The Data information collection consisted of five methods: case study, observation, audiotape interview, video taping of each session and an evaluation form. Each tool has its own significance for the research report.

\section{Observation and Audio Tape Interviews}

The researcher audio-taped six pre-Study Circle managerial interviews and three employee interviews in Group A. In Group B all nine manager interviews were audio-taped. During these interviews the participants discussed aspects of their trauma experience. Each interview was professionally transcribed and served as a reference for the researcher in preparing for the Study Circle. Many of the participants were eager to share their experience with the Study Circle group. The audio-tape was an invaluable tool; it allowed the researcher to play back portions of the recorded interview for review of the dialogue. This also clarified the questions and answers between researcher and interviewee. The recording also served as a back up for the researcher in retrieving information.

\section{Videography}

Each Study Circle session was video-taped with a total of nine hours of filming. the video taping of each Study Circle session served several key purposes.

- The video tape provided a "second set of eyes" to assist in data collection. The researcher was be able to review the group process what was said and how it was said in the Study Circle. This served as an excellent method of monitoring the dialogue of each Study Circle session.

- The communication process could be observed more clearly and directly, for example, observing more precisely how participants expressed their fears, hopes, concerns, reservations and 
expectations during each Study Circle session.

- Group participation and group interaction could be monitored. The video tape quickly revealed the body language and enthusiasm of the participants. The researcher was able to replay the video tapes to report accurately on the group interaction.

- Certain topics developed in each Study Circle, such as employee performance problems in Group A. The video taping enabled the researcher to fully recognize and study the differences in each group.

- The video taping provided an accurate way of comparing the two groups. The researcher was able to replay portions of each Study Circle sessions to analyze participant behaviors and reactions.

- The video taping has assisted the researcher in refining the Study Circle process for future Study Circle sessions.

\section{Evaluation Form}

An evaluation form was developed by the researcher and distributed to Group A Study Circle managers and employees. After reviewing Group A's evaluations, the researcher added two more questions (see Appendix G, questions 5 and 6). These questions were added to improve the evaluation form distributed to Group B participants. The new questions assisted the researcher in determining what participants learned in the Study Circle sessions.

In general, the evaluation form served as a vehicle in getting feedback from the managers and employees relative to the Study Circle sessions, and can be used to redesign the sessions or revise any of the related reference material given to future Study Circles participants..

\section{Pilot Case Study}

The researcher conducted a pilot study of the three Study Circle topics with an executive in the Human Resource Office of HHS. The researcher interviewed this participant prior to the Study Circle sessions. The participant was a manager and a returning TLE. Here, the researcher found the importance and effectiveness of the pre-Study Circle interview. It assisted the manager by acquainting him with the topics for the Study Circle sessions, practicing the telling of his trauma story, and understanding the verbiage used by the researcher.

Even though the pilot study lacked multiple participants, it worked out according to the 
format. Each session was an hour in length and the participant felt that after each session he had learned much about the topic and how he himself could apply what he had learned in helping other returning TLEs. In his evaluation he gave the researcher suggestions and reactions on ways the proposed sessions could be improved. His suggestions helped the researcher in planning the proposed research study.

\section{Jacques and Robert--A Case Study in Understanding and Approaching a Traumatic Life Experienced (TLE) Employee in Today's Organization.}

This case study of Jacques and Robert will demonstrate how unsophisticated our organizations are in understanding and dealing with individuals who have experienced a traumatic life experience (TLE) and are making a re-entry back to the workplace. The researcher is using a case study approach because interviews, observation and dialogue best illuminate the experiences of these individuals. This approach will illustrate the importance of the re-entry dimension of organizational life and the deep need for more exploration and examination.

My purpose as an observer is to provide the clearest, most accurate look at the behavior of managers and employees in today's organizational setting in dealing with traumatized employees returning to the workplace.

\section{The Organization and Jacques Place In It}

The organization from which case studies herein are taken is the Department of Health and Human Services (HHS), one of the three largest government agencies in Washington, DC. Its budget is the third largest in the world, and the people who work there reflect the ethnic, social, cultural, religious and educational diversity of the country. It's no different from any other organization where people are concerned with serving their constituents and customers.

Jacques is a manager in the Division of Personnel. He is one of $15 \mathrm{men} /$ women who manage a large segment of human resources. He has a total of 32 years of government service, including service in the Air Force. In his late 50's, he is tall with grayish hair and can be described as Anglo.

In all his years of work, except for an occasional cold, flu or sinus condition which most of Washington residents experience, Jacques rarely complained of anything wrong with him. To his peers he is a walking encyclopedia of historical knowledge within the agency. He is respected by 
his colleagues and all those who have worked with him. He has received numerous awards. He enjoys the camaraderie of senior management officials in the agency, since he is frequently called upon to brief them in his areas of personnel expertise.

Two-and-a-half years ago, Jacques had a heart attack at his home in Beltsville, Maryland. On a Saturday afternoon he was gardening and felt pains in his chest. Rushed to the hospital, he was diagnosed for bypass surgery within a few days. Jacques was out of work for ten weeks following his surgery. The office provided him with the necessary electronic technology to communicate from his home.

Jacques recuperation from surgery fell hard on him and his family. Since his wife was fully employed and could take off only briefly to care for him, he had to depend on one of his children, a son, who lived somewhat near his home. He is the parent of five children, three adult children and two teenagers. Jacques was always an independent person; however, he had to become dependent on his son and wife during his recuperation. His convalescence took longer than expected because minor complications set in after the surgery. He experienced sporadic pain in his back and was diagnosed as having sleep apnea.

Eventually he was able to return to work, but he had to drive a number of miles in rush hour traffic to get there each day. At work he became fatigued easily.

When he returned to work, he experienced a real dichotomy between the response of his colleagues and that of upper management. His colleagues were interested in what had happened to him; they were supportive and assured him they would be there for him if he needed anything. In contrast, the managers and senior staff who came by to say hello to him stayed in his cubicle "all of 8 seconds." They were not unkind, but neither did they show an interest in his condition or how he was faring as he re-entered the work community.

As Jacques states, "They just left all that to me, basically, over time I found it very frustrating. They really had no interest in how I was doing ... I was left alone to drift through the process of re-entry and cope with it as best I could."

Gradually Jacques negotiated with his supervisors to work three days at the office and two days at home, mainly because of his continued back pain, fatigue and the long commute. He says this worked. With regard to productively, management was willing to provide him with any 
computer technology Jacques needed to do his job, but they offered him nothing emotionally.

\section{The Organization and Robert's Place In It}

Prior to Jacques heart bypass surgery he supervised an employee named Robert, a professional personnel specialist who worked mostly in classification and compensation. At 50 years old, Robert was generally in good health.

When Jacques was assigned to this division, Robert was scheduled for brain tumor surgery at John Hopkins University Hospital in Baltimore, Maryland. The surgery was classified as experimental, because it involved new procedures.

In learning of this surgery, Jacques stated he found it very scary. A tumor had been found in Robert's pituitary gland, and to remove it the surgeon would have to go into the center of the brain using a laser procedure.

When Robert returned to work, there was no apparent disability or lack of ability to do his job, and he picked up rather quickly. But Jacques noticed that Robert wanted to continually talk about what had happened--his brain tumor and surgery. He would volunteer this information to anyone who would listen. He might stop his colleagues and go into a long description of the specifics of his surgery. He would explain how he lost his sense of taste and smell--how he remembered smelling burning flesh.

Some colleagues found this very unpleasant and felt embarrassed or annoyed. Some would avoid Robert.

After a while Robert had a relapse. He suffered a small stroke and lost his memory. When he returned to work again, he had a short attention span. Robert was aware of this, and when someone approached him about it, he became defensive.

As his supervisor, Jacques stated Robert was able to do his work but Jacques was not sure of his role as manager. "I really didn't feel that I knew what I should be doing or not doing. I had no idea how to help him deal with the situation...I certainly felt that I wasn't really prepared."

\section{Jacques Dilemma As A Manager}

As organizations are challenged to deal with traumatized employees, managers feel they are without the necessary skills to understand what the traumatized person needs when they return to the work place. As the researcher talked with Jacques about his experience, the 
researcher--if there was anything he missed when he thought about Robert? He said "...knowing what I know now, both from my own experience and the experience with Robert and some other employees who have had people who had traumatic experiences, I think I would wish I had, first of all, a structured and specific plan before they come back."

We talked about what employees go through when they are traumatized in their life, especially when they lose their jobs, and what managers think and feel who have to deal with such people. Jacques had strong feelings on this subject. He believes, management gives only "lip service and very sporadic communication, and immediate supervisors, co-workers and returning workers have to shift for themselves."

Jacques began to reflect on his role as a manager in relationship to the traumatized employee. He said, "I would like to be more sensitive to the returning employee. I would explore with them exactly what they felt and what they were able to do and what their concerns were in getting their jobs done."

Jacques became descriptive of Robert's behavior and wondered how he could have done things differently, "Robert never gave me the opportunity to talk in a private setting. I fault myself for not doing something. I took the easy way out and let him volunteer information, instead of helping him talk about it in a safe environment."

\section{Robert's Dilemma As An Employee}

The employee coming back to the workplace after experiencing a trauma is very ambivalent. On the one hand, Robert felt helpless to tell people what he needed; on the other the hand the manager and organization were at a loss as to how to approach him. The trauma Robert experienced was unusual because it affected his mental capabilities, and he was afraid he would not be able to function as intellectually as he had before. He was frightened and really could not anyone. Robert did not know how much to ask of his manager or the organization. What does the manager and organization do under these circumstances?

\section{Trauma in an Organization--What Do We Do?}

This case study raises the issue of how a person copes with a their trauma when they reenter the workplace. Survivors feel stranded and unable to define what they need.

Organizations trying to answer these questions, find themselves in transition in redefining 
their roles, functions and responsibilities to employees.

People in organizations tend to minimize the impact of a trauma on an employee. For example, co-workers are unsure of how to behave and avoid talking to the re-entry employee, behaving as though the trauma did not occur. Managers do not know how to make the re-entry easier or the environment safer. The current workplace situation is not a healthy situation for the survivor, co-workers or the manager of the organization.

In the reseracher's interview with Jacques, they explored what the organization does for TLE's and he emphasized that, "Returning employees here have not been dealt with in any sensitive manner. ...nothing is done to get out their concerns or feelings. It certainly is a situation. It does have an impact on productivity and people's motivation."

Because Jacques had gone through a trauma himself, he felt he would be sensitive to a reentry person's needs. If needed, he would search out a close friend of the TLE to get information or go to the Employee Assistance Office for assistance.

As his interview concluded, Jacques was given some reading material to prepare him for the second part of the case study. This included an approach to intervention using a new adult learning technique called Study Circles.

\section{Observations}

As the researcher observed Jacques in this interview, his deep concern for Robert, his former employee was evident, and how he struggled with the memory of his own trauma recovery. He would stop talking at times and just stare into space, perhaps to think but not make eye contact with the researcher. He repeatedly said that no senior managers reached out to help him. At one point he said, "I would like to know how to make it easier for the re-entry person."

\section{A Study Circle Intervention}

One way to assist managers in helping re-entry employees is to adopt the three-stage plan set forth by Judith Lewis Herman (1992) in her book entitled "Trauma and Recovery". The researcher created three Study Circles using the following three stages that Ms. Herman postulates. TLE's and managers can cooperate with each other in fostering these three stages: (1) establish a safety net for the traumatized person in the workplace; allow the traumatized person to (2) reconstruct the trauma story; and (3) restore the connection between 
the survivor (TLE) and the work community.

\section{Why a Study Circle?}

Study circles are being introduced as a new intervention to assist managers in dealing with a traumatized person in an organization. Study Circles are used throughout the United States not only in organizations, but also in civic groups to discuss numerous topics such as racism, sexual harassment and domestic violence.

The forum consists of 8-10 individuals meeting for three to four sessions for discussion of a specific topic. The process is driven by the needs of the participants. It enables individuals, through the sharing of information and experience in respectful open dialogue, to gain knowledge and skills to make appropriate decisions for themselves in their "communities" and in their lives.

The study circle is designed to help people make decisions based on knowledge, awareness of these experiences and concern for others.

It is well documented that people who feel they have some sense of control over their lives are better able to manage change and are more likely to adopt positive behaviors. The Study Circle format will be introduced as a learning tool in an organization to assist managers to become more effective in dealing with traumatized employees.

As a pilot effort, the researcher conducted additional interviews with Jacques to test the methodology for later conducting a series of Study Circles. In this pilot the researcher examined on a one-to-one basis the themes that will be the subject matter of the Study Circles.

\section{Study Circle (Interview) Theme I. A Safety Net}

The researcher explained the process to Jacques and prepared to meet him to participate in discussion of the first theme--Establish a Safety Net For The Returning TLE.

The researcher and Jacques started to talk about what was meant by a safety net. The researcher explained to Jacques that the environment meant a lot to a returning TLE and an individual's basic needs must be taken care of by the organization. These needs include feeling safe in their bodies and not feeling out of control in their environment.

Jacques told the researcher he had really given the topic some thought after the original interview. As he reflected on the TLE, he realized a "wide range of things go into making the employee feel comfortable and safe." He recalled his own trauma and said people were 
superficially reassuring, and "he felt no depth to their feelings."

Jacques started to talk about the TLE feeling "out of control." He explained, because of the absence of not being on the job, you re-enter the workplace being "visible" and you are not "sure of yourself."

Jacques kept referring to Robert and wondered whether he had created a "safety net" for him. He pondered a little and said that Robert's mental capacity was his main concern when he returned to the workplace. He said, that the maintenance issue around a TLE is one thing. Communicating to the person that his pay check and duties will continue, but when a person cannot do the work, that's serious.

Jacques said trust was an issue under the safety net theme. He compared the situation of a new supervisor who may have not established a bond with the TLE prior to the trauma, and then one who had established a relationship with the TLE. He said the new supervisor's behavior would be viewed as "insincere and hypocritical" if he suddenly showed interest in the returning TLE.

Jacques returned back to the empathy issue and stressed that the TLE would recognize the manager's concern, because those feelings cannot be faked.

Jacques and the researcher ended this session with an important insight gleaned from his own trauma. He said, "Physical recovery may take less time than mental recovery, but mental recovery was as important and could take a longer time.

\section{Study Circle (Interview) Theme II. Telling the Trauma Story}

Jacques began the second session with wanting to talk about his life before the trauma. He said that his work world had revolved around preparation for hearings on Capitol Hill and buy-out legislation. His calendar was always filled with appointments and meetings. The trauma was an emotional shock, because for three months he was not part of the organization.

He continued by personalizing the situation--he had always been an independent person but after the trauma he had to become dependent, both physically and mentally. His two teenage children were scared, but he kept trying to reassure them that everything was going to be all right.

He said his wife had to make the biggest transition to--paying bills and maintaining the household, things he had done for 25 years. Jacques said it was a very stressful time. The 
researcher pointed out to him that Gail Sheehy, author of Passages, states that after a meaning $\underline{\text { crisis, }}$, people are different and asked how different did he thought he was after having experienced a trauma. Jacques said after a trauma one sits back and revisits mortality. It causes you to look differently at your spouse and children. It makes you want to create more balance in your life.

The conversation shifted to his ability to talk about his trauma. He said discussion about his trauma experience depended on the people. Some asked questions about how he felt and how the trauma happened; others did not.

The researcher asked Jacques if he felt his values or beliefs were destroyed by the trauma. The trauma had been a religious experience for Jacques. People were calling him and saying they were praying for him and that was comforting. He felt it had a lot to do with his recovery. He stressed the trauma had a strong religious impact in his life.

The researcher and Jacques talked about how he told his trauma story to others. He saw his story as a "reconnection with other people." He felt that, "Saying the story out loud made it more part of a reality for me."

As we concluded, Jacques made reference to the past and present. He said, "A trauma shakes you out of habits you may have had for years. Its hard to develop a new habit when you don't have the stability of the past and the future around you like you did before."

\section{Study Circle (Interview) Theme III: Reconnection To The Workplace Community}

Prior to beginning our third session, Jacques said that our conversations were helping him to understand his role as a manager. He felt that because of the topics that we had discussed he would be able to empathize more easily with a person who was making a re-entry. He said our discussions were making him more aware of employees who were recently affected by organizational changes in his office (i.e., downsizing and reinvention).

As we started our third and last Study Circle, Jacques was eager to begin talking about his thoughts on reconnection. Jacques smiled a little and said, "It certainly was not an organized process. I just hung in there every day until the daily habit and routine set in for me."

Jacques said it was very difficult for him to return to work as a re-entry employee. As a returning TLE he felt conflicted. He said, "Returning to work, you don't know where you stand, 
how people are going to react to you and, most important, you can't predict how much work you will be able to accomplish." Jacques went on to say it is difficult to set any kind of expectations for himself.

Jacques believes workplace culture comes into play also, claiming that if you are not part of a certain group you may experience "not being included". These are organizational culture shortcomings. His solution would be to have the whole organization attuned to dealing with people who are trying to reconnect to the workplace. Its not a matter of policy, but caring for people.

Jacques said he was "left alone." He felt people did not want to be bothered or were too busy with other organizational matters.

On the other hand, Jacques elaborated by saying he came back to the organization with a slightly different personality. He was changed. He had more faith in life and a broader perspective of what is important.

Jacques said he was glad to come back to work because he missed his work and colleagues, but he was also very anxious. Though he was behind in his work, no one was interested in whether he would get his work done. It was left to him to take the initiative, to figure out where he fit in and how he could be useful to the organization. No one did that for him.

In talking about Robert's re-entry, he said, "Robert made a good re-connection only because he had an out-going personality (extrovert). It seemed easier for him to talk with others about his trauma."

The meeting was coming to a close when Jacques started to discuss the reading materials the researcher had given him prior to the third session. He was impressed with information on memories. In talking about his trauma and its memories, he pointed out that the article had said that a person has control of his/her memories and should learn how to deal with them. In recognizing this he said, "Memories should not control you, you should control your memories." 


\section{Observations of Interviews}

This experience in observing a person through a study case process was fascinating for the researcher. She was to watch Jacques' interest in the topic grow and his energy level become more intense as he proceeded through our three meetings.

The safety net study interview pointed out the most important aspect of this first encounter with the re-entry employee was the presence of someone when the employee returned to work. Over and over again, Jacques would shake his head and say how he had to "go it alone". There was no structured plan or manager who seemed to care about his welfare when he returned. He thought a lot about how he felt and how he as a manager would behave toward returning TLE employees. In the second Study Circle on Telling the Trauma Story, Jacques' eyes filled with tears when he started to talk about how his trauma affected him spiritually. He noted that other people's concern for him was very moving and it expedited his recovery. People communicated their love and concern for his well-being by praying. This really touched him.

The third Study Circle, Reconnection To The Workplace Community, Jacques' observations had two aspects: (1) the expectations, joy, and adventure that one feels when returning to the workplace because a person wants to reconnect, and (2) when you return to the workplace, everything seems so ordinary. He thought this was an important insight because from each stage of the process a person puts the trauma in a better framework--both from a personal level and work-related perspective.

\section{Interpretations and Assertions}

For this case study, the researcher chose the subject that was to be interviewed and personally asked the participant (Jacques) to participate in the three Study Circles. The researcher was relatively acquainted with his organization and knew of his trauma and his visible role as a manager in the department. The case study was controlled. If this were done in an organization and people were picked randomly and without knowledge of prior reading materials, the researcher is not sure the feedback and dialogue would be as descriptive. From the researcher's perspective in evaluating this case study, it would seem important to interview participants prior to the Study Circles. This creates a comfort level for with the reading materials and the subject matter. 
The pilot Case Study circles lacked participants. This was planned because of my research project. However, the researcher believed that if Jacques was able to have a dialogue with others and listen to managers who would share their feelings in a group setting, all participants would benefit from this experience. They would add to each person's knowledge, awareness, and hopefully transform their concern and interest to the workplace.

Each Study Circle was an hour in length. The researcher anticipated future Study Circles should be two hours in length. This would give 8-10 managers an opportunity to gather together and exchange thoughts, information and suggestions for each participant to take back to the organization. Jacques was given an evaluation sheet after the third Study Circle (Appendix H ) and he positively noted that after the Study Circles, he was able to communicate more effectively about trauma, he recognized the problems surrounding trauma, he had a better understanding of his attitudes and beliefs on the subject of trauma, and his ability to discuss this topic openly and frankly increased.

The researcher asked Jacques to list in order of preference which study circle did he saw as most significant. He listed in order (1) Establish a Safety Net (2) Reconnection and (3) Telling the Trauma Story.

In the researcher's view Telling The Trauma Story was the most important area of discussion because an individual needs to release his/her feelings about what had happened to them. Jacques' ranking pointed out that the employee/manager is very concerned with what the organization/manager will be doing for them upon his re-entry into the work environment. 


\section{CHAPTER 4 \\ RESULTS-PART I \\ Introduction}

There are two major purposes of this study: (1) to determine how the Study Circles format can be utilized as an educational intervention in the workplace to facilitate the return of an individual after having experienced a trauma; (2) to develop a strategy for expanding how the workplace can utilize the Study Circle as an ongoing model.

Part I of this chapter describes specifically the following topics: (1) the Study Circle model and its components, (2) identification of critical elements for discussion, (3) group participation in the Study Circle and (4) a summary of the Group A Study Circle sessions.

\section{The Study Circle Model and its Components}

Study Circles are usually formed around issues involving social problems, public policy or the organization. The Study Circle provides an opportunity for people to learn together in a democratic participatory setting.

\section{Profile of Participants}

Participants for this study were all personnel from the Department of Health and Human Services (HHS). Their participation was voluntary and all participants were interested in the topic. Referrals were also made to the researcher by individuals who were interested in the topic and research study. Eight managers and three employees were part of the first set of Study Circle sessions (Group A).

All of the managers and employees were in the age bracket of 45-64 years of age except one female manager who was in the age bracket of 30-44. All but one manager had supervised a returning TLE. Four of the eight managers had experienced a personal trauma and were also considered re-entry TLE employees and all of the employees who participated had experienced a personal trauma. Seven of the eight managers had previously supervised a returning TLE employee.

\section{Study Circle Format}

Three Study Circles sessions on this topic were held in the Conference Room at the Department of Health and Human Services (HHS). These Study Circle sessions were held once a 
week during the hours of 11:30 a.m. to 1:30 p.m.

The Conference Room was large, attractive and accessible to everyone. Each session was video-taped. Video equipment such as microphones for speaking and floor lights for proper lighting were visible in the conference room. The researcher provided a boxed lunch prior to each Study Circle session. The socializing that occurred during this period created a social warm-up for the participants. Each Study Circle session lasted $1 \frac{1}{2} 2$ hours.

The researcher introduced participants to each other and then passed out notes on "The Role of the Participant" (Appendix I). Here the researcher reviewed the participant's role and then referred to the discussion handouts received by each participant prior to the Study Circle. The researcher then opened the Study Circle session.

\section{Pre-Study Circle Interviews}

Personal interviews were conducted by the researcher prior to the Study Circles sessions. All interviews were arranged by e-mail or telephone and were conducted face-to-face in an enclosed office at HHS (Room 510-B) or in the interviewee's private office. Each interview was audio-taped and was professionally transcribed. Prior to the taping, the researcher met with each interviewee and explained what the interview would entail, the types of questions that would be asked and what his/her involvement in Study Circle sessions would include. During the preparatory interview, the researcher left no mystery regarding any part of this process, explaining their role in a face-to-face dialogue. The researcher informed them that they would all receive an invitation to the Study Circle session one week prior to the first session along with the "confidentiality agreement" which they would sign and return the day of the first session (Appendix D).

The following questions were asked to participants during the interviews prior to the Study Circle session:

1. Did you have a personal experience with trauma? If so, how did you handle it?

2. Did you ever supervise a person who returned to the workplace after having experienced a trauma? If so, how did you handle it?

3. Did you ever have a co-worker who experienced a trauma and returned back to the workplace? What did you say to that person upon their return? 
4. If an employee was returning back to the workplace after having experienced a trauma, how did you behave toward that person?

5. Would you ask the returning employee to tell their trauma story?

6. Have you ever observed an employee telling their trauma story to anyone upon their return to the workplace?

7. How comfortable do you feel approaching or talking to a person who has just returned to work after having experienced a trauma?

8. Do you know what to say to a returning TLE?

9. What approach would you use if you had to communicate your expectation to the person who is returning to the workplace after having experienced a trauma?

10. How would you go about explaining to your staff the importance of greeting and talking with the person who is returning to the workplace after their trauma?

11. How would you go about assisting the returning TLE participate in office activities?

12. What would you do if you had to set limits with a returning TLE when he/she returns to work (i.e, lateness/tardiness)?

13. How would you respond to a TLE who refuses to work and begins to have emotional outbursts?

14. How would you state work assignments and expectations of productivity to the returning TLE?

15. Do you think gender plays a role in dealing with a returning TLE? Do women behave differently than men when they return to the workplace?

These interviews proved very informative to the researcher/facilitator and served as a guide in preparing for the Study Circle sessions. The questions asked of the participants during the interview provided an opportunity for observing of reactions to the topic. The pre-Study Circle interview also gave participants a chance to think about each Study Circle session prior to meeting and what would be discussed. Two days before each Study Circle session written materials were distributed to participants to them in understanding the types of discussion 
questions that the group would be reviewing (Appendix F).

The interviews gave the researcher knowledge of each participant's personal trauma experience. This prior knowledge provided a source of information that the researcher could evoke, if necessary, during the sessions. For example, when the Study Circle participants seemed to move away from the focus of the discussion, the researcher was able to redirect the group participation. During the second Study Circle sessions, certain managers who began to dialogue on the session topic, "employees who continue to talk about their traumas," then jumped to another subject, "guidelines that managers need in dealing with a returning TLE employee." The facilitator interceded and brought the participants back to the session topic of dealing with employees who repeatedly talked about their trauma, and asked the group to list what a manager should do when this occurs again. This dialogue resulted in a group discussion on "what to do."

The pre-Study Circle interview also assisted the researcher in creating opportunities for better transitions during the Study Circle session and in keeping the Study Circle sessions moving at an interesting and lively pace.

\section{Facilitator}

The facilitator played a pivotal role in all Study Circle sessions. In this educational format the participants are the key players, so much so that the facilitator is not considered a member of the Study Circle. The main objective of the facilitator is to keep the group process moving autonomously by maintaining a neutral position on the topic being discussed. A facilitator needs a variety of skills and abilities, as identified by Schwarz (1997), which include the following: accurate listening, observing, and remembering behavior and conversation; communicating clearly; identifying similarities and differences among statements; understanding multiple perspectives; analyzing and synthesizing issues; identifying assumptions; diagnosing and providing appropriate intervening responses to effective and ineffective behavior; being a model of effective behavior; providing feedback without creating defensive reactions; accepting feedback without reacting defensively; monitoring and changing one's own behavior while working with a group; developing the trust of clients; empathizing with clients; providing support and encouragement; and having patience (p. 10).

As the leader in a Study Circle dealing with individuals who are returning to the workplace 
after having experienced a trauma, a facilitator can be especially effective if he or she personally experienced a personal trauma or supervised an individual who re-entered the workplace after having experienced a trauma. Although prior experience of a trauma is not required, the facilitator's sensitivity and ability to share such an experience in the group assists the participants in identifying with one another's trauma. It also presents an invitation and gives permission for others to share their stories. For example, in the second session the researcher shared her trauma story with the group. Soon afterwards, other members began to talk of their own traumas and a new level of interaction and trust began. Telling one's personal story enables other participants to feel a level of comfort with that person. It also sets the tone for further openness, encouraging other participants to retell their trauma story.

In a Study Circle the roles of the facilitator are unique and should not be confused with leaders in other types of group work. For example, often a Study Circle facilitator is inaccurately described as a mediator. At the outset, the facilitating roles may seem similar, but their objectives are totally different. In mediation, parties are brought together to negotiate a settlement agreement and resolve a conflict. This is not so in a Study Circle. The main task for the facilitator in a Study Circle is to assist and improve the group process and help people learn more effective interpersonal behavior.

\section{Evaluations}

After the Study Circle sessions, evaluation forms were handed out to all participants. Eleven individuals made up the first Study Circle group--eight managers and three employees. Two managers attended only two sessions due to travel commitments. The overall evaluations of all three Study Circle sessions were very positive and seen as beneficial to the participants (see Appendix J). Participants expressed a desire to participate in more Study Circles and hoped that the Study Circles on trauma and the workplace could continue for one or two more sessions.

Participants stated that after the sessions they felt they were "not alone" in their trauma, and they now knew other people who were experiencing much of what they had gone through in the healing process after their trauma. When in the future they would have to deal with a returning TLE, the participants felt that the Study Circle gave them some "concrete examples of what may be helpful and appropriate." The participants liked the round table "staff meeting" style 
of discussion. The Study Circle session that created the most dialogue was the second session titled Telling the Trauma Story. Although some participants told their stories in the second session, others chose to wait until the final session to share their trauma stories. The facilitator did not press people to tell their trauma stories. These stories simply came out at the appropriate moment in the interpersonal context of the session, thus they had a much more powerful and emotional affect on the participants.

In comparing the evaluations with the pre-Study Circle interviews, the researcher found that in general individuals were much more verbal and open to discussion during the Study Circle sessions than they were in the interview. The evaluations indicated that the pre-Study Circle interviews assisted the participants in the Study Circle sessions. The questions in the pre-Study Circle interview were specifically designed to acquaint the participants with the subject matter and gain some insight as to what the discussion may entail. In the Study Circle the participants elaborated more on the details of their own specific trauma and shared their experiences freely with each other. Also, the managers in the group were very concerned about their specific role and their responsibility toward the re-entry TLE.

\section{Assessment of the Study Circle as an Educational Model in the Workplace}

Participants volunteered for this project because they thought it would be useful to them in dealing with re-entry employees. They were interested in the topic and wanted to learn more about their own reactions as managers and the quality of their interactions with returning TLEs. All managers and employees were eager to participate. In designing this learning experience, the researcher was guided by Jarvis' (1991) interactive model and Silberman's (1990) ABC approach to learning (Affective learning, Behavioral learning and Cognitive learning). The findings of the research confirm the interactive structure (Jarvis) and the integration of affect, behavior and cognition (Silberman) in this educational learning model.

The Study Circle intervention contributed to the ongoing learning of both managers and employees and to understanding the issues of re-entry for traumatized employees. Jarvis' (1991) interactive model places importance on learning in a social context, not in isolation (Appendix A). Learning is best accomplished by doing and participating, thus producing a person who is changed and more experienced. The group-interaction model is a strong educational model, 
strong because it deals with the variety of responses one can have from an interactive learning experience. During the Study Circle sessions interactive learning did occur in many different ways, with outcomes personalized to the individuals going through the experience.

Individuals in the Study Circle liked the group interaction and felt that it was instructive to them. From the researcher's observations, during the second session a bond began to form between participants and, therefore, individuals seemed more personally interested in each other.

Participants stated that they left the Study Circle with "more knowledge of returning TLEs and the importance of supervisors and co-workers to prepare themselves for returning TLEs." They also stated they gained more insight into the "feelings" of a returning TLE.

Silberman's (1990) ABC approach was ideal for this type of learning experience. Content was not as important as participant understanding and valuing of each Study Circle session's "ABC" learning. The researcher had a clear sense of what objectives were to be accomplished from each session. The participants were active partners, not mere attendees.

The following three levels of learning were covered in the Study Circle sessions.

\section{Affective Learning}

Participants got in touch with their attitudes, feelings and preferences regarding returning TLE employees. This occurred through the dialogue, sharing, interaction and networking that was created among the participants. The Study Circle leader allowed the dialogue to emerge by letting participants ask each other questions and inquiring about the extent of their own traumas. In the first Study Circle session when managers were discussing performance and behavioral problems of employees, they felt that these problems could become borderline trauma problems if they were not dealt with in the workplace. They were not sure how to approach the returning TLE. After the first Study Circle session, the researcher observed that four of the men in the group remained in the room to carry on an extensive dialogue on how to handle a returning TLE. One manager who had been a TLE expressed the importance of hugging and making the employee feel comfortable. He specifically mentioned the expressions "dialogue," "sharing feelings," "physical associations" and stated that all of this "means a lot" to him and felt it would "mean a lot" to another person.

The affective learning goals were accomplished in the Study Circle sessions through the 
interaction and discussion which allowed managers and employees to become aware of each other's perceptions and feelings.

\section{Behavioral Learning}

Managers and employees practiced "active listening skills" in each of the Study Circle sessions and received feedback from participants when retelling their trauma stories. One manager shared the story of her trauma when her fiancé was diagnosed with cancer; she was at the time in an upward career path and then had to refocus her energies to take care of him. She

found her anxiety level escalated and that she was exhibiting behaviors which she did not view as normal. Because of the trauma she constantly talked about what she was experiencing. She stated this was how she "coped." Participants asked her questions and wanted feedback from her experience.

Fairhurst (1996) states story telling provides an excellent way to relate to people about a difficult experience or a problem. This technique worked effectively during the sessions. Participants stated that "hearing other people tell their stories," "how they handled their trauma and what worked and what did not work" was important for them to hear. Another participant stated that "All of the sessions were helpful, especially the last two sessions when several people 'opened up' and shared their experiences."

All managers stated that the Study Circle sessions assisted them in their skill-building in understanding how to "approach a TLE" and what "a manager's expectations may be."

\section{Cognitive Learning}

The Study Circle's cognitive component assisted the participants in learning new responses from each other. They were able to apply new concepts and information related to what they learned. One participant stated that it was important for the managers to show "empathy" towards the returning TLE. Participants then engaged in a discussion about the meaning of "empathy" and addressed their questions to each other on how a person shows "empathy." This created an on-going dialogue throughout the three Study Circle sessions. Another subject that provoked cognitive discussion among the managers was "productivity versus compassion." Some managers were concerned with recent downsizing within their organizations and the loss of resources. Conflict and ambivalence surfaced among them when they started to differentiate 
between being concerned with "the bottom line" and showing "compassion" to the returning TLE.

The reading materials provided by the researcher prior to each Study Circle Session (Appendix F) provided a cognitive learning resource to the participants. Both managers and employees referred to the helpfulness of these handouts which guided them through each session.

The Study Circle educational model presented the participants with an opportunity to think, feel and act differently about a new topic. From their evaluations and feedback, managers stated they would be able to integrate this learning into their behavior. One manager, commenting on the timeliness of the Study Circle, stated that within a week of the first session two employees under her care experienced deaths in their family. After listening to the participants exchange ideas in the first Study Circle session, she was able to offer a better level of comfort to these employees upon their return to work. This was something she did not know how to do prior to the Study Circle.

\section{Case Studies}

Two individual members of the Study Circle were interviewed in depth and are introduced and discussed as Case Studies.

Case Study I (Robert-Bob A Case Study in Understanding the Effects of a Personal Trauma of a Returning TLE to the Workplace). This Case Study addressed the trauma a returning TLE experienced not only in negotiating with his workplace environment but also in coping with a daughter who was diagnosed with cancer. His story not only moved the Study Circle participants, but also helped them to identify with an employee's dilemma when confronted with something so unexpected in life. The lesson that was learned from his experience helped others articulate their fears and anxieties in the recovery process.

The second Case Study (Verl-Case Study of a Manager and his Learning of Workplace Trauma) illustrated a manager who did not experience a trauma or supervised a returning TLE. His reaction was one of appreciation for being asked to participate. However, during the last session of the Study Circle, he stated one of his employees was experiencing a personal trauma and he was able to approach her and create a "safety net." He also allowed her to work from her home until she was able to return to the workplace.

The case studies presented portray real life experiences with participants who have had to 
deal with a trauma and returning to the workplace and knowing how to intuitively pace their own recovery process. The case study is a powerful tool and provided insights into the perceptions and reactions of individuals participating in the current investigation of traumatized life experienced (TLE) employees.

\section{CASE STUDY I}

\section{Robert (Bob)--A Case Study in Understanding the Effects of a Personal Trauma of a Returning TLE in the Workplace.}

This Case Study of Robert (Bob) will demonstrate how unaware our organizations are in understanding and dealing with individuals who have experienced a personal trauma in their family and are returning back to the workplace. The researcher used a Case Study approach to illustrate the effects trauma had on one person and how this employee tried to function in two worlds--his professional life and his personal family life--for a period of two years.

The researcher's purpose was to illuminate a specific case where she was able to not only observe Bob during the Study Circle but also ask and listen to him reply to personal questions in the interview process. This two-level observation process assisted the researcher in following his story and gaining new perspectives on trauma and the realities of what an individual needs when he returns to the workplace.

\section{The Organization and Bob's Place In It}

The organization from which the case studies are taken is the Department of Health and Human Services (HHS), one of the three largest government agencies in Washington, DC Its budget is the third largest in the world and the people who work here represent the ethnic, social, cultural, religious and educational diversity of our country. HHS is the hub of activity for all major social programs sponsored, funded and observed by the federal government.

Bob is the Senior Information Systems Security Officer for the HHS. He oversees policy guidance to information systems security (computer security). He works in the Office of Information Resource Management and has been employed by the government for 26 years. He is a white Anglo male, 52 years old, medium height with light grayish brown hair. He wears a mustache and gold-trimmed glasses.

Bob was born in Worcester, Massachusetts. His ancestry is French Canadian, but he 
speaks with a Bostonian accent which accentuates his oxford button-down collar and navy blue blazer look. He was raised Roman Catholic and grew up in a family of two older sisters and parents who placed a high value on hard work, education and an active church and community commitment.

He came to Washington in 1968 obtaining his first job with the Census Bureau, then took employment with a private corporation before joining HHS. He married Margaret in 1969 and together they raised five children (Jonathan 27, Andrew 26, Maria 23, Suzanna 19, and Robert 16).

\section{Bob's World Turned Upside Down}

Bob's trauma story began in August, 1989, with a telephone call from Dr. Harlo of the Children's Hospital in Washington, DC informing him that his daughter Maria who was 15 years old at the time, was diagnosed with cancer, specifically Hodgkins disease. Early that month, Maria had found some lumps near her collar bone and brought it to Bob's attention. After two weeks they seemed to get larger. She then went for an examination and a biopsy and the cancer was identified. The doctors performed an emergency laparotomy and splenectomy--making a full incision all the way down the chest and abdomen area to examine the internal organs to see if the cancer had spread beyond the initial area. The cancer had not spread, and she then began six months of chemotherapy treatments and ten days of radiation.

\section{Bob Rearranges His Priorities}

Upon hearing the diagnosis of his daughter Maria, Bob's priorities immediately changed. No longer was he concerned about his career, getting ahead, his status or earning a lot of money. None of these seemed important to him. His total focus was his daughter and her well-being and trying to figure out what to do.

Bob immediately began to research her illness through the libraries at the National Institute of Health at Bethesda, Maryland. He became an expert on her drugs and treatment. Because Bob's wife was an elementary school teacher and could not take time to escort their daughter to the doctor appointments, Bob took care of everything.

\section{Bob's Life at the Office}


During these months Bob's days were erratic. He lived a dual life. He had to be there for his daughter, and he had to go to work. He said he did not function very well at the office. He told his bosses of his trauma and they told him to do whatever he had to do. Although they took care of Bob's physical needs such as allowing him to take annual leave whenever he had to leave the office, he realized his emotional needs were not being met. He had nowhere to go to talk out his feelings. He said he did not even know how to express his feelings. He stated his "heart was ripped in two and he physically ached." As a father he could only support his daughter and do nothing else. He felt helpless. This trauma went on for one year and a half. In the early Spring of 1990 Bob and his family were told that the cancer treatment had worked and his daughter had become $95 \%$ free of the cancer.

\section{Bob's Worst Fear Reappears}

However, in September of 1990, Bob received another phone call from Dr. Harlo stating that the Board of doctors and specialists had run two sets of test on Maria, and they confirmed that the cancer had spread around her heart and other lymph nodes. Maria had been going for tests every month.

Bob froze at his computer, he felt paralyzed. He could not focus. He checked his watch and it was close to 12:10. He left the office to go to mass at St. Dominic's Catholic Church. After mass he sat there in a daze for two hours. Trying to compose himself and think of how he would get through the next phase of his life--he had to go home to tell his wife and daughter.

Bob said he was angry. He asked God, "Why me? Why us? Why my daughter? Why are we going through this again? Is there a God? Why are we getting punished? What did we do? Bob wasn't sure how to "collect himself."

When Bob arrived home he called his wife and daughter and told them about the phone call he got from Dr. Harlo. They cried together.

The doctors did not want to perform surgery so they began the treatment therapy immediately. Bob's nightmare only gets worse. He had to go to Maria's school to arrange for her to be tutored and then talk to the Cheerleading Coach (Maria was a cheerleader). As Bob took complete charge of Maria's care, all types of feelings were welling up inside of him. He says, "I felt inadequate. I wanted to make it more comfortable for her, and I couldn't. I felt her pain and 
wanted to take her place and I couldn't." Bob and Margaret decided to join a support group for parents. This helped them to understand what other parents were going through. Many evenings after leaving the group, they found themselves being thankful they were not going through what other parents were experiencing.

Bob said his relationship with his wife was stressed also. Being an elementary school teacher Margaret would come home and would want to talk about her classes. Bob admits that he was not interested in her work, only with his daughter's health. Because of the stress Margaret sought a counselor to deal with her emotions. The counselor, instead of helping Margaret stay in the marriage, suggested they separate. Margaret returned home and discussed her feelings with Bob, and for the first time they talked about their relationship together. They ended up staying together and supporting each other.

At the same time, Bob's two sons who were in college seemed uninterested in their work and wanted to come home to help the family through this crisis. Bob urged them to stay in school. His younger son Robert said, "I wish I had the cancer and not Maria." Maria's answer to her younger brother was, "I can handle this I couldn't if this was happening to you."

\section{Re-entering Bob's Work World}

Bob's supervisors began asking him to take on more responsibility. He told them, "I cannot handle any more work at this time." He felt he could only do routine tasks, those he was familiar with; he did not want to take on any new policy issues. This went on for over a year. Bob said he tried to talk to his co-workers, but he found it very difficult to express his feelings and he was not sure that they cared. In our interview Bob said, "Some people are comfortable asking for help and some people are not."

\section{The Family Miracle}

On October 1, 1990 Bob's daughter Maria was scheduled to go to The Children's Hospital for her first check-up after months of chemotherapy and radiation treatments. That same day Bob went to St. Dominic's Church and prayed. He had discovered a book on the lives of the saints in the Catholic Church--especially St. Solanum Cagey, he read his story which was entitled "Nothing Short of a Miracle." This saint had a healing ministry and died in the early 1960's. He said that one should be thankful first and accept the will of God. Bob began to pray thanking the saint and 
said, "If my daughter's cancer is worsening and we would lose her, I want the strength to live with this disease." Bob then continued to pray.

On Friday, October 5th at noon, Dr. Harlo called Bob and told him that the team of doctors had just completed two tests on Maria, and there was no sign of the cancer at all. He said they wanted to do another set of tests the next week. The following week, October 8th, the oncologist called Bob and said the doctors from the cancer board reviewed the third set of test and there no sign of cancer. The doctor told Bob there would be no additional treatment.

Bob, Margaret and Maria made an appointment to meet with the team of doctors. They could not explain what had happened. Bob said, "A miracle has happened to our family." The doctors did say they would never forget this case and could not offer a medical explanation.

\section{Bob's World Today}

Bob decided to become a Deacon in the Catholic Church and now ministers to people who have gone through different phases of trauma. His work world is busy with assignments and travel; he and his wife just returned from their first trip in Europe.

Two sons are married, one daughter is in college and Maria became a bio-medical engineer with her first job at the National Institute of Health, Bethesda, Maryland, administering and operating the machinery to patients who are ill and seeking assistance in their trauma. She soon leaves for California for a new career doing the same type of work. Although they will miss her and wish her well, a part of them feels the "effects of the wound" and how their life has unfolded.

The researcher asked Bob how this trauma changed him and his life. He admitted that prior he could never talk to anyone about a terminal illness. Everything has changed now, he is very comfortable in talking and administering to the ill and dying. We then focused on the workplace, and the researcher asked him if he thought supervisors were able to deal with returning TLEs. He said no. He said supervisors avoid the returning TLE and they do not know how to relate to them. He suggested that more team projects at work could help people support each other more when a trauma occurs in their lives.

From my observations of Bob in the Study Circle and afterwards, he was a pivotal person in the Study Circle. He shared his trauma story and this helped others talk about their trauma. He 
was very forthcoming and articulate.. After the Study Circle he thanked me, he made a friend in the Study Circle Group. Another gentleman who was in the Study Circle had left the priesthood got married and began working for HHS asked him if they could have lunch.

He felt he benefited immensely from the group and felt it helped him to understand how he could he helpful to other returning TLE employees.

\section{Observations of the Interactive Process}

As the researcher observed Bob in the interview and Study Circle, I recognized a man who was eager to share his experience with someone. Although his mother had passed away six months earlier, he not only shared every detail of that traumatic experience with the researcher but also wanted to share the experience of his daughter, Maria. In the interview he was articulate and clear and felt good that he could now assist other people in their trauma. He stated that, "God has become the focus of my life--the center of my life."

As part of the interactive dynamics of the Study Circle, he was the first person to tell his "trauma story." He not only set the tone for other people to talk openly, he took the biggest risk. He talked about "a man and his feelings, and how he struggled every day because no one was available in the workplace to comfort me." Individuals were visibly moved by his story and others started to share their own trauma experiences.

Jarvis' (1991) interactive learning model supports the use of an educational model in bringing individuals together to discuss a sensitive topic which they all share and have strong feelings about proves to be a powerful educational force. Because of the interactive nature the Study Circle, participants became part of a new and intimate group culture. Because each Study Circle finds its own pace and rhythm, it's hard to predict what will happen when a diverse group of people join together to discuss an emotionally-charged topic. However, as evidence from the continuous interactive involvements the process proved very beneficial to all the participants.

Silberman's (1990) ABC approach to learning was also evident in this the Study Circle model. Affective, behavioral and cognitive learning all were part of this experience. The Study Circle will be remembered by all, because of the "stories" the participants shared.

Cognitively, managers and employees asked questions and probed each other to new levels of understanding during the Study Circle sessions. Bob, in particular, said he had learned 
new concepts and new approaches while listening to some of the others responses. He also stated that he learned a lot during the dialogue when managers and employees were each trying to come to agreement about the conflict between "empathy and productivity." He reported learning "a new perspective" from the manager's point of view during those discussions.

Affectively, the participants were open about their experiences and feelings. Bob, in particular, had an emotional shift when he told his "trauma story" and another manager asked him to elaborate on "Why he decided to become a Deacon." Bob then went on to tell the group about his feelings, his faith and how his daughter's trauma affected him.

Behaviorally, the facilitator observed a major change in group behavior after the first Study Circle when managers returned and said they had "implemented some of the thoughts and ideas when an employee returned to the workplace." Bob reported that he had gone back to the office and was able to talk more openly and freely to an employee who had just experienced a death in her family.

Cognitively, also managers also learned new responses from each other. Bob recognized through the dialogue of another participant (manager) the crucial importance of dealing with a "volatile employee" and how his behavior could affect co-workers in the workplace. Other employees and managers began asking questions on how this situation was handled. They wanted to know the steps the manager took and the verbiage he used with the employee. Bob took the initiative to ask the group if guidelines could be set up for managers and employees as a kind of reference tool. He felt this would be helpful.

The three Study Circles Sessions and the topics that introduced these sessions created both structure and content for the participants. This yielded cooperation and an exchange of ideas. The model is effective as a learning tool for workplace trauma experiences. 


\section{CASE STUDY II}

\section{Verl-A Case Study of a Manager and his Learning of Workplace Trauma. The Early World of Verl}

Verl was born July 19, 1947 in Valacia, Florida, about 50 miles south of Jacksonville.

Because Verl's dad was in the army, they moved around a lot and he considered himself an army brat. Verl just loved it, stating "Every three years I had a new home, new experiences and met new people--it was "an adventure." However, he spent the longest time in the Washington, DC area. Verl's parents were very influential in his life. His father is a very organized and conscientious person; his Mom is a very outgoing person and makes friends easily. His mother's keen sense of style, fashion and skill helped her establish her own business in cosmetology. Although she was not formally trained, she ran her business from their home and because of her friendliness always did very well. Verl described his mother as a "really classy person."

Verl has three siblings, two brothers and a sister. One brother lives in Washington, DC the other in California, and his sister lives in Atlanta.

Verl was the only person who volunteered to participate in the Study Circle sessions who did not experience a personal trauma. His only recollection of a trauma occurred when he got married. His wife came from a very close-knit family, and when they would go to visit her family in Kentucky it would take her days to readjust when they returned home. It was "traumatic," he said, for her to leave them.

\section{Verl's Personality}

Verl is a large man. He is Afro-American with an effervescent personality. He has black wavy hair and his wardrobe is the envy of every other manager in the Department of Health and Human Services (HHS). He is stylish in every sense of the word and his style matches his extroverted personality. He wears pastel shirts with cuff links and always wears a silver bracelet on his right wrist. This bracelet has a personal significance since Verl bought it in Mexico and had watched the silversmith create it for him.

When you meet Verl, he seems "larger than life." He spends a lot of time on the phone negotiating and talking with colleagues and the general public. His supervisor had heard of my 
research project, called me and suggested that the researcher invite Verl to participate. When approached, Verl agreed before the researcher could explain what the research project would entail. In the Study Circle sessions, he was the one to speak out first and engage many of the managers in a dialogue about the topic that was being discussed. He also affirmed many of the employees for sharing their trauma stories and took the risk of asking the managers very sensitive questions about their own personal trauma. He played the role of catalyst and everyone seemed to respond to him. He also was the only manager who outwardly disagreed with the group's consensus on topics. Surprisingly, this created more energy in the Study Circle, because the group then seemed to participate in a more active manner by asking questions and probing for more information.

\section{Verl's Work History and Personal Life}

Verl started his career with the Department of Defense--the Defense Logistical Agency. He was a Procurement Officer/Contracting Officer until 1978 when he left for a position with the Small Business Administration. He became the SBA representative to several government agencies including HHS and in 1989 officially joined the team in HHS as Deputy of the Small Business Program. He considers himself a policeman for HHS because he is asked to do things others do not want to do. When his mentor retired, he applied for his job and got it. He has been in his present job since 1993.

Verl has three children--a daughter Zanita from his first marriage and two sons from his second marriage, Zachary and Zarad. His wife decided to quit her job and be a traditional mother. Verl did not consider the divorce from his first marriage a trauma.

\section{The Race Issue and Verl--His Thoughts and Feelings}

In 1961 when Verl was a teen, his family was traveling from Kansas to Fort Belvoir, Maryland. When his family arrived, they were part of the group that was going to be integrated into Mr. Vernon High School in Alexandria, Virginia. Verl said there were 1,500 students in the school and only five blacks. He was in the 11th grade at this time. Verl adjusted very well. He joined the basketball and football teams in the 12th grade and became co-captain of both teams. He states that he still goes to reunions with his friends and they talk about how it felt to all of them to handle the issue of integration. 
Verl says he is not intimidated with racism. It exists, and he feels we as a people a society should deal with it.

\section{Verl's Experience in the Study Circle}

Verl was the only person the researcher had encountered when seeking individuals to volunteer for Study Circles who had not experienced personal trauma. Verl said he truly felt "blessed" compared to people who had no choice in the way some events unfolded in their lives. Verl said he knows of people who just "give up," but in the Study Circle sessions he said he did not observe anyone who did this. He considered the participants in the Study Circle his "heros." They had not walked away from their trauma and pain and became better people for it.

The researcher watched Verl as other people were telling their trauma stories. He was quiet and pensive. When one employee described the Long Island Train disaster of 1993 where a deranged man stood in the aisle of a passenger car and shot bullets everywhere, the employee said he crawled under the seat and stayed there in complete shock. Verl was the first person to ask him questions as to how he felt when he returned to the workplace as a TLE. The employee elaborated his feelings in detail, which continued the dialogue among the participants. Verl stated that he had watched the trial of the shooter on television and could describe it in very graphic details, but when he realized that he was hearing an eye-witness report in the Study Circle, this overwhelmed him. Verl stated that he was angry while watching the trial and admired the returning TLE (Jim) retelling his trauma story without any malice for the man who almost killed him. This story had a strong impact on Verl.

Verl felt the Study Circle group allowed him to see beyond his own situations in life. He stated it gave him "balance" in his thinking, and that was refreshing to him.

\section{Verl's Real Life Experience with Trauma After the Study Circle}

During the Study Circle sessions, one of Verl's employee's came to him and stated that she had cancer. This came as a total shock to Verl, because this same person had filed an EEO complaint against him, and he did not know what to do. Verl said he had a conflict that had to be resolved. He stated he approached the situation in a "clinical manner." He felt that the EEO complaint was going to be resolved by the standard procedures within the system, and he was ready to accept the decision that the system would give him.However, dealing with the employee 
was totally different. Verl states he followed the suggestions and ideas from the Study Circle. He tried to create a "safety net" for her by allowing her the necessary leave for her treatments, he was there for her if she wanted to talk and would do all that he could for her in the crisis.

Verl stated that the dialogue in the Study Circle helped him in dealing with his returning TLE employee. Because he is a "bottom line" manager and always concerned with productivity, he seldom would allow for people to get extensions on work assignments. Now, he was confronted with a totally different situation, one with which he never had dealt--approving sick and annual leave in advance for someone who was really trying to hurt him as a manager. He said the Study Circle put a lot of these issues into perspective. He had listened to other Study Circle participants talking about their supervisors and their trauma and, as a result had become more sensitive to his returning TLE employee.

Verl stated that the presence of employees in the Study Circle assisted him in understanding what the returning TLE was dealing with internally. When employees were sharing their trauma stories, it helped him put his workplace requirements in perspective and offer the returning TLE employee more of a safety net than he previously would have done.

\section{Verl and How He is Coping}

Verl says it is difficult coping with his TLE employee. He has been unable to completely reconnect the employee back to the workforce and does not know what to do. He has tried to talk with her about her trauma, but she refuses to discuss anything with him. Verl feels she has come back to the workplace with a "victim mentality" primarily because she has not resolved the issues that brought the EEO complaint against him. Verl says he has put the past behind him and wants to move forward. The researcher suggested he call labor relations and the Employee Assistance Program (EAP) for guidance.

Verl states the Study Circle assisted him in putting the TLE's trauma in perspective and he became a better person for it.

\section{Identification of Critical Elements for Discussion}

From each of the three Study Circle sessions, the following critical elements were seen as needed in an organization to assist managers and employees to deal with a returning TLE. The critical elements evolved from the themes of the Study Circles which were, creating a safety 
net, retelling the trauma story and reconnecting the TLE back to the workplace.

\section{The First Session}

Participants in the first Study Circle session focused on the need to establish guidelines for managers dealing with returning TLEs. All of the managers felt unsure how to approach a returning TLE. Specifically, they needed guidance on how to tell the co-workers about the returning TLE, how to assure the TLE about work assignments, and how to create an environment that was not threatening for the returning TLE.

Many managers agreed that HHS has many resources available to its employees for dealing with returning TLEs, e.g., training, counselors, workshops, etc., but managers felt they were not aware of the extent of these programs. Managers stated that an informational program should be institutionalized for managers and employees to get assistance when individuals are dealing with incidents such as a trauma. For example, a manager in the Office of Civil Rights told the researcher that he received a phone call from the Director of the New York Regional Office stating that his employees were experiencing different types of traumatic events and he felt helpless in offering his managers assistance. The HHS Civil Rights manager stated he had shared his experiences in the Study Circle with the New York Regional Manager and was pleased he was able to assist and offer suggestions to him.

During the first Study Circle session, conflicting views were acknowledged by managers who wanted to emphasize the need for "productivity and compassion." Managers are responsible for the "bottom line" and getting the work done. They felt conflicted if they had to spend an enormous amount of time tending to a TLE. After the first session, one employee talked with the researcher and stated how amazed he was that managers were making such a "hard call" on performance when the TLE returned. He had experienced a very uncomfortable transition upon his return to the workplace and said it was very difficult for him to concentrate on his work when he returned because of his trauma. The researcher encouraged him to share his views with the group if and when he felt comfortable.

All the managers agreed that, at first, the returning TLE should be "acknowledged" when he/she returns to the workplace. A returning employee (TLE) in the Study Circle group stated, "Use common sense; treat a person as you would like to be treated." 
The element of safety came up pertaining to the types of "safety net" a trauma person needed. All managers agreed that there were two essential safety nets that would reduce the stress for a returning TLE. They were physical and financial, which included their physical work area (where the TLE can go and no one can bother him/her) and the continuance of their salary.

Observations from the first session showed some managers hesitated to take responsibility for the returning TLE. Some managers stated they would prefer to send the TLE to a professional counselor for therapy. They stated they did not have the skills and felt that the amount of time needed to nurture the employee back would jeopardize the work assignments that had to be completed. However, in the second session the facilitator presented the group with "notes from the previous sessions" (see Appendix L) and the group clarified what they could do that didn't take very much time but would still be very helpful. As a result the following guidelines were suggested:

(1) Acknowledge the TLE's presence when they come back to work.

(2) Suggested greeting would be--"I am glad you're back to work, what can I do to help you?"

(3) Have a "listening ear"--show the returning TLE that you are interested by practicing listening skills.

(4) Body language plays a part here--watch for cues from the employee.

(5) If a TLE does not want to talk to you--suggest that they talk to a colleague or someone.

\section{The Second Session}

In the second session there were differing comments about how a managers should interact with TLE employees. They concluded that it was important to understand the culture and personality of the person. For example, some individuals may have been brought up not to talk about personal problems to anyone outside the family. Perhaps they may not have been comfortable sharing the "intimate side" of their personality. Managers and employees agreed that they should honor this wish if the employee chose not to share their experiences.

The Myers Briggs Type Indicator (MBTI) was introduced into the discussion relative to 
an individual's personality. Participants talked about personalities being introverted or extroverted. Introversion and extroversion are preferences in the way people interact with each other. Kroeger and Thuesen (1992) state that "when discussing extroversion and introversion we look at people and how they prefer to interact with the world, and the way they prefer to receive stimulation and energy" (p. 16).

Managers agreed that understanding the MBTI would assist them in understanding their employees, but some pointed out that managers also have different personalities (i.e., some are outgoing, others aloof and cool), and managers need to understand themselves, too.

Managers discussed performance of the TLE by noting that a bad performance and behavioral issues create a potential for trauma in the workplace. All agreed that work assignments should be given to returning TLEs gradually, allowing the TLE to familiarize slowly when returning after a trauma.

On the other hand, what does a manager do when the employee talks incessantly about his/her trauma? After much discussion the group suggested the following guidelines:

(1) If a TLE employee by talking incessantly is consuming a lot of their co-workers' time, the manager must intercede. One suggestion can be for the TLE to see someone in the Employee Assistance Program for counseling.

(2) Try to focus on the task that needs to be accomplished and in a gentle way, with some diplomacy, try to get the returning TLE back on the work track.

(3) Give the returning TLE work options when he/she returns. Try to understand that there are different types of trauma and the recovery process may be longer for a specific type of trauma.

(4) When the person returns to the workplace, how and when the manager approaches the TLE is important.

This discussion affirmed the importance of the TLEs personality and the need to allow for a variety of performance expectations for a returning TLE employee. Here, because some managers in the group had been returning TLEs, they were more sensitive to the needs of a returning TLE. Some comments were, "My trauma changed me--we can use the wound and help someone else in their pain." Also, the managers felt free to approach a returning TLE and let them know, "I am available for them." One female manager who experienced the loss of her son 
stated, "Allow the TLE space to discuss the trauma. Don't push, but don't let this become disruptive."

\section{The Third Session}

In the third session managers focused on how to discuss the trauma with co-workers and what tone to set in the organization when the TLE returns to the workplace. One male manager stated, "The managers must send out the right signals to the staff." Another manager added, "We should include the returning TLE in staff meetings, and reassure the person that his/her status has not changed because of the trauma."

A male manager stated that co-workers can get stressed out by returning TLE employees, especially if the returning TLE previously exhibited violent behavior in the workplace or verbally threatened individuals. He asserted this is a serious problem which he had to deal with, and the manager cannot shirk from these responsibilities.

The participants were asked to rank the three Study Circle sessions they attended in their order of importance. They responded that the third session was the most important (reconnecting back to the workplace) and the remaining two were similar in importance (establishing a safety net and retelling the trauma story (See Appendix J).

The last issue that was discussed in the third session was the different ways gender might affect coping with trauma. The facilitator asked whether women or men cope better after a trauma when coming back to the workplace. One employee stated that after her trauma, the men in her car pool showed feelings and shared their life stories, but only in the car pool. Outside of this they would not talk about their personal incidents. A female manager whose son was killed stated, "My husband keeps his feelings inside, and I went to a therapist, which helped me. My husband still has not dealt with the death of our son." Another employee whose daughter had been diagnosed with cancer stated his wife went to a support group, and they both went to a Cancer Support Group for parents. He also stated that men want guidance, not support. Some men in the group stated that men will internalize their feelings and "work" them out, but will not talk about their traumas. 


\section{Group Participation in the Study Circles}

This section discusses, group dialogue and interaction, communication and group climate.

\section{Videography, Group Dialogue and Interaction}

Group participation is essential in a Study Circle. The group was assembled by voluntary participation and referral within HHS. The researcher had no idea how the individuals chosen would work together or react to each other in a group setting but they were all interested in the topic.

The Study Circle topic created a bond among members of the Study Circle mainly because $50 \%$ of the participants of the group had experienced trauma and some managers were returning TLE employees themselves. One manager who neither experienced a trauma nor supervised a returning TLE stated that the sessions "enhanced his sensitivity towards a returning TLE."

Each Study Circle session was video-taped. After each session the facilitator viewed the video twice. The first viewing was to hear the dialogue and discussion. The second served to clarify and document the participant comments that the participants made during the sessions in order to share these with the group at the following meeting.

The facilitator opened each session of the Study Circle by reading notes from the previous session (Appendix L). This created an opportunity for group members to refresh their memories on what had been discussed, to improve or refine what had been said. In carrying out this activity, the notes served as a guide.

The group interaction among participants worked quite well. In the beginning, some individuals dominated the exchange of ideas, but as the Study Circle progressed all members became active participants. The main reason can be found in the fact that the group was assembled for a specific need, to assist managers and employees with the re-entry process of an employee. This need was shared by all the participants.

\section{Communication and Group Climate}

Group participation can create either a "defensive" or "supportive" climate. Gibbs (1961) states, "Defensive behavior occurs when an individual perceives threats or anticipates threat in the group" (p. 207). On the other hand, supportive behavior has the opposite effect. Johannesen 
(1990) observes that "supportive communication is essential to a dialogical ethic of group communication; only in this positive climate can people maintain their own values, dialogue openly and make ethically acceptable decisions"(p. 207). Lumsden and Lumsden (1992) state that a supportive climate "builds openness, trust and empathy." These three elements are interdependent, each contributing and reinforcing the other.

Regarding openness, the participants were interested in the perceptions of the others and listened to their points of view. They also were open-selved. They were all willing to risk and were generous in sharing their trauma stories, which created a very positive climate of trust.

Trust in a group setting comes gradually. Trust is built in small increments. For example, in the second session when an employee shared the trauma story of his daughter's cancer, it had a rippling effect of trust within the group. Soon, another manager talked about her son's murder. Each story created another layer of "safe trust." By the last session, an employee who was a passenger on the Long Island train where thirteen people were gunned down by a crazed man, described for the group this horrible story and how he crawled underneath the train seat to protect himself from the man who just kept spraying bullets at people. He described his feelings, his fear and frozen body during this disaster. He remained under the seat hearing individuals accost the killer who then ran off the train. Participants in the Study Circle listened attentively for every detail and then asked questions like "What was it like to return to work after this trauma?" He gave a detailed report of his experience.

Soon after that, another manager shared his trauma and challenge to the facilitator. This manager from the Office of Civil Rights stated to the group that his son is in a coma three years after an automobile accident. The son is unable to recognize anyone and cannot even squeeze his father's hand. This manager asked the group how they could help him deal with his on-going trauma, because it is with him every day. He shared with the group how, in the early months of the trauma, everyone was very attentive to him and his needs, but as time went on not very many people asked about his son. His story left an impression on every person who participated in the Study Circle.

Empathy was discussed at length, with managers admitting not knowing how to show it and asking, "What is it?" Broone (1991) suggests that empathy means learning to understand "the 
values, meanings and symbols of another person." Lumsden and Lumsden (1992) describe empathy as "walking in another person's moccasins, or feeling what another person feels"(p. 209). Managers were not sure how much empathy to show the returning TLE employee, but they realized that productivity in a returning TLE would be lower if managers did not deal with an employee and his/her trauma.

\section{Summary of Group A Study Circle Sessions}

Many authors have confirmed that we are living in turbulent times and that our organizations are undergoing many changes in the allocation of resources, compressed budgets and dealing with many human resource issues. This research project examined an issue never before explored in the workplace--the re-entering of an employee after having experienced a trauma as seen through the lens of the Study Circle, a new application of the educational model. The Study Circle focuses on an interactive process where people are engaged in a dialogue of interest to the whole group. Although only four and one-half hours over a three-week period were devoted to this intervention, participants reported qualitative changes and insights using this new educational format.

The pre-Study Circle interviews served as an introduction to the material, questions, discussion and learning format. The Study Circle itself, provided an opportunity to bring together, for the first time in a government setting, managers and employees to, listen and dialogue about an issue important to all levels of the organization. Examples of major learning for the two groups follow.

The managers learned that they needed training and guidelines to effectively deal with a returning TLE in the workplace. They learned from the employees how important it was to "acknowledge the employee" and "allow the employee to return to the workplace at his/her own pace," and "be there for the employee."

The employees came to realize the many responsibilities of a manager. They more clearly understood the pressures that managers are under when deadlines must be met and work priorities must be completed. The employees openly expressed their concerns that managers need to "take the time with returning TLEs." If this were done there would be "a much more productive staff and a motivated employee." 
As discussed above, both managers and employees were able to report tangible results from the Study Circle. Learning occurred in all three sessions, and participants walked away from the sessions with a deeper knowledge of themselves and each other. 


\section{CHAPTER FOUR}

\section{RESULTS--PART II}

\section{Introduction}

The second part of Chapter Four will give a profile of Group B participants and will include a comprehensive review of both Study Circle groups (A and B). This chapter will profile Group B participants, discuss their overall reaction and the effects of the pre-Study Circle interviews on the group members and summarize group composition, dialogue, observations, the dual role of the researcher in the Study Circle sessions, the videography, the group's evaluations and concluding thoughts on both Study Circle groups.

\section{Profile of Group B}

The second group of Study Circle sessions were conducted with fourteen participants, nine (9) managers and five (5) employees. The managers included four (5) Caucasian males (of this group two were attorneys with expertise in alternative dispute resolution and mediation), one (1) American Indian female, two (2) Afro-American females and one (1) Caucasian female manager.

In selecting the participants for Group B, the researcher consciously included participants who were skilled in group process, human resource and mediation. This was done to bring these experts together in the hope that a strong relationship would form among the participants and they would stimulate positive interaction. However, the participants in Group B did not seem to connect with each other as closely and openly as did the members in Group A. The interaction of managers in Group B seemed more formal. They offered examples of workplace incidences of trauma, but were uncommunicative about their personal feelings and their own trauma experiences, which the researcher knew about. Both of the Caucasian male lawyers who were experts in dispute resolution had experienced a trauma and one had lost a parent six months prior to the Study Circle sessions; they had expressed this in the pre-Study Circle interview but did not share their personal experience with the group. The female American Indian manager who had revealed to the researcher that she had lost a sister only two weeks prior to the Study Circle, spoke only about the experiences with her employees who had come to her with workplace 
trauma but she never engaged the group about her own personal trauma and the coping mechanisms she had tried.

Self-disclosure was much less universal with Group B participants than Group A participants. Group B seemed more controlled and less spontaneous. Group B managers looked for cues from each other about how to respond. Instead of becoming more open, they seemed to remain "professional." The participants in Group A including the managers were able to step out of their "career role" and talked about their life and their trauma experiences. For example, the female Afro-American black manager in Group A, after talking about her return to work following a trauma, went on to elaborate how she does not like some of the work that she is engaged in reviewing and how she tries to make it creative for her and her staff.

Despite the difference in the amount of personal openness and sharing in the two groups, both groups dealt effectively and thoroughly with the themes, issues and educational objectives of each session..

\section{Pre-Study Circle Interviews with Group B Participants}

Pre-Study Circle interviews with Group B were conducted in a conversational manner. During the interview process, both participants were very forthcoming in sharing their personal traumas.

In Group B, the researcher interviewed all the nine (9) managers but by design did not interview the five (5) employees, all of whom had been TLE employees. All nine (9) managers had also experienced a personal trauma, but only two had supervised a returning TLE. The researcher was aware that the five (5) employees in Group B had experienced a trauma, but was not aware of the nature and extent of their traumatic experience prior to the Study Circle. It can be concluded that the pre-Study Circle interviews are not necessary to generate the level of open dialogue and sharing that takes place in a Study Circle even with such a sensitive topic as employees who are returning to the workplace after having experienced a trauma. Indeed, the pre-Study Circle interviews assisted the researcher in knowing more about the participants and their trauma, but the interview was not the deciding factor to ensuring that participants would be open and involved.

At the beginning of each interview as with group A, the researcher carefully explained the 
process of the interview, described the types of questions that would be asked and gave participants an explanation of the Study Circle intervention process--this included the signing of the Confidential Agreement to protect each participant, along with an invitation to the Study Circle that each person would receive prior to the first session (see Appendix C and D). The researcher also mapped out the steps of the Study Circle and made each participant aware of what to expect during each of the two-hour sessions. For example, the researcher pointed out that each participant would receive discussion questions two days prior to each session, and during the Study Circle session an outline of the role of the participant would be handed out (see Appendix I).

\section{Composition, Dialogue, Observations and the Dual Role of the Researcher in Study Circle} Sessions.

Both Study Circle groups consisted of managers and employees of the Department of Health and Human Services (HHS).

For Group A, the researcher recruited eleven participants (11)--eight managers and three employees. For Group B, participants numbered fourteen (14)--nine managers and five employees. The researcher recommends an optimum size of ten individuals. Because Group B was larger, it required more attention. It was difficult keeping everyone's trauma story straight, and reticent participants didn't have to participate because others were always ready to speak up. Also, the need for more time for dialogue was evident in both groups because participants were interested in asking each other questions relative to the experience of talking to returning TLE employees.

In Group A, the mix of individuals involved were Afro-American and Caucasian. There was no specific reason for selecting this group other than the availability of participants. As a result, the discussions in this group were consistently spontaneous and open. By "open" the researcher means a person is willing to talk about their experiences. In group A, all those individuals who had experienced a personal trauma talked openly about their trauma experiences.

In Group B, the researcher varied the selection of the group by creating a more diverse group of participants, including Afro-American, Caucasian, American Indian and Hispanic. Group B also had another element, there was a wider age range and grade level (salary scale). 
The researcher assumed, because Group B was more diverse and larger, there would be more personal sharing and openness. The diversity of Group B did not make a difference. As a matter of fact, Group B participants (consisting of nine managers (9) and five (5) employees) were not as open and spontaneous as Group A participants. Even though the researcher had interviewed all nine (9) managers in Group B (all of these managers had experienced a trauma in their life), created a conversation partnership with them, along with establishing an excellent rapport with each one, only one manager out of the nine who himself was a returning TLE shared his trauma story with the group. The topics that had emerged in Group B were very similar to the topics that had been discussed in Group A but the emphasis and conclusions differed in both groups. For example, when the researcher asked for suggestions to implement easing the returning TLE employees back to the workplace, Group A participants wanted the facilitator to create a set of guidelines for the organization and its managers, while Group B stressed the need for developing listening skills, dialogue and communication. Both groups also felt that the organization needed a place where the manager could go and accompany the returning TLE to talk to a professional counselor. They suggested an on-site facility for this process, giving the managers the immediate support they needed when a TLE returns to the workplace after having experienced a trauma.

Among the returning TLE employees in both Groups A and B, there was spontaneous openness and sharing. The returning TLE employees in Group B even challenged the managers by asserting what managers needed to do and say in different situations to help make the transition easier for the returning TLE. This could have occurred because the researcher made a conscious decision in the second session of Group B to directly ask one employee to share her trauma story with the group, which she did. When she finished, the other employees began to tell their trauma story. At one point, two returning TLE employees in Group B wanted to speak about their experiences. The first employee (male) shared his anger because his supervisor remained passive and non-supportive when he returned after his trauma. He asked the group for advice, wanting to know when and if he should discuss this incident with his boss. The other managers did not know how to advise him. They told him his manager did not know how to show "empathy." The employee stated he felt "lost" and was behind in his work. When he 
returned, his boss treated him with a "business-as-usual attitude." He stated his boss never asked how he felt after his illness.

The second employee (male) also shared his frustration and anger with the participants about his supervisor. He told the group members that his son had a head injury and he had to be out of work a month. When he returned, his boss never asked about his son. He said it's been five years, and to this date, he has never approached him about the matter. By sharing their trauma stories, these returning TLE employees gave the managers a "new lens" to see how an employee actually feels when returning to the workplace and to a disinterested manager.

The managers in Group B started to use the employee's stories as an illustration of what "should" happen to an employee when he/she returns to the workplace after a trauma, but none of the managers themselves took the "storytelling" one step further and offered to share with the group what they themselves had experienced as a returning TLE or share their philosophy after their trauma experience. The researcher speculates that the managers in Group B remained in their "professional roles" throughout the Study Circles sessions, where Group A managers did not and talked more about their personal experiences. In Group A the opposite occurred. After one of the returning TLE employees shared his trauma story with the group, he stated he began taking instructions to become a deacon in his church. This led to a discussion of trauma and the lessons that are learned in life about individuals and managing their crisis. The returning TLE went on to suggest that there is a "gift" in the traumatic experience that cannot be explained, and through this experience they can become better people. The other participants in Group A then joined in this discussion, creating a rich dialogue with group members. This did not happen in Group B, and this puzzled the researcher.

Prior to the planning of the second group of Study Circle sessions, a conscious effort was made by the researcher to recruit individuals with specific types of group process skills to participate in the Study Circle sessions who would be willing to engage in open dialogue with group members and create an ambiance equal to or better than what occurred in Group A. After the first Study Circle session, it was obvious to the researcher there were two distinct groups with different characteristics--one that was willing to share and be open and another that was not. It is not clear why Group B responded so differently from Group A. 
The composition of participants was different for Group B because it included individuals with specific types of skills: Two lawyers (male) were skilled in alternative dispute resolution $(\mathrm{ADR})$ and one female had expertise in labor-relations management. All were experienced workshop leaders and were skilled in group process. Because they had these special skills their presence dominated the group and swayed the dialogue. The themes and concepts they continued to emphasize were communication and listening skills, but as members of the group they were not doing this. Group A participants had suggested that the researcher propose a "handbook or a set of guidelines" to assist managers in dealing with the returning TLE employee; however, Group B focused mainly on emphasizing the importance of listening to, interacting and dialoguing with the returning TLE employee. At times the researcher suggested to Group B the need to establish managerial guidelines, but they negated the suggestions. While Group A was more resultsoriented in wishing to create procedures for managers, Group B was more concerned with the quality of interactions between managers and returning TLE employees.

Only one manager "let his guard down." He was a returning TLE and was open about his trauma and his managerial approach to his own employees. It seemed the other managers were disengaged from the group dynamics. To the researcher they were "posturing and pontificating." For example, the chairs in the room were of a swivel type; all of the men managers kept swiveling back and forth in the chairs during the discussion period. This did not happen in Group A . All participants sat around the table attentively making eye contact and having a discussion. Also all the participants in Group A finished their lunch before each Study Circle session, where in Group B the participants continued to eat their lunch throughout each session. The researcher worked hard at keeping the discussion focused and the momentum moving forward.

Even though Group A participants were asking for technical guidelines to cope with a returning TLE employee, the participants in group A were "real." They shared their feelings with the group and were not afraid to risk being vulnerable. On the other hand, Group B members did not. Eight (8) of the nine (9) managers in group B acted like they were in their "career role," and their behavior was "robotic." To the researcher, it seemed they were representing their division or branch as a participant without sharing their feelings or showing their own vulnerability. The researcher did not know how to elicit a reaction from some of the individuals; this could have 
been because of the dual role the researcher/facilitator had to constantly play in the research project and the conscious effort the researcher made of remaining neutral.

\section{Dual Role of the Researcher}

The researcher had two roles to fulfill: researcher and facilitator. First, the researcher is a person who is attempting to look studiously at the facts and data that are presented aiming to analyze and interpret this data to draw some conclusions for the research study. Second, as a facilitator, the main task is to increase the group's effectiveness by improving its process.

Schwarz (1994) states "process" refers to how a group works together. However, the two roles are not mutually exclusive, and can work in tandem in the design of a successful research project.

In this project the researcher initially had to complete all of the administrative and logistic tasks that needed to be accomplished to successfully conduct six Study Circle sessions. Some of these tasks included the following:

1. Confirm attendance of each participant.

2. Arrange Study Circle invitation.

3. Ensure confidentiality statement is signed by participant.

4. Conduct and transcribe pre-Study Circle interview.

5. Confirm conference room arrangements for the Study Circle sessions.

6. Determine the lunch menu for each participant and call in the order for delivery.

7. Distribute the discussion questions two days prior to the Study Circle sessions.

8. E-mail each participant the day before the session as a calendar reminder.

9. Distribute "The Role of the participant" at first session.

The role of the researcher never changed but folded into the facilitator role with additional responsibilities once the sessions began. For example, the discussion questions that were distributed prior to each Study Circle session assisted the facilitator in creating structure for the introduction of the topics. Participants in both groups stated that these handouts were very beneficial in preparing them for the sessions.

During the first session in Group A, the researcher handed out copies of a published newspaper article relative to employee behavior and performance. The study, reported in The Washington Post, had been conducted by the Merit Systems Protection Board (MSPB). The article was helpful in getting participants to express their views on employees who do not do their share of the work, but it did not generate any new insights about welcoming back TLEs to the 
workplace. Although the researcher did not show this article to Group B, the participants themselves brought up the same topics for discussion.

Prior to the beginning of the Group B sessions, the researcher had certain expectations of the group process which did not occur. For example, during the pre-Study Circle interview all of the nine (9) manager participants shared not only their trauma stories, but information about their careers and life experiences. When the sessions began, the researcher expected that because these individuals were seasoned managers, even though some had known each other, and some did not, they would "come together" as a group and there would be excellent group dynamics. This did not happen.

The researcher, herself a seasoned facilitator, experienced a conflict. Realizing group cohesion was not happening after the first session, she was not sure what to do. To ensure the continued group process, the researcher reviewed some important elements for facilitating according to Schwarz (1994). They are as follows:

1. The whole group is the facilitator's client; the facilitator is not a group member and cannot help certain members at the expense of others.

2. The main task of the facilitator is to increase the group effectiveness. Here both content and process are important.

3. Facilitators must remain neutral, and allow the group to solve their problems.

\section{Identification and Discussion of Critical Elements for Groups A/B}

The researcher felt there was a fine line that she needed to walk in this process, not only to engage the participants but to have successful Study Circle sessions. Each session of Group A and $\mathrm{B}$ will be discussed along with the behaviors and issues that emerged in each session.

\section{The First Session}

In their first session of the Study Circle, both Group A and B discussed the "safety net" concept. Each group placed a different meaning on "safety net". Group A suggested the need to create a "safety net." They defined the concept of a "safety net" and what the workplace needed in a "safety net" for the benefit of the returning TLE employee. They included as part of their "safety net" financial assistance and/or support from the organization, time off relative to the leave 
that may need to be taken for psychological readjustment, flexibility with work assignments, empathy and trust. On the other hand, Group B focused on a different approach, suggesting that natural "safety nets" already exist in organizations. They defined these "natural safety nets" as the ongoing friendships at the workplace, the natural bonding that occurs between colleagues, managers and supervisors. Group B stated that these "friends" are the people who provide the "safety net" and help with the adjustment process when an employee returns to the workplace after having experienced a trauma. Group B offered some advice to the manager upon the TLE's return especially because mangers do not always know what to do or say. Here is a short summary of their advice:

-Let the TLE employee set the pace--follow the flow of the employee.

-Express empathy toward the returning TLE.

-Remember that when individuals return to the workplace they want normalcy.

The main difference between Groups A and B surfaced during their respective first sessions when the discussion turned to "productivity and empathy." One manager in Group A stressed that "productivity will definitely drop in an organization if individuals are not prepared for a returning TLE." When employees stated that managers should show "empathy." managers agreed this was difficult. The discussion continued and ended with the managers stating they faced a very complex issue because they were dealing simultaneously with individuals who had performance issues, behavioral issues and were returning TLEs.

In Group B, the topic of productivity was not as openly discussed as in Group A. Instead, Group B focused on a conflict of values when dealing with a returning TLE--the need for balancing compassion and communicating with the returning TLE when he/she returns to the workplace.

Another point to be brought out with Group A after the first session, when the video camera went off, two of the male managers and an employee were demonstrating to each other how they relate to their returning TLEs. They said they liked "to hug" people when they welcome them back to the workplace. They were demonstrative and touching, a quality that was missing among participants in Group B.

\section{The Second Session}


In their second session, Group A participants were open and spontaneous. Group A participants spoke of fourteen (14) different incidents relative to their trauma story. They gave each other feedback, told their trauma stories and shared their philosophy of life. Group B in their second session were not focused on the trauma story, even though the facilitator began the session by telling her trauma story. After the facilitator told her trauma story, she asked an employee to tell her trauma story. When the employee (female) completed telling her story, the group complimented her. The returning TLE went on to say that her boss encouraged her to talk about her trauma story. The group affirmed her on having the courage to risk telling her story in the workplace and told her that her boss had excellent listening skills. The ADR attorney sat across the table from her with his hands folded in a "closed position" and offered nothing else, he just complimented her on her courage. His body language seemed to contradict his words of affirmation. This did not lead to him tell his trauma story nor did the researcher understand what was going on with him or the group dynamics.

The managers and employees in Group B made reference to their trauma stories only four (4) times during the second session. The focus of Group B was not on telling the trauma story, but on managers responsibility in dealing with the returning TLE.

In Group A, the participants discussed the importance of respecting a person's personality and his culture during the re-entry process. For example, some individuals may have been brought up not to talk to anyone outside their family about personal matters. In Group B participants also talked about the influence of culture, but in a different context. Their reference to culture was more focused on the political environment of the organization, not on individual personality and ethnic or cultural values.

For example, in Group A it was mentioned that some individuals were introverts and some extroverts, and this aspect of a person's personality influenced whether they were open to talking about their trauma. It was concluded in Group A that individuals who are returning to the workplace after having experienced a trauma be acknowledged by someone in the organization. People should ask them what their colleagues can do for them, and watch for cues from the employee and not to intrude if the person is unwilling to share their feelings at work. Knowing where to send a person who was returning to the workplace after having experienced a trauma 
was seen as an essential step.

Group A participants focused on "problem employees" during their first session, and this theme naturally arose in the second session. The group talked about the manager's dilemma and what he/she should do when returning employees do the opposite of what they are asked to do and repeatedly talk about their trauma. Some of the suggestions were as follows:

-If a person is taking a lot of his co-worker's time, the manager must intercede. Suggestion can be to see someone in the Employee Assistance Program (EAP) for counseling.

-Try to focus on the tasks that need to be accomplished and in a gentle way, with some diplomacy, try to get the TLE back on track.

-Give the employee options when he/she returns. Understand that there are different types of trauma and that the recovery process may take longer for a specific type of trauma.

-When the TLE person returns, how and when the manager approaches the TLE is important.

Since Group B focused on the importance of communication skills in their first session, they naturally continued with this topic throughout in the second and third sessions. They encouraged managers to develop good listening skills in dealing with the returning TLE, but never practiced "openness" among themselves.

The following suggestions were highlighted by Group B managers:

-Developing active listening skills is important when dealing with an individual returning to the workplace after experiencing a trauma.

-Show compassion. Employees/managers agreed that a person either has compassion or they do not. It is a quality that should be shown towards a returning TLE.

-Offering false compassion is worse than saying nothing at all to an employee.

-Be cautious in approaching a returning TLE and be sincere in your acknowledgment.

-Send the employee to the Employee Assistance Program for counseling or to talk out his/her problem. Don't try to play therapist in the workplace. 
In Group A, one employee shared his trauma story and gave insight to what he was feeling relative to his work, supervisor and organization. Individuals in the sessions probed and asked questions. By elaborating on his own trauma, he continued to take the risk in sharing his insights, which created a trust among the participants and set the tone for the next meeting. Individuals seemed to bond with each other. This bond continued outside the Study Circle. After the second session, some of the members attended a retirement party for a colleague in the department. The researcher noticed some of these participants, who did not originally know each other, talking with each other and sharing work experiences at this party.

An employee in Group A gave insights of her trauma story to the group. She said when she returned to the workplace after her trauma, she "was there, and not there." She explained that the returning TLE employee is "not the same person" when he or she returns to the workplace. In contrast to Group A, the Group B participants had few questions to ask the returning TLE's after they told their trauma story. Group B participants seemed reluctant to share their own trauma stories, even though everyone had a story to tell. The researcher concluded that their willingness to risk was much lower with members of Group B, whose main area of concern in their "career role" was to encourage risk.

\section{The Third Session}

In the third session, Group A focused on the topic of the "different types of trauma" that exist in society. The dialogue continued to flow freely. Managers wanted to make each other aware of these differences and asked for feedback on how to define them and deal with them. For example, they asked whether the death of a child or spouse would be more traumatic than witnessing an accident or the loss of a career. Managers wanted to make each other cognizant of these differences in dealing with returning TLEs who had experienced different types of traumas.

In Group B, participants did not discuss this topic in any detail, they merely alerted each other that they must be aware of trauma and the different types that exist.

Group A participants emphasized two suggestions for dealing with a returning TLE. First, time was an important factor; it was important to determine how long it would take for the returning TLE to heal from his/her trauma. Second, managers should play a key role when an 
employee returns to the workplace after their trauma. One manager felt TLE employees return to the workplace far too soon, before they are ready to work. Managers must be sensitive to this too early return policy in receiving the employee back to the organization.

Group B focused on the relationship the manager had with the TLE prior to the trauma. They all agreed that the reconnection to the workplace depended on this prior relationship. If the relationship had been good, then the returning TLE's transition would be easier; however, if the manager were dealing with a problem employee or an employee who had been a borderline performer and did not always do his/her work, this could create special challenges for the manager in dealing with the returning TLE. It was observed that, no matter what problems a person may have had as a worker when a TLE returns after a trauma, that person is different and is in need of "special efforts" and "understanding." Managers must realize that the TLE is in a recovery process.

One manager in Group B, speaking from personal experience, said that the returning employee should be "greeted" and his/her "absence should be acknowledged." Another manager (who had expertise in ADR) stated that the day a TLE employee returned to the workplace would be an excellent time for a dialogue, in essence, as part of welcoming the employee back to the work environment and helping them feel once again part of a team. This particular manager never shared his feelings in the group, yet he is considered the "guru" in the department relative to "mediation" and "conflict resolution." This was an interesting disparity to observe.

Another manager in Group B (female), who herself was a returning TLE in the workplace, stated that when she returned after her trauma her supervisor did not "hurry" her reconnection. He gave her a "choice" of what she could do. She explained in the Study Circle that he handed her a paper with a list of activities and meeting schedules and told her when she was ready she could choose to be involved. She stated that she did go to some meetings and was present physically but not mentally. She said this freedom given by her manager helped her tremendously because she did not feel pressured to perform. She monitored her own emotional state and created her own time frame for getting reinvolved in the organization. Also, this manager had recently lost her mother and in the pre-Study Circle interview shared her loss and trauma with the researcher, but did not come forward to share her trauma story with the group members. It 
should also be noted that this manager in her "career role" is the director and team leader of the human resource area in her organization. She was recommended to the researcher by her supervisor who was a member of Group A.

All Group B managers agreed that the reconnection process was a lot more difficult than it seemed. Each manager needed to be sensitive and creative. One manager was adamant about the importance of sending out e-mails to the returning TLE. She stated the human contact was a priority here and managers needed to know and understand that priority, and to take time to do their part.

In Group A, one manager stated, "Managers tend to over-protect the returning TLE" rather than create opportunities for more open dialogue with them. He also suggested that a manager should alert other staff members in the group when a person was returning to the workplace and to treat that person as a member of a team. Both Groups A and B agreed that the returning TLE wanted normalcy above anything else when they came back to work.

Group A faced a special challenge near the end of the last session. One manager (male) stated he had a situation that was rather unique and asked the group to assist him. His trauma was ongoing. His son had been in a car accident and was presently in a semi-comatose state. He visits his son daily and his condition has not changed. This situation has gone on for three years. His organization (supervisors) were very helpful in the beginning, but now they do not ask any questions or show any concern for his situation, and it's "business as usual." He said he would welcome some concerned inquiry from his colleagues. He asked the researcher and group to consider his situation and think about what he could do. As it was the end of the session, the most that could be offered by the group was its sympathy and compassion. But this manager's problem points to another area of trauma research beyond the scope of this paper, the "chronic trauma," in contrast to the "single traumatic life experience" studied herein.

\section{Videography}

All of the Study Circle sessions (Group A and Group B) were video-taped by a professional videographer. There were three session for each of the Study Circles and the time for each Study ran one hour and a half. All sessions were held in the same conference room and at the same time, from 11:30 a.m. to 1:30 p.m. The researcher provided a boxed lunch for each participant. 
Each participant was aware that the sessions would be video-taped, having been told of this during the pre-Study Circle interview. The researcher informed the non-interviewed participants about this prior to the Study Circle. The video camera did not hamper the discussion nor the openness of the Study Circle. Participants moved around the room and asked questions in a normal fashion as though the video camera was not there.

The videos were used by the researcher as a "second set of eyes," allowing the researcher to review the group process of what was said and how it was said. It helped answer questions such as: Who was participating more? Were participants sharing their experiences, or were they only asking questions to those individuals who were taking the risk to share?

Also, the video tape revealed the body language of the participants and enabled the researcher to make comparisons of group interactions between Group A and Group B.

\section{Evaluations}

Evaluations forms were passed out to each participant after the third Study Circle session. For Group B the researcher added the following two questions:

1. What part of the Study Circle did you consider significant or helpful to you personally and/or professionally?

2. What is the most important quality a manager should have to assist a returning TLE employee?

These questions assisted the researcher in gaining specific insights from the managers and employees as to what each gained from each session. It also assisted the researcher to focus on what resources the workplace may need after the first group of Study Circles. Participant comments from the evaluations of Group A can be reviewed in Appendix J.

Overall evaluations by Group B were very positive. The participants stated they benefited from the Study Circle sessions and became more aware of the sensitive role that managers need to learn more about. It also gave employees as opportunity to dialogue with managers on how it felt to return to the workplace as a returning TLE. Group B's suggestions to managers focused on communication skills and practicing engagement when the TLE returns to the workplace.

When the evaluation forms were tabulated Group A responded that the third session was the most important (reconnecting back to the workplace-scoring 26 points) and the remaining two 
were similar in importance (establishing a safety net and retelling the trauma story-scoring 21 points. Group B scored all three sessions equally important-scoring 25 points) (see Appendix J).

\section{Conclusions}

After reflecting on both groups of Study Circles, the following conclusions can be drawn from the research.

Study Circles can and do work quite successfully in the workplace. Study Circle groups A and $\mathrm{B}$ were conducted during the lunch time hour because the time was significant in attracting senior managers to participate. Also, the researcher who herself works in HHS was able to ask participants to volunteer and had a general knowledge of the culture and workplace surroundings.

\section{Behavioral and Interaction Observations}

The researcher assembled two Study Circle groups in order to compare them. Group A consisted of managers and employees in the department with no specific skill base, only because of availability and referral. Their "chemistry" was excellent. They were the ideal Study Circle. This group got along exceptionally well and freely "shared" their experiences with each other. There was also light humor and no one seemed to up-stage another participant. On the other hand, Group B participants who were selected because of their expertise( of ADR experts, lawyers, labor-relations, workshop leaders and a human resource manager) did not have the "chemistry" with each other. Except for a few, they also did not share their trauma experiences with the group members. This was a puzzling outcome.

The researchers theory believes this occurred because Group A's orientation was toward finding a solution to a problem. They were more concerned with getting a result and giving guidance on how a job could be done better. On the other hand, Group B participants were swayed and perhaps awed by the experts in the session. They seemed most concerned about teaching communicating and listening skills, not with solutions. Over and over again, they pointed out how the managers needed to be trained and skilled in good communication and active listening skills; but as representatives of their work, they did not "walk their talk."

It is important for future Study Circle sessions, for the facilitator to be aware that the types of individuals recruited for the sessions will make a difference in the quality and tone of the Study Circle sessions. For example, if all engineers are recruited, because of their technical 
expertise their views on approaching a returning TLE may be different from individuals who are counselor or group process oriented. An observation that was made relative to group selection, when the researcher selected individuals at random, preferably volunteers as was done with Group A the participants seemed to treat one another more as equals.

Another finding occurred in recruiting individuals with a specific expertise. It had been noted that some of the managers in the Study Circle sessions were lawyers and skilled in group process. Their technical skills did not appear to help them in the Study Circle sessions; their skills seemed to inhibit them from "opening up" and "sharing" their own life and trauma experiences. It seemed that these same managers were "posturing and pontificating" during the Study Circle sessions, as one employee pointed out, much to the surprise of the researcher. Group A participants seemed more "humble and sympathetic," where group B participants merely talked about the need for "empathy" in the managers and the TLE returning to "normalcy". However, their advice in the group was directed outward and not inward toward themselves.

The managers in Group B all had "power" in their "career roles." They were able to sway and influence the group to agree on what managerial skills were needed in dealing with a returning TLE. What they appeared unable to do was "relate" to each other and build a rapport among the group members to allow participants to "share."

Another important observation was about self-disclosure. The closest and most meaningful relationships that humans have involves self-disclosure. Self-disclosure is not meant to make people more separate or alone, it tends to do the opposite. It frequently brings coworkers and friends closer. During the second session the researcher asked a returning TLE to tell her trauma story. This was a conscious decision by the researcher to try to create more "sharing". It worked, but only for the returning TLEs in Group B; the managers did not react. The researcher feels that if the managers did share their stories and life experiences in the second and last Study Circle session, this would have provided a richer learning experience for the participants.

The researcher would like to take this research one step further and determine whether these same managers in Group B who did not share their trauma stories would be able to create a "welcome environment" for a returning TLE, since they were unable to do that among themselves 
in the Study Circle sessions.

\section{Administrative Observations}

Distributing a list of discussion questions for each session in advance worked successfully in the workplace. Participants said the handouts got them thinking about the content prior to the sessions. This indicated that preparing questions for each session was an excellent guide and gave the group members ideas, topics and verbiage to engage in a dialogue about a sensitive subject. Group A and B participants repeatedly made reference to the fact that they had reviewed the questions and noted in the sessions that some of the topics would be essential for managers to focus on when greeting a returning TLE. For example, "good listening skills" were highlighted on the sheet, and managers and employees had extensive discussion on this topic.

The pre-Study Circle Interviews were universally seen as helpful by participants. Numerous benefits about the interview were mentioned by the participants both in the evaluations and from conversations. However, in group B none of the employees were interviewed beforehand, yet all of them were very involved in the Study Circle, freely sharing their trauma stories, and reported as having had a successful educational experience. Thus it seems that preStudy Circle interviews are not a critical factor in the learning process. Although the researcher concludes that pre-Study Circle interviews are not necessary to conduct a successful Study Circle, all those who were interviewed stated that the interviews assisted them in getting a broader framework for the topic. 


\section{CHAPTER 5}

\section{SUMMARY, LEARNING EXPERIENCES AND RECOMMENDATIONS}

\section{Introduction}

Chapter Five will summarize the researcher's original purpose and educational objectives in using the Study Circle as an adult learning format. It will also discuss the learner's educational experiences and "awakenings" while planning, producing, conducting and evaluating the research project. It will conclude with some suggestions for further research.

The researcher's original purpose was to see if the Study Circle, an interactive adult learning format, would be an effective learning tool in the workplace. If the Study Circle is successful it may be more efficient than traditional approaches in dealing with certain sensitive topics such as traumatic experience.

To this end, the researcher designed a Study Circle around the sensitive topic of facilitating re-entry to the workplace of people who had a traumatic life experience (TLE).

\section{Achieving The Educational Learning Experience}

The researcher's educational objective was approached by bringing together, for the first time, both managers and employees who were then asked to teach and learn from each other through the Study Circle process about the very sensitive topic of traumatic life experiences.

During the Study Circle sessions participants listened to each person's contribution and offered their own stories and experiences. Some of the participants were willing to risk sharing their personal stories of trauma, which created a very positive learning environment. Because of the personal cohesion and trust that was built up among participants during the three sessions, both managers and employees reported that, through the textual material provided by the researcher and the shared experiences and wisdom of the participants, they learned much, theoretically and practically. Managers and employees said they better understood the process of recovery from trauma and were confidently able to implement some of the strategies and suggestions discussed in the Study Circle sessions. Although in the workplace, there is normally a sense of "difference" between employees and their managers, the interactive dynamics of the Study Circle process proved to be a gentle "equalizer," enabling a free and respectful exchange a among all participants. 
To learn means to acquire knowledge of something or to acquire skill in something by study, instruction, or experience. Ideally, after learners become informed or acquainted with the subject matter, they may alter the way they respond to certain situations and stimuli.

When people normally talk about "learning something" the idea seems simple and easy. However, this study proved that learning--especially about a sensitive topic--is much more complex than the researcher had initially anticipated. This chapter will discuss the lessons learned in the research project, the educational and psychological process involved and conclude with the recommendations for future research.

\section{The Lessons of This Project}

The personal experiences of the researcher are relevant to an understanding of the operation of Study Circles and will be summarized here. The researcher was very confident within her organization since she had cultivated senior personnel and knew her way around HHS. However, she had never conducted a Study Circle. She shared the idea with senior management and felt confident that with the backing of her supervisor the process would evolve as she continued to work on it.

This project was a challenge to undertake, since nothing had been tried like this at HHS. It worked quite successfully as indicated by the evaluations of both Study Circle groups, but as the researcher had expected more sharing of experience, both personal and traumatic, with Group B.

These concerns, however, were insightful; they gave rise to an important insight about Study Circle groups and how they are different from other educational techniques, e.g., lecture or training session. Study Circle participants are invited to share their experiences, ask questions and enter into dialogue; each group's spirit may vary widely from that of any other.

The researcher was not prepared for the contrast between Groups A and B. The researcher has a keen ability to relate to others and to build rapport; this is a strength she uses in conducting training workshops, where she acts as trainer and leader. However, in conducting the Study Circle sessions, her role was to be facilitator, not trainer or leader. Just as she delighted when Group A built cohesion and trust, she was concerned when group B apparently failed to do so. 
The researcher is savvy about organizational climate and knows how, as trainer and leader, to create a good working climate. However, as a Study Circle facilitator, she did not have the mandate to "influence" anyone. She had to allow the participants to meet and be with each other. She could not control the nature of their trust or sharing. She was not there to control the outcome, as she would have been in a traditional training session.

Study Circle groups may have tremendous variation in their "group personality," but that the Study Circle process if handled properly can work successfully within such variation. Even though the researcher was disappointed in the quality of Group B's trust and interaction, she determined that for a Study Circle to be successful she did not have to be in control of the participants' relations and behavior. The evaluation forms filled out by the participants assured the researcher that both groups had achieved their educational objectives quite successfully.

\section{The Study Circle: An Educational Format}

In conducting this research project, much was learned about the Study Circle as an adult educational format and its use in workplace settings.

Traditionally, in the workplace the three most common educational formats are the lecture, the seminar and the workshop. The lecture is best for communicating and clarifying information, procedures, policies, regulations and the like. It is also used by executives to stir and motivate employees. The seminar format is most often used by the corporate leadership to explore and formulate new ideas, policies, procedures--to debate and discuss them before implementing them. The workshop is used primarily for training people in various skills; it is a very practical educational model.

What has been missing in the workplace is an educational process for dealing with topics that need to be learned attitudinally, that is, topics that are aimed at transforming not only knowledge and behavior but also attitudes and emotions. In a topic such as dealing with the reentry of a TLE employee, it is not enough to present the kinds of knowledge and information given in a lecture, nor is it enough to include a set of behavioral skills that one might learn in a workshop. The "missing" educational format needs also to provide ways to educate attitudes and emotions as well. The Study Circle was able to provide this missing dimension of the traditional learning process in the workplace. The personal sharing in the Study Circle by participants who 
had experienced a traumatic life event or had managed a returning TLE employee provided the context for the needed attitudinal and emotional learning to take place.

Another educational dynamic characteristic of the Study Circle process is its "democratic" spirit. When properly conducted, a Study Circle makes every participant equal and values everyone's contribution. This democratic spirit in the TLE Study Circle allowed managers and employees to share their experiences and discuss the topic as equals. A rather revolutionary event in corporate life!

Whereas the task of helping the successful re-entry of a TLE employee would normally fall to a counselor or therapist, the Study Circle format allowed participants, not to assume the work of the therapist, but to support and promote it in ways appropriate to managers and coworkers. This work of support and promotion could not have been produced in a traditional lecture or workshop, but only in a holistic learning format where personal experience and empathy along with the expression of attitude, emotions and values are provided. The Study Circle format puts these experiential and emotional factors at the center of its learning process.

The Study Circle as an educational format can also prove useful with a topic around which organizational policies and procedures which have not yet been formulated and institutionalized. Treatment of the returning TLE employee by managers and co-workers is one such focus. Because such treatment requires a major involvement with empathy, attitude and other emotional sensitivity, it is not an appropriate topic for legislation by executives in seminar, none of whom may have had the direct experience of returning to the workplace after a traumatic life experience. The Study Circle format invites participants to share their personal views around such topics, and it views this personal experience as important data in helping shape procedures and policies.

\section{The Study Circle: A Psychological Process}

Some may object to the researcher's claim that the Study Circle is an educational process, not primarily a psychological one. They may assert that the participants use the sessions as a psychological process, no matter what the researcher may claim.

In response, it might be clarifying to make a few distinctions. First, although the Study Circle topic might be a psychological process, e.g., the reentry process of the TLE employee, such a topic may still be treated educationally, for example, as having concepts and procedures to be 
identified, defined and understood, that is learned. Thus, participants learned the concept of the "safety net" and the procedures for "retelling the trauma story."

Secondly, since the Study Circle process involves the physical, mental, emotional and social dimensions of all participants, it is not surprising that the participants notice emotional and attitudinal changes happening in themselves, as well as conceptual and behavioral ones. Moreover, workplace participants are more likely to notice the psychological dynamics happening in a Study Circle, since in most other forms of workplace education such as lectures, seminars and training workshops, psychological dynamics play an insignificant part.

On the other hand, the Study Circle is not a group therapy session. Although the two processes have some elements in common--both call for trust, group cohesion and a willingness to share personal experiences--there are many elements that differentiate them. Each Study Circle has its own specific topic, e.g., the returning TLE employee, while the topic of group therapy is always the same--the psychological health of the group members. In a Study Circle, specific conceptual material is discussed, and the facilitator has a list of questions about the topic that help define the sequence of the process. Thus, each Study Circle on the returning TLE will follow the same sequence, and in the end each Study Circle group will have covered the same material. None of these elements is true of therapy groups.

Finally, it is not surprising that Study Circle participants are very aware of the interplay of emotions and attitudes that happen during the sessions. This is precisely because the topic of a Study Circle is one in which participants are personally and emotionally involved. It is because the participants are so involved that the Study Circle process is so effective as an educational format; it allows people who have strong feelings about a certain topic to meet together in a structured learning process that allows everyone to share their own personal experiences, not merely "thoughts," about the topic. The Study Circle format ensures that this is done in ways that end up, not in debate and competition, but in learning from each other. 


\section{Recommendations for Future Research}

Since this is a first level effort at implementing the Study Circle as an educational format in the workplace setting, there appear to be a numerous avenues of future research with the Study Circle format, using a variety of topics, participant groups, and even cultures.

Study Circles need to be applied to other workplace issues which have different levels of emotional significance to managers and employees. This will broaden the understanding of any underlying constructs of Study Circles operation.

Regarding participant groups, the researcher barely scratched the surface. Her primary intent was to create Study Circle groups that contained both managers and employees. Regarding this educational format, many questions about how the mix of participants influences a successful outcome still remain unanswered. For example, what participant mix best facilitates "openness" in a Study Circle group? What conditions will ensure that participants share their trauma stories? Does the number of managers and employees need to be about equal, or will the Study Circle outcome be uninfluenced by the proportion of managers to employees? In Group B, three participants who were professional workshop leaders seemed to bias the group's participation, but is this always the case?

Regarding cultural, gender and ethnic differences, will participants from different cultures challenge the core assumptions of this adult learning model? Will the spirit of participation differ, for example, if participants were required by management to attend? The participants in my two groups were all volunteers. All of them were senior managers and employees with excellent track records relative to career and credibility. Would the Study Circle have achieved its objectives if the participants were, for example, all senior managers, all employees, all women or all Afro-American? Would the Study Circle be as effective if few or none of the participants had experienced a traumatic life experience? 
CHAPTER 6

MANUAL FOR FACILITATORS 


\section{MANUAL FOR FACILITATORS}

\section{STUDY CIRCLES IN THE WORKPLACE}

helping employees readjust after a traumatic life experience

In cooperation with:

Department of Health and Human Services (HHS)

Office of the Assistant Secretary for Management and Budget

Office of Equal Employment Opportunity

200 Independence Avenue, S. W.

Washington, D. C. 20201 
This material is strictly produced for educational purposes.

This material is produced as part of the research project and dissertation of Barbara Barski-Carrow in conjunction with the Department of Health and Human Services (HHS).

All the material is original with guidance from The Study Circle Resource Center, Pomfret, Connecticut and "A Guide for Training Study Circle Leaders." 


\section{Study Circles in the Workplace}

\section{CONTENTS}

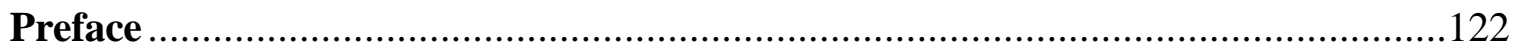

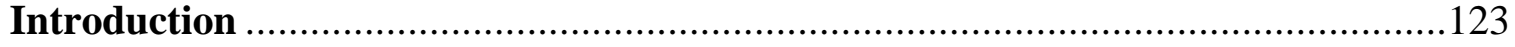

Part I Guidelines and Notes for Designing a Study Circle.......................................124

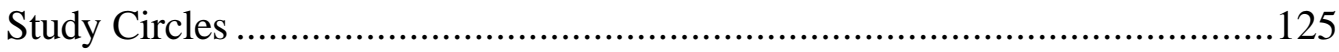

Role of the Facilitator ……......................................................................126

Pre-Study Circle Interview Suggested Questions...........................................128

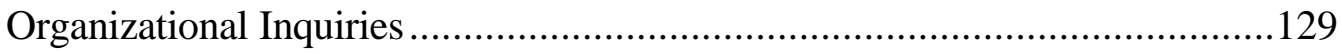

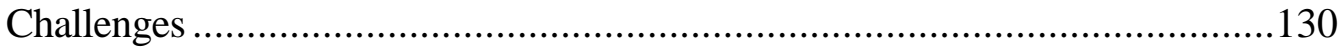

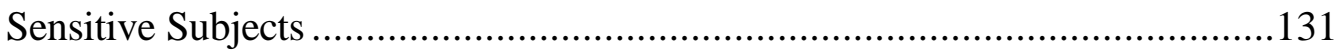

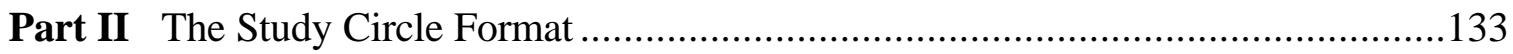

Pre-Study Circle Exercises for Facilitators ……………..............................134

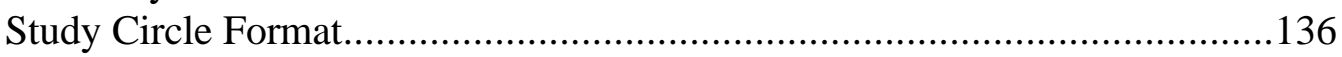

Session 1. Creating a Safety Net................................................................136

Session 2. Telling the Trauma Story .........................................................139

Session 3. Reconnecting Back to the Workplace...........................................142

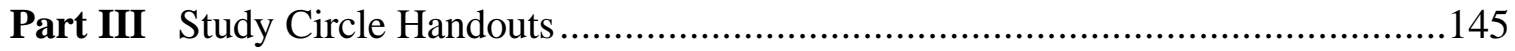

The Role of the Participant..........................................................................146

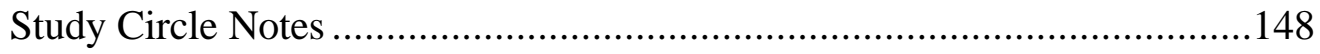

Suggested Evaluation Form .....................................................................151 


\section{PREFACE}

The purpose of this manual, Study Circles in the Workplace, is three fold: to help people create and design other Study Circles for the workplace; to provide helpful suggestions for facilitators who may want to conduct Study Circles; to review the process by which the author designed and conducted a particular Study Circle. The author's Study Circle was created to assist managers and employees in understanding the process of recovery from a trauma and how to effectively deal with employees who are returning to the workplace after having experienced a traumatic life experience (TLE).

A traumatic life experience (TLE) refers to a single overwhelming traumatic incident, such as a suicide, sudden death of a loved one, rape, witnessing a murder, bombing, break-in, hold-up, robbery, serious accident, bypass surgery or other major surgery, divorce, job demotion, major financial loss, etc. A TLE is in contrast to a chronic traumatic situation such as a terminal illness, an abusive relationship, or debilitating disease.

The issue of trauma concerns everyone. At some point we have all had to experience some type of trauma in our lives and have had to then return to our work environment. Upon returning, we may have been greeted with indifference, ambivalence or fear. Our supervisor may not have known what to do or say. This manual outlines the steps that a facilitator can use to help both managers and employees understand this process and gain a better perspective on how to assist the returning TLE.

The material presented here originated as part of the author's doctoral research project. It was started after years of observing managers in the workplace unable to successfully cope with individuals who returned after a traumatic event.

Initially, this process was used to introduce a pilot program, after which the author conducted two groups of Study Circles in the Department of Health and Human Services (HHS). Senior managers and employees participated. Each session lasted one hour and half and was held during the lunch hour. The material in the manual can be used at a work site or at another site in the community. 


\section{INTRODUCTION}

The educational content for the Study Circle on the returning TLE employee was based on the approach of Judith Lewis Herman (1992) found in her book entitled Trauma and Recovery. Dr. Herman states that the healing process of traumatized individuals is achieved in three stages, which form the three topics for the Study Circle sessions.

Session 1. Establish a safety net for individuals who have suffered a TLE.

Session 2. Allow the TLE to reconstruct the trauma story.

Session 3. Restore the connection between the survivor and the workplace community. The objectives of the educational intervention are as follows. When participants complete the sessions of this Study Circle, they will be able to:

o Recognize a TLE and its effects (for managers and employees)

o Identify the states of the healing process for a returning TLE.

(for managers and employees)

o Communicate helpfully with a returning TLE.

(for managers and employees)

o Coach co-workers in creating an appropriate atmosphere to foster the healing process. (for managers)

o Appropriately manage a returning TLE. (for managers)

In achieving these objectives, participants engage in dialogue about the steps that should be taken to help in welcoming back a returning TLE.

The manual consists of three sections. Part I consists of guidelines and notes for designing a Study Circle; Part II, presents the steps the facilitator can follow in each Study Circle sessions; and Part III identifies samples of handouts, evaluation forms and other important textual material. 
PART I

GUIDELINES AND NOTES FOR DESIGNING A STUDY CIRCLE 


\section{STUDY CIRCLES}

This manual introduces Study Circles to the workplace. The Study Circle is an adult educational process. It is a collaborative learning environment, driven primarily by the participants' needs and interests. In a Study Circle, when individuals meet and share their experiences, learning occurs collectively as each person hears and relates their personal experiences to that of other group members.

Employees returning to the workplace after a traumatic life experience has become an increasing concern both to managers and co-workers, requiring that they possess a theoretical and practical grasp of the problem. Theoretically, this Study Circle will introduce participants to the concepts of trauma and the stages of recovery. Practically, it teaches managers how to cooperate and talk and act with the TLE employee in such a way that their healing process is helped, not hindered. It is a learning environment that brings people together.

Participants: The Study Circle participants consist of the facilitator, and learners. In the author's Study Circle, the participants included supervisors and employees (returning TLEs). It is suggested that the organization requesting the Study Circle, canvass for volunteers to participate in the Study Circle sessions. A Study Circle's success depends on participants who are very interested and invested in the topic and want to participate. Confirm their participation with a telephone call or an e-mail message. A good mix of volunteers for a Study Circle on returning TLE employees should include people from the 4 following groups:

1. Managers who have supervised a returning TLE.

2. Managers who have not supervised a returning TLE.

3. Managers who have/and have not had a personal trauma.

4. Employees who have experienced a trauma.

Suggested Study Circle Sessions: Each session requires $1 \frac{1}{2}$ hours, plus some socializing time beforehand. So in a workplace setting, a brown bag lunch is appropriate. Suggested time is 11:30 a.m. to 1:30 p.m. Schedule Study Circles sessions one week apart to give participants an opportunity to digest and, if possible, practice what they learned. The author's Study Circle required three sessions. Some may require more sessions, though it may be difficult to obtain commitment to more than three sessions.

The sessions should be held in the workplace building, perhaps in a large conference room with ample space for individuals to move around in comfort. The maximum size suggested for the group is fifteen individuals--the minimum size is eight (8) or ten (10). Ask participants asked to sit in a circle so that each person can see the face of all others. Prepared notes on the participant's role are handed out to the group members prior to the Study Circle (see Part III Study Circle Handouts). 


\section{OVERVIEW OF A STUDY CIRCLE}

1. Invite introductions. Begin the Study Circle by having all the participants sit around a table or in a circle and introduce themselves. It's important to ask each participant to tell the specific division or branch that they are working in; this helps identify the organizational setting better.

2. Explain ground rules. Discuss the facilitator's role and the importance of keeping the Study Circle discussion focused. Explain to the group not to be afraid of conflict issues that may come to the surface and encourage participants to engage in a dialogue.

3. Discuss topic. Express to the group the importance of sharing their commitment to the topic that is being discussed. If the participants have strong feelings about the topic, this is generally good because it increases the participation. It helps to have a list of questions for discussion that keeps the discussion moving and focused.

4. Summarize points. Encourage participants to engage other colleagues to share their points of view and probe for more answers when an explanation may not seem clear. Watch for patterns that may occur in the group and summarize those for the participants.

5. Evaluate the session. Talk about group process with the participants. Find out what they liked and did not like. What could be improved? Remind the individuals about the reading assignments and the discussion questions for the next Study Circle session

\section{ROLE OF THE FACILITATOR}

Significant Point: It is important to note that if the facilitator is assisting the organization in recruiting the volunteers for the Study Circle sessions, a mix of personalities is preferred. For example, if the organization includes all accountants the session may not result in a dialogue with diverse opinions because of composition of the group. It is important to note that when the author completed her research project, the composition of the groups were different and the diversity did not make that much of a difference in the overall reaction to the topics and dialogue in the Study Circle.

The facilitator must also be aware of participants may not want to dialogue or share their thoughts with the group, this can frustrate the facilitator, since the object of the Study Circles is to create a dialogue with group members. The situation may call for the facilitator suggesting to a participant to share with the group their life (trauma) experiences.

The facilitator does not have to have expert knowledge on the topic of the Study Circle, however he/she must be familiar with the topic to guide the participants through each session. If the organization chose to have the facilitator conduct pre-Study Circle interviews, the facilitator 
will have first hand knowledge of individuals trauma. If interviews are not conducted, the Study Circle can move along as planned.

\section{Significant Points to remember:}

1. Understanding the group process. Remember that your group will be composed of many different personalities who may share different values. Usually each group forms its own group culture and develops its own timing and style for sharing their thoughts, feelings and experiences with each other. It's important to keep the group focused on the content of the subject matter. As a facilitator "silence" at times may be good for the group, to assist them in processing different thoughts and ideas.

2. Setting a participative tone. Welcome all the participants and encourage group members to participate. If this Study Circle is one where a sensitive subject will be addressed, the facilitator should remember to allow participants to be themselves, and assure them that their experiences will add to the group dialogue.

3. Working with Content. Its important for the facilitator to focus on the topic and foster a lively exchange between members of the group. Asking probing questions and referring to specific discussion questions may help getting other members to participate.

4. Discussion questions. The discussion questions handed out before each session can assist the facilitator immensely. They serve as a reference both for the participants and the facilitator.

5. Closing the discussion. When the topic has been discussed sufficiently, the facilitator takes the initiative to ask the group anything has been missed in the group discussion. The following points are highlighted:

1. What thoughts are you leaving this Study Circle with today?

2. When you return to the workplace, will you feel more comfortable in dealing with a returning TLE?

3. Will you be able to share some of your concerns with others?

4. What did you learn today that you can use practically? 


\section{PRE-STUDY CIRCLE INTERVIEWS}

It is suggested, but not required, that the facilitator of the Study Circle interview all named participants prior to the Study Circle sessions. Usually interviewing is done in an organization where recently there has been intense trauma such as the Oklahoma Bombing or the Post Office shootings, since it has been documented that managers and employees have a difficult time returning to the work place. Pre-session interviews can help participants, become comfortable with the facilitator and the ambiance of the proposed Study Circle.

The interview assists the facilitator in knowing the kinds of trauma people have experienced and their comfort level in talking about their trauma. If the organization chooses not to do the pre-Study Circle interviews, the Study Circle will still be effective.

\section{PRE-STUDY CIRCLE SUGGESTED INTERVIEW QUESTIONS}

Significant Point: These questions can be used by the facilitator prior to the Study Circle sessions to interview returning TLE managers and employees. A determination can be made by the organization and the facilitator if pre-Study Circle interviews should be completed.

The following questions are suggested to explore a participant's experience and understanding of traumatic life experiences and their effects in the workplace:

1. Did you have a personal experience with trauma? If so, how did you handle it?

2. Did you ever supervise a person who returned to the workplace after having experienced a trauma, how did you handle it? (managers only)

3. Did you ever have a co-worker who experienced a trauma and returned back to the workplace? What were your feelings toward that person upon their return?

4. If an employee was returning back to the workplace after having experienced a trauma, how did you behave toward that person?

5. Do you think it would be helpful to ask the returning TLE to tell their trauma story?

6. Have you ever observed an employee telling their trauma story to anyone upon their return to the workplace?

7. How comfortable do you feel approaching or talking to a person who has just returned to work after having experienced a trauma? 
8. Do you know what to say to a returning TLE employee?

9. What approach would you use if you had to communicate your expectations to the person who is returning to the workplace after having experienced a trauma? (managers only)

10. How would you go about explaining to your staff the importance of greeting and talking with the person who is returning to the workplace after their trauma? (managers only)

11. How would you go about helping the returning TLE participate in office activities?

12. What would you do if you had to set limits with a returning TLE when he/she returns to work (i.e, lateness/tardiness)? (managers only)

13. How would you respond to a TLE who refuses to work and begins to have emotional outbursts?

14. How would you state work assignments and expectations of productivity to the returning TLE? (managers only)

15. Do you think gender plays a role in dealing with a returning TLE? Do women women behave differently from men when they return to the workplace?

\section{DEALING WITH ORGANIZATIONAL INQUIRIES, CHALLENGES AND SENSITIVE TOPICS:}

Its very important to note that during the Study Circle session you, as the facilitator, may be challenged by questions from participants as to the importance of the topic and the need to engage in a dialogue about a sensitive topic such as trauma. Here are a few common statements and reactions that you may hear from participants of your Study Circle.

\section{Why do I need to be here?"}

It's important to point out to the participants that the subject of a TLE returning to the workplace involves all sectors of the organization--this includes both employees and managers. This must be stressed. Everyone in the workplace either has had a trauma in their life, or are close to someone who has been through a transition that involves a trauma. This Study Circle will assist the participants in becoming more sensitive to the subject of a returning TLE.

\section{"How will I learn?"}

Participants will all learn from each other. The exchange of ideas and the dialogues that are shared create an environment of curiosity and learning. 


\section{"How will this Study Circle help me do my job?"}

This Study Circle will make you more aware of employees when they return to the workplace after having experienced a trauma in their life. You will hear comments from both managers and employees. This shared experience with others and your own personal experience will enable you to understand the TLE better.

\section{“As a Manager how will this Study Circle make me more effective?"}

Hopefully, you will become more aware of your role through the eyes of the employees who will give feedback on the discussion and topics that emerge, and you will be able to communicate better with the returning TLE, and you will be able to identify the stages of trauma recovery.

\section{"As an Employee, what information will I take back to the office that will make my relationships with my colleagues better?"}

Information about relating to an individual who has just returned to the workplace after having experienced a trauma: How to approach that person and what to say to welcome the employee back to work appropriately.

\section{"How will the organization benefit from people participating in this Study Circle?" \\ A change in attitude and behavior toward the returning TLE employee will begin happening throughout the organization.}

\section{Challenges:}

Most Study Circles run smoothly because participants who volunteer for this type of Study Circle and want to learn more about the topic. However, there may be come instances where an individual's behavior or verbal comments may cause some slight disruptions during the sessions. Some of these behaviors can be expected, as group interactions become intense with different personalities and diverse opinions surfacing on sensitive topics. The following situations may occur during the Study Circle sessions and may need to be addressed by the facilitator.

Situation: The employee in the Study Circle does not want to talk or share personal experiences. Response: The facilitator should not make the employee feel uncomfortable in the Study Circle. If a participant does not want to share, the facilitator should move on with the subject or ask another participant to share their experience. A non-judgmental approach is the best in this situation, since the participant may have a good reason why they do not feel comfortable discussing certain points. 
Situation: If a participant consistently dominates, interrupts or monopolizes the session with their experiences and stories.

Response: Sometimes in groups we do encounter individuals who have a great need to talk, thus preventing other people from getting their share of group time. As time goes on, the group will become less tolerant of such an individual. A person who exhibits this type of behavior needs to be gently challenged to look at the effects of their behavior. You, as the facilitator, can confront the person and say, "Let's focus on another person's experience for awhile."

Situation: If a participant begins to cry in (as can be expected in the second session if the participant reconstructs their trauma story).

Response: The facilitator should allow the participant to cry and try to comfort the participant by assuring them that it is okay to cry/weep. It is also appropriate if one of the participants reaches out to comfort the upset person. Continue with the Study Circle.

Situation: If a participant in the Study Circle starts giving advice to other participants e.g., a manager or a returning TLE, creating a disruption for the group.

Response: Participants should be advised in the beginning of the Study Circle that this is a learning experience for everyone and it's important to maintain a learning environment. If a person does not heed this advice, then the facilitator should have a private conversation with the participant after the session.

Facilitator Note: If a participant asks the facilitator a question that the facilitator cannot answer, the facilitator should acknowledge that person and promise to find the answer and get back with them. Also, many times in a well planned session something may go wrong and there may be some time constraints that may inhibit the facilitator from moving forward in the discussion. Make adjustments by watching the clock, paying attention to the group process and the content that may need to be covered.

\section{Sensitive subjects:}

If an organization makes the Study Circle a requirement for managers and employees, some employees may not want to participate because they may think it is an inconvenience, imposition, invasion of their privacy and robbing them of their work or lunch time. If this happens, there may be some questions about and resistance to participating.

Here are some forms of resistance:

-I really don't want to be here, I feel this is just a waste of my time.

-We have been dealing with this problem before, how are you going to make it easier for me by requiring me to attend a Study Circle?

-Do I have to change my whole personality for this returning TLE? I rather not deal with him. 
-Does this mean that I won't have to go to the Employee Assistance Program (EAP) when I have a problem?

\section{Suggested ways to respond:}

If the participant is adamant about not wanting to attend, perhaps you can speak to his supervisor and have him excused. The best participants are those who attend willingly. A few angry and vocal participants can ruin a Study Circle.

If the participant is merely hedging, he or she may simply need some encouragement, such as, "Every participant has said how helpful and useful the sessions were, you'd probably enjoy being part of the group."

Suggest to the participant to talk to a colleague who has participated in Study Circle to get some feedback as to the nature of the dialogue and interaction. 


\section{PART II}

STUDY CIRCLE FORMAT 


\section{PRE-STUDY CIRCLE EXERCISES FOR PARTICIPANTS}

The following suggestions are offered to a facilitator who is introducing this Study Circle in the workplace for managers and employees. The goal is to stress the importance of participation and developing a trusting connection with their colleagues, since they will be spending three successive sessions together.

\section{Opening Exercise:}

-Define a traumatic life experience (TLE) and gives some examples. Ask if every understand the concept.

Definition: A traumatic life experience (TLE) refers to a single overwhelming traumatic incident, such as a suicide, sudden death of a loved one, rape, witnessing a murder, bombing, break-in, hold-up, robbery, serious accident, bypass or other major surgery, divorce, job demotion, major financial loss, etc.

This exercise is considered a warm-up. It will help the participants to engage in a dialogue on the traumatic experience topic and make them feel more comfortable. This exercise will also help each participant to become aware of each person's trauma and their feelings. It will also begin to create a bond of trust between managers and employees prior to the Study Circle.

If participants are not in a circle ask them to form a circle, or sit around a table in a circle and raise their hands to the following questions.

-Are there managers in the group who have supervised a returning TLE? -Are there managers in the group who have not supervised a returning TLE? -Are there managers in the group who have/have not had a personal trauma? -Are there employees in the group are who are returning to the workplace after having experienced a trauma?

-Are there managers who are returning TLEs in the group?

II. Listening Exercise:

Write the following questions on a flip chart:

-Do you know anyone who has come back to work after traumatic life experience?

-What was it like for them? For you? For others?

-Do you feel the employees re-entry was handled well?

-Do people seem to know what to do? 
Ask each participant to pair off with a partner. Using the questions from the previous exercise, two individuals should discuss any or all of them. An ideal partnership would be a manager and an employee where each could learn from the other in discussing their question. If either of the two were returning TLEs, they could talk about the experience of returning to the workplace and what it felt like and how the organization reacted to them when they returned.

Significant Point: This exercises can create a comfort zone for both managers and employees. It will offer them the opportunity to talk with one other person prior to the Study Circle and identify their feelings about their traumatic experience and traumas that happen to others.

III. Theme Exercise:

List on a flip chart the three themes of the Study Circle sessions:

1. Establish a safety net for individuals who suffered a TLE.

2. Allow the TLE to reconstruct and retell their trauma story.

3. Restore the connection between the survivor and their workplace community.

The facilitator could explain what each one of these themes mean and ask the group to discuss their importance and relevance to a TLE returning to the workplace.

Significant Point: This exercise can be very helpful to all the participants because each session will have one of these themes as a specific focus. 


\section{STUDY CIRCLE FORMAT}

\section{FIRST SESSION: CREATING A SAFETY NET}

The following pages offer suggestions for a 2 hour Study Circle Session. This Study Circle is specifically designed for a readjustment after a traumatic life experience. This design can be adapted to more sessions, depending on the organizational needs. It can also have an introductory Study Circle Session where the facilitator could spend the complete 2 hours introducing the topic and engaging participants in different exercises relative to group process. An outline of an Introductory Study Circle is included in this manual the previous page.

I. Welcome Participants to the Study Circle (First Session)

(10 minutes)

A. Welcome the individuals who will participant in the Study Circle Sessions and thanked them for volunteering.

B. Refer to discussion questions that participants received prior to the Study Circle.

C. Ask participants to go around the table and state their names and where they work.

D. If this is a boxed lunch session use this time as a social warm-up for people to get to know each other and share their work experiences. (20 minutes)

II. Introduction to the Topic: The Safety Net (10 minutes)

Begin the background discussion:

A. Facilitator refers to Part III: The Role of the Participant.

-Review with participants their role as a Study Circle participant.

-Stress that participants are the most important ingredient of the

Study Circle.

-The goal of the Study Circle is to deepen understanding of the topic.

-Encourage all participants to:

o Make an effort to attend all sessions.

o Communicate needs to the leader/facilitator.

o Help keep the discussion on track.

o Listen carefully to others.

o Speak freely and not monopolize the discussion.

o Engage in friendly disagreement.

o Maintain an open mind.

-Discuss any comments about the above points that participants may want to discuss. 


\section{Summarize for the participants the research of Dr. Judith Lewis Herman author of Trauma and Recovery (1992) by reading the following:}

According to Dr. Herman's approach, the first stage in fostering the recovery process of the TLE employee would be that the manager and co-workers establish a safety net in the workplace for the individual returning to work after a traumatic life experience.

Usually when TLEs return to the workplace, they are anxious and ambivalent about how they will be seen and treated by their co-workers. Consequently, they may not want to socialize with fellow employees and feel they don't belong to the organization. Outside work, they are usually seeing a social worker or therapist for depression, and are taking some medication.

TLEs are not sure how to behave in situations where they previously had been confident. Because they have difficulty sleeping and concentrating, these effects are seen in the workplace as an inability to complete tasks they could easily do before the trauma. They feel unsafe everywhere and they tend to have little control over their emotions and reactions. After a trauma, some may want to go into seclusion. Their old reality seems broken and nothing feels solid anymore.

Usually, there is little or no support from organization when TLE employees return to the workplace. Managers and co-workers are confused and uncomfortable relating to the returning TLE.

III. Discussion Period:

-Facilitator refers to the discussion notes and questions that were handed out to each participant prior to the session (See Appendix C) and begin the discussion by the reading first stage of the recovery process which is creating a safety net for the returning TLE employee. This will naturally lead into the following group of questions..

-What would it mean to you to establish a safety net in your workplace environment for the returning TLE employee?

-What would constitute a safety net?

-How would you act to establish a safety net?

-How would you encourage co-workers to act?

-What would you tell them to do? Not to do?

Significant Point: Ask people to volunteer to answer from their experience. If people are shy, the facilitator can take the lead and answer a question to start the discussion.

-Continue the discussion with these questions:

-What would it look like in your workplace if it was emotionally

"unsafe" for returning TLE employees?

-How might co-workers speak and act to make

it "unsafe" for a returning TLE survivor? 
Significant Point: Ask individuals to speak from their own experiences or of a friend's experience. Telling a personal experience helps the group identify with a participant's own vulnerability.

-Continue the discussion with these questions:

-In your workplace, what are the current reactions of co-workers to returning TLE employees?

-What are your typical reactions to such returning employees?

-Are you or the co-workers especially nervous or uncomfortable in adjusting to the returning TLE employee?

Significant Point: Ask participants to think of a co-worker who recently had a trauma and ask them to recall what it was like when the returned to the workplace after their trauma.

-Continue with these questions:

-What kinds of questions might you ask the returning employee to find out what would make them feel safe?

-Do you think the following questions to the TLE employee would help?

-Why or why not? If not, how might you change or restate the question?

-Are you especially nervous or uncomfortable in readjusting to the workplace?

-What can your co-workers do to assist you?

-Is the work schedule we have arranged for you flexible enough?

-Do you have any special requests of me or the organization?

-Are you aware of the resources in the organization that can assist your return to the workplace?

Significant Point: You may not be able to address all of the above questions, but it is important to touch on most of them. Your goal in the first Study Circle session is for both managers and employees to leave the sessions knowing more about the concept of a "safety net."

Bring Session to a close (10 minutes):

-Ask the group if there are any additional comments or questions.

-Thank the group for their participation.

-Refer to the next Study Circle--the time and date and the discussion questions that will be distributed. 


\section{SECOND SESSION: THE TRAUMA STORY}

I. Welcome participants to the Study Circle (Second Session)

A. Welcome participants to the session.

B. Ask the participants if there are any questions or thoughts regarding the first session.

C. If participants make observations or comments, ask for volunteers to reply or give an interpretation.

D. If this is a boxed lunch session, allow participants to complete their lunch and enjoy a social warm-up.

II. Introduction of major topic: Telling the Trauma Story

Begin the second session by reading the following: (90 minutes)

According to Dr. Herman's approach, the second stage in fostering the recovery process of the TLE employee would for the manager and co-workers to allow the survivor to reconstruct and retell their trauma story.

TLEs find it difficult to reconstruct the trauma after it has occurred. Even though, psychologically, it would be helpful for them to talk about their trauma, they are reluctant to do so and do find themselves avoiding people who would encourage them to talk. Some may be tempted to turn to drinking or brooding, blaming themselves for the traumatic incident. Depending on the trauma, survivors may feel degraded, shameful, humiliated, helpless, isolated, pain, fear, rage, etc. They may be feeling much emotional turbulence.

\section{Facilitator Note:}

The facilitator has a choice here to begin the session telling her/his trauma story or asking someone in the group if they would like to share their story. This is very effective. By hearing the facilitator tell her/his story and how she/he coped with the experience paves the way for other participants to share their stories.

-Solicit participants to tell their trauma story:

Remind participants that this stage is a crucial stage for the returning TLE. Telling their story is difficult. The facilitator can ease into the session by asking these questions. What were the circumstances of your trauma? What did it feel like to return to the workplace without a support system and how vulnerable a person feels? This step is helpful because it allows participants to identify with a person whom they know and a trusting relationship can begin to form. 
Significant Point: If no one volunteers to tell their trauma story, the facilitator can refer to a question from the previous session: "Focus on your organization and begin identifying with a person who may be returning to the workplace, or think of a particular person who had a difficult time returning after their trauma--did they share their story with their colleagues?"

-Continue the discussion with these questions:

-What would it mean to you to "allow" the returning TLE employee to tell his or her trauma story?

-What would you do if the TLE employee said he or she wanted to be left alone?

-Are there ways you could, verbally or nonverbally, "not allow" the employees to tell the trauma story?

-How could you hinder or stop this process?

-Do you sometimes feel you would rather not hear the trauma story?

Significant Point: Some participants may tell of employees who cannot stop talking about their trauma and how they disrupt the workplace. Continue with this discussion because it may evolve into personnel and behavioral issues that both managers and employees need to talk about.

-Continue the discussion with these questions:

-Are there ways you could allow the employee to tell the trauma story that would not be helpful in the employee's healing?

-What if, you didn't empathize with the employee but just wanted to hear the gory details?

-What if in telling the story, you denied the employee's expressed feelings, or told him what he should have done, or disapproved of his behavior during the trauma?

Significant Point: There are some individuals who may never share their feelings with you or the group, that does not mean they are not assimilating the knowledge and learning in the Study Circle. Since participants are becoming aware of new behaviors and words be patient with them as they learn and watch the process.

-Continue the discussion with this question.

-Do you know how to exhibit "active listening skills" with a TLE employee?

Significant Point: How to help people who are unable to share personal information. Verbal and non-verbal behavior plays a very important role here. Some people pretend to care and some people know how to show empathy. The facilitator can open the discussion about "how much compassion" should be shown the returning TLE. What happens if culturally a person 
is not comfortable sharing their grief or any personal information about themselves, how does a colleague reach out to him/her?

The facilitator can directly ask someone to share their trauma story with the group. If the person says no, just move on. Usually someone will feel comfortable in the group to share a workplace incident with group members. Sometimes group members do not share their stories until the last session. Be patient as a facilitator. If a returning TLE had a recent trauma, it may be difficult for a person to share their thoughts. Time is part of the recovery process.

III. Bring Session to a close (10 minutes):

-Ask the group if there are any additional comments or questions.

-Thank the group for their participation.

-Refer to the next session--the time and date and the discussion questions that will be distributed. 


\section{THIRD SESSION: RECONNECTION TO THE WORKPLACE}

I. Welcome Participants to the session. (10 minutes)

A. Welcome participants to the third Study Circle session.

B. Ask the participants if there are any questions or thoughts left over from the prior session.

C. Since this is the third week, ask participants if they have had a chance to observe any returning TLEs in their office and what was their reaction, or if they have been able to use any of the material in the Study Circle.

D. Continue to encourage participants to use this brief time as a social warm-up.

II. Introduction of major topic: Reconnection to the Workplace (90 minutes)

Begin the third session by reading the following:

"According to Dr. Herman's approach, the third stage in the fostering the recovery process of the TLE employee would invite the manager and co-workers to restore their connection with the survivor."

Survivors feel disorganized, disoriented and disconnected. Their sense of trust is severely weakened, their sense of control over things is shaken, their connection to others is infected with mistrust. For some, their life meaning falls apart and they question their fundamental beliefs.

Usually co-workers are unable to understand the unusual behavior of a TLE and show very little support toward him/her. Co-workers do not know how to treat the TLE. They expect the TLE should have gone for counseling and have gotten "straightened out" before returning to the job. Just as TLEs themselves have difficulty reconnecting with the organization, co-workers are not sure what to do, how to relate to them or suggest where they can go for assistance.

Facilitator Note: The facilitator may want to open the session reminding the participants that this is a crucial stage for the TLE and each TLE may take a different approach to their coworkers and their supervisors. The facilitator can open the session with the following question:

Discussion Questions:

-What are some kinds of "connections" that exist between managers and workers and between workers and co-workers?

-Can you list some of these "connections" that exist in the workplace?

Significant Point: This will begin the group talking on many different points. For example, some people who are introverts may not want to share and those who are extroverts may draw a 
distinction between the two different types of behavior. The facilitator should prepare an example from her/his organization so this can be illustrated.

-Continue the discussion with these questions:

-How do people in the workplace re-establish such "connections" after they have been broken?

-How do people re-establish trust and confidence?

Facilitator Note to Managers: Trust can be a difficult subject to talk about for the returning TLE. A returning TLE may feel vulnerable and scared, so the manager has a responsibility to take the lead in approaching the TLE. If there is a good relationship with the manager prior to the TLE leaving the workplace, this is good. The reconnection coming back will be made easier. If there was not, the manager will have to work harder.

-Continue the discussion with these questions:

-What kinds of questions might you ask the returning employee to help reestablish connections?

-Do you think the following suggestions to a manager would be appropriate and helpful? If not, how might you change or restate the suggestion?

-Demonstrate to the TLE employee that their status has not changed because of the trauma.

-Don't overload the TLE employee with work. Give no more than normal work assignments.

-Prepare a flexible work schedule for the returning TLE employee, and discuss their schedule and other needs with them.

-Watch for signs of stress from the TLE employee.

Significant Point: Timing is important when approaching a returning TLE. The TLE will probably feel overwhelmed when he/she returns. Reassurance and acknowledgment from the supervisor is suggested. This contact will make the TLE feel comfortable and the dialogue with the TLE will follow.

Continue the discussion:

Here are some questions that have been suggested for managers to ask co-workers in reestablishing connections. Do you think they are helpful? Do you have any other suggestions for managers to ask co-workers from your own personal experience?

-Is the employee participating in conversations with other co-workers? -Is the employee socializing with others, e.g., going to lunch with them? 
-Is the employee argumentative with others?

-Is the employee having difficulty communicating with others-managers or co-workers?

Significant Point: The facilitator can be very effective here if she/he give some examples of behaviors that suggest that an employee is not "connected", e.g., staring out the window during the day, crying and unable to talk to their supervisor, wanting to be left alone. Also, it would be important to ask the participants for some examples in their own lives or of their friends who were returning TLEs.

III. Bring session to a close: (10 minutes)

-Ask the group if they have any additional comments or questions.

-Thank the group for their participation.

-Urge the group to return to the Manager/Employee Manual for reference of the materials if dealing with a returning TLE.

-Suggest if they have a problem to contact the Employee Assistance Program.

-Complete the evaluation form. 
PART III

STUDY CIRCLES HANDOUTS 


\section{The Role of the Participant}

The participants in a Study Circle are the most important element of a Study Circle. Their commitment, eagerness and interest help make the Study Circle a success.

An important point to know about the Study Circle is that textual material does not have to be memorized and participants do not have to learn a lot of facts, but rather encourage them to focus on the interaction with each other and thereby gain a deep understanding of the topic through listening to their experience. The process -- an open democratic dialogue with colleagues -- is an important part of this experience.

The following points adapted from The Study Circle Handbook (1993) will assist those participating in a Study Circle:

1. Make a commitment to attend all Study Circle sessions. Each Study Circle creates its own culture and getting to know the people with whom who you will spend this time is part of the ongoing learning experience of a Study Circle.

2. Communicate your thoughts and feelings to others. Share your perceptions and suggestions with the group and ask for clarification of others' experiences when issues are not clear. Even though you may feel alone in your experience, you may be helping the group by sharing it.

3. Keep the discussion focused. Try not to bring in other ideas or topics that have no relevance to what is being discussed in your Study Circle. But don't hesitate to bring in relevant points for discussion.

4. Speak to the group. When addressing your remarks, address the whole group, not just the leader/facilitator. Feel free to engage directly in dialogue with other participants; everyone learns from attending to the interactions among the group members.

5. Listen to others. Give everyone a chance to speak and be heard. If you have a question for a group member, don't hesitate to ask the person to elaborate more on a specific point. Also, be aware that some people may not be as assertive as others and may take time to come forward with their thoughts.

6. Speak up. Don't hesitate to engage in the Study Circle discussion; however, be sensitive that you do not monopolize the discussion. Encourage others to participate and express their points of view.

7. Don't withdraw from the group. Each person in the Study Circle brings unique skills and experiences to the topic. It's important to draw on these experiences during the Study Circle sessions. Not participating keeps the whole group from learning what you know. 
8. Friendly disagreement. Conflict among participants is not discouraged. We all learn when people disagree and share their opinions with the group. Ideas can be challenged and individuals can be the catalyst in the group for bringing up new ideas. However, it is important that group emotions not get out of hand.

9. Humor. Your personality is key is the group participation. If humor can be used to lighten up a session, it is encouraged. Be aware of your body language and the body language of others.

10. Keep an open mind. Your participation is appreciated when you come to each Study Circle with an open mind to learn and engage others. Don't hesitate to engage others in a dialogue about points that may need clarification or an idea that you may want to discuss.

11. Evaluate critical faculties. Think about what is being said in the sessions. It's important for you to keep a critical eye on statements made by authors of readings, the leader/facilitator, or other participants. Don't allow yourself to be intimidated by false assertions.

12. Understand the people who you may disagree with you. Its important to understand another person's point of view, before outwardly criticizing that individual. They usually have a very good reason why they do not see a situation the same way you do. If you show empathy and understanding, many times your point of view will be heard with a different ear.

Adapted from The Study Circle Handbook: A manual for Study Circle discussion leaders, organizers and participants. Topsfield Foundation, Inc., (1993) 


\section{STUDY CIRCLE AS AN EDUCATIONAL PROCESS EMPLOYEES RETURNING TO THE WORKPLACE AFTER A TRAUMATIC LIFE EXPERIENCE}

CURRENT SITUATION: Violence and trauma cost U.S. business over 4 billion annually. Much is written on how to observe and report warning signals of potential outbursts, and most organizations provide or recommend some form of psychotherapy--personal counseling or Group work--for such trauma survivors. But what is not available is training for managers on how to deal with returning employees who have undergone a traumatic life experience (TLE), whether in the workplace or elsewhere. With the rise of violent incidents, more assistance is needed on how to manage such employees and ways to educate supervisors and managers to work with such traumatized employees.

PARTICIPANTS: Employees, Managers and Supervisors.

PURPOSE: To help managers and supervisors deal effectively with an employee returning to work after having survived a TLE.

DEFINITION: A Traumatic Life (TLE) refers to a single overwhelming traumatic incident, such as a suicide or sudden death of a loved one, rape, witnessing a murder, bombing, break-in, heldup, robbery, serious accident, bypass or other major surgery, divorce, job demotion, major financial loss, etc.

A TLE in contrast with a Chronic Traumatic Condition, whether of self or of a loved one, such as continual abuse, alcoholism, drug addiction, terminal illness, etc. This Study Circle is not designed for helping employees in chronic traumatic conditions.

OBJECTIVES: After the Study Circle, participants will be able to:

o recognize a TLE and its effects.

o identify stages of the trauma healing process.

o communicate helpfully with a returning TLE employee.

o coach co-workers in creating an appropriate workplace atmosphere to foster the healing process.

NOTE: This Study Circle is not a psychological process but an educational one, teaching managers how to cooperate with the TLE employee's psychotherapeutic process. It is not teaching managers to be psychologists, but simply how to talk and act with a TLE employee in such a way that their healing process is helped, not hindered.

STUDY CIRCLE PROCESS: Participants achieve the objectives of the Study Circle by studying appropriate texts, sharing personal experiences in the group and discussing in depth questions posed by the facilitator. 


\section{STAGES OF THE HEALING PROCESS FOLLOWING A TRAUMATIC LIFE EXPERIENCE (TLE)}

According to Judith Lewis Herman in her book Trauma and Recovery (1992), recovery happens best and most effectively for trauma survivors when they can return to their jobs and begin to work and relate normally and effectively. Their path to recovery and healing can best be achieved if managers can contribute to the following three stages of the healing process:

1. Establish a safety net for the individuals who suffered the TLE.

2. Allow them to reconstruct and retell their trauma story.

3. Restore the connection between the survivor and their community, namely their co-workers.

\section{Characteristics of Returning TLE Employees}

When TLEs return to the workplace they express an inability to concentrate on work because of the trauma they have experienced. Often, they prefer to be alone and work alone. In general, men tend to lose themselves in their work and repress their feelings, while women are more aware of how they were wounded by the experience and are able to talk about their feelings.

\section{Tasks of Returning TLE Employees}

When TLE employee are returning to the workplace, they must first of all reacquaint themselves with their workplace as if it were a new environment. Second, because they have experienced a trauma, they must accept that their energy level for work productivity maybe lower than that of a normal employee. Third, TLE employees will probably already be in counseling trying to cope with their loss and may feel unable to truly function as normal people would.

\section{Treatment From Others of Returning TLE Employees}

Managers often find it difficult to cope with a returning TLE. Managers say they do not know what to say or do when the individual returns to the workplace. Even though most managers try to talk to the returning TLE employee, their organizations usually do not offer preparation, training, guidance or in-house support for such managers.

Workplaces are likely to go into a turmoil when hearing of the TLE's trauma, and managers, unprepared themselves, find it difficult coaching co-workers when the TLE returns to the workplace. Managers may want to create a trusting environment for the TLE, but for many this is a new and confusing experience.

\section{Tasks for Others Regarding Returning TLE Employees}

Each of the three Study Circle Sessions will focus on one of the three healing stages, as outlined by Herman. The purpose of each session will be to recognize the dynamics of that stage and how managers and co-workers can best facilitate the healing process related to that stage. 


\section{EVALUATION FORM}

Please take a few minutes to read and answer the following questions as honestly as possible. You do not need to sign your name to this form. Thank you for your time.

1. How has the Study Circle affected your attitudes and beliefs about traumatic life experiences?

2. How has the Study Circle affected your ability to communicate with and manage employees returning to work after a traumatic life experience?

3. After participating in the Study Circle, what ideas or approaches would you take back to the workplace?

4. What parts of the Study Circle did you consider most significant or helpful to you personally and/or professionally?

5. What is the most important quality a manager should have to assist a returning TLE?

6. Name one resource the workplace needs to assist a returning TLE employee?

7. List in order of importance (1-3) which of the three Study Circle themes you considered most significant. (1) lowest (3) highest.

(__ Establishing a safety net for the re-entry person.

(_ Telling the trauma story.

(_) Reconnecting to the workplace.

8. Did the Pre-Study Circle interview assist you in participating in the Study Circle? Is so, how?

9. Which age group are you in?
Under 18
$18-29$
30-44
45-64
65- and over

10. What is your sex?

What is your grade level?
Male
Female
SES
GS-15

11. What is your job title? How long have your worked for the Department of Health and Human Services?

12. Manager Question: Approximately how many TLE employees have you had to supervise in your years as a manager? 
13. What would you change to improve the effectiveness of the Study Circle?

14. Additional Comments:

The foregoing information will be used for research purposes.

Names will not be used.

Thank you for your cooperation. 


\section{REFERENCES}

Aicher, P.J. (1990). The study circle experience in Sweden compared with the United States. Journal of the Folk Education Association of America, 15 (2), 17-23.

Baron, S. A. (1993). Violence in the workplace: A prevention and management guide for business. Ventura, Ca: Pathfinder Publishing.

Bass, E., \& Davis., L. (1988). The courage to heal. New York: Harper Perennial.

Bathrop, R.W. (1977, April). Depressed lymphocyte function after bereavement. Lancet, p.p. 834-36.

Beck, A. T. (1972). Depression: Causes and treatment. In Feeling good: The new mood therapy. New York: Signet New American Library. (p 3).

Benson, H. (1996). Timeless healing: The power and biology of belief. New York: Scribner.

Blid, H. (1990). Study circle: Education by the people. Stockholm: Artetarnas BiildungsForbund.

Bowlby, J. (1969, 1973, 1980). Attachment and loss. No. (Vols I-III). New York, Basic Books.

Bradshaw, J. (1992). Creating love: The next great stage of growth. New York: Bantam Books.

Brevskolan (1980). The study circle: A brief introduction. Stockholm,

Braverman, M., \& Braverman, S.R. (1994, May). Seeking solutions to violence on the job. USA Today, pp. 29-32.

Bridges, W. (1994). Jobshift: How to prosper in a workplace without jobs. New York: Addison-Wesley Publishing.

Bridges, W. (1988). Surviving corporate transition. New York: William Bridges and Associates.

Broome, B.J. (1991). Building shared meaning: Implications of a relational approach to empathy for teaching intercultural communication. Communication Education, 40, 235-250.

Burns, D. (1980). Feeling good: The new mood therapy. New York: Signet Publishing. 
Bystrom, J. (1976). All study circles are not study circles. In Stockholm, Sweden: Report of the Institute of Pedagogy of Stockholm University. (pp. 303-313.)

Carkhuff R. (1993). The art of healing. Amherst, Ma.:Human Resources Development Press.

Christensen, W. (1983, November). Study circles: Learning in small groups. Journal of Specialists in Group Work 8, 211-217.

Corey, M.S. \& Corey, G.(1997). Groups: Process and practice. New York: Brook Cole Publishing Co.

DeCarlo, D., \& Gruefeld, D.(1989). Workplace alternative for the working wounded. LRP: Fort Washington, Pa.

Doss, J. (1993, September). Strategies for coping with workplace depression. In Black Enterprise, pp.1-5.

Downs, A. (1995). Corporate executions. New York: American Management Association.

Egan, G. (1990). Exercises in helping skills: A training manual to accompany The skilled helper. Pacific Grove, California: Brooks/Cole Publishing Company.

Engel, G. (1961). 'Is grief a disease: a challenge for medical research', Psychosomatic Medicine 23, 18-27.

Egendorf, A. (1985). Healing from the war-trauma and transformation after vietnam. Boston: Shambhala Publications.

Erikson, E. H. 91968). Childhood and society, New York: W.W. Norton.

Fairhurst, G.R. (1996). The art of framing: Managing the language of leadership. San Francisco: Jossey Bass.

Fitzgerald, H. (1994). The mourning handbook: A complete guide for the bereaved. New York: Simon \& Schuster.

Freud, S. (1940). Trauer and melancholi, 10.

Gibb, J.R. (1961). Defensive communication. Journal of Communication 11, 141148. 
Glassner, B. (1994). Career crash: The new crisis and who survives. New York: Simon \& Schuster.

Golden, T. (1996). Swallowed by a snake: The gift of the masculine side of healing. Kensington, Maryland: Golden Healing Publishing.

Gould, J.E. (1961). The Chautauqua Movement: An episode in the continuing American revolution. New York: State University of New York.

Greenstone, J., \& Leviton, S. (1993). Elements of crisis intervention: Pacific Grove, CA: Brooks/Cole Publishing Co.

Herman, J. L. (1992). Trauma and Recovery. New York: Basic Books.

Hornestay, D. (July, 1996). Reconsidering downsizing., Government Executive. Washington, DC.

Humphrey, J.W. (1977). Cited in L. LeShan's You can fight for your life: Emotional factors in the causation of cancer in P.B. Medawar (Ed), New York review of books, 24.

Janoff-Bulman, R. (1993). Shattered assumptions. New York: The Free Press, A Division of MacMillan.

Jarvis, P. (1987). Adult learning in social context. London: Groom Helm.

Johannesen, R. L. (1990). Ethics in human communication. (3rd. ed). Prospect Heights, Il: Waveland.

Kassorla, I. (1986). How to be a total person: Putting it all together. New York: Warner.

Kennedy, E., \& Charles, S.C. (1990). On becoming a counselor: A basic guide for nonprofessionals. New York: Continuum.

Kleinfield, N.R. (1996). The company as family no more. In The New York Times. New York: Random House.

Kroeger, O., \& Thuesen, J.M. (1992) Type talk at work. New York: Delacorte Press.

Kubler-Ross, E. (1969). On death and dying. New York: Macmillan. 
Kurland, N.D. (1982, February). The Scandinavian study circle: An idea for the U.S. The college board review (Winter 1979-80). 5.PP Reprinted in Lifelong learning: The adult years. (February 1982): 24-30.

Leick, N., \& Davidsen-Nielsen., M. (1993). Healing pain: Attachment, loss and grief therapy. London: Routledge.

Levine, S.L. (1994). Study circles: A mode of learning for older adults in the community college setting. Unpublished doctoral dissertation. Columbia University..

Lindeman, E., (1995). Crisis intervention. London: Jason Aronson.

Lumsden, G., \& Lumsden, D. (1993) Communication in groups and teams: Shared leadership. Belmont, Ca: Wadsworth Publishing Co.

Mackay, H. (1997). Dig your well before you're thirsty: The only networking book you will ever need. New York: Currency Doubleday.

Mantell, M. (1994). Ticking bombs: Defusing violence in the workplace. New York: Irwin.

McCracken, G. (1988). The long interview. London: Sage Publications.

Merriam, S., \& Caffarella, R.S. (1991). Learning in adulthood. San Francisco: JosseyBass.

Meyer, G.J. (1995). Executive blues: Down and out in corporate America. New York: Dell Publishing.

Miles, M.B., \& Huberman, A.M. (1994). Qualitative data analysis. London: Sage Publications.

Miller, A. (1986). Thou shalt not be aware: Society's betrayal of the child. London: Pluto.

Mitchell, J. (1988, December) Stress: Development and Functions of a critical incident stress debriefing team. Jems.

Napier, R.W., \& Gershenfeld, M.K. (1987). Groups: Theory and practice. Boston: Houghton, Mifflin Company. 
Newman, K. S. (1988). Falling from grace: The experience of downward mobility in the American middle class. New York: The Free Press, Division of McMillan.

Noer, D. M. (1993). Healing the wounds: Overcoming the trauma of layoffs and revitalizing downsized organizations.(1993). San Francisco: Jossey Bass.

Oliver, L. (1987). Study Circles Coming together for personal growth and social change. Washington, DC: Seven Locks Press.

Oliver, L. (1995, March/April). Is the United States ready for a study circle movement? Adult Education, pp. 14-19.

Oliver, L. (1990, November). Study Circles: A new life for an old idea. Advocacy. pp.20-22.

Osborne, K. O. (1991). Informal learning and public policy issues: The study circle approach. In Harold Stubblefield (Ed), New directions for continuing education for community leadership.(pp. 73-80).

Osborne, K. O., \& Shevat, R. (1982, June). Study circles: Personal professional fulfillment for employees.Management Review, pp. 37-42.

Parkes, C.M. (1972). Bereavement: Studies of grief in adult life. London: Tavistock.

Perlman, H. (1983). Relationships: The heart of helping people. Chicago: Jossey-Bass.

Piper, W.E., McCullum, M., \& Azim, H. (1992). Adaptation to loss through short-term group psychotherapy. New York: The Guilford Press.

Powell, G.N, (1988). Women and men in management. London: Sage Publications.

Ramsay, R.W. (1979). "Bereavement: A behavioral treatment of pathological grief." In P.O. Sjuden, S.Bates \& W.S. Dockens (Eds) Trends in behavior therapy, No. (pp.217-248) New York: Academic Press.

Rubin, H.J., \& Rubin, I.S. (1995). Qualitative interviewing: The art of hearing data. London: Sage Publications.

Seyle, H. (1956). The stress of life: New York: McGraw Hill

Schneider, J. (1984). Stress, loss and grief, Baltimore,Maryland: University Park.

Schwarz, R.M. (1997). The skilled facilitator: Practical wisdom for developing effective 
groups. San Francisco: Jossey Bass.

Sheehy, G. (1976). Passages. New York: Bantam Books.

Silberman, M. (1990). Active training: A handbook of techniques, designs, case examples \& tips. New York: Lexington, Books.

Simonton, O.C., (1978). Getting well again. Los Angeles: J.P. Tarcher.

Slaby, T. (1989). Aftershock: Surviving the delayed effects of trauma, crisis and loss. New York: Villard.

Smith, T. (1996, July) The bombing of the Oklahoma city federal office building: Its aftermath and the office of the inspector general. Unpublished Manuscript.

Sobel, D.S. (1994). RX: Surviving traumatic experience. Mental Medicine Update. 3. (1), 3-6.

Staff, (1994). Planning is best weapon against workplace violence. LRP publications: Federal human resources week. pp. 185.

Stake, R. E. (1995). The art of case study research. Thousand Islands, CA: Sage Publications.

Stubblefield, H. W. and Keane, P. (1994). Adult education in the american experience: From the colonial period to the present. San Francisco: Jossey-Bass.

Stubblefiled, H.W. (1981). Helping communities through continuing education. New dimensions for continuing education: Continuing education for community leadership. 11, 117-122.

Strauss, G. (1991, April). When workers grieve: The high cost of losing a parent.USA Today, pp. 1-2.

Swett, L. (1979, February). The study circle: An idea whose time has come to the United States. New York State Educational Department College Board and Rockland, Community College, p.28.

Tatelbaum, J. (1980). The courage to heal. New York: Harper \& Row.

Tedeschi, R.G., \& Calhown, L.G. (1995). Trauma and transformation: Growing in the aftermath of suffering. London: Sage. 
Tomasko, Robert M. (1990). Downsizing: Reshaping the corporation for the future. New York: American Management Association.

Tyler, M. (1996). A manager's handbook: Handling traumatic events. (Contract No. HRSS-OERWP-15). Washington, DC. Office of Personnel Management.

Uchetelle, L. (1996).The price of jobs lost. In The New York Times: The downsizing of America. New York: Random House.

Ulman, R.B., Brothers, D. (1988). The shattered self: A psychoanalytic study of trauma. Hillsdale, New Jersey: The Analytic.

Viorst, J. (1986). Necessary Losses. New York: Simon and Schuster.

Viscott, D. (1992). Emotionally free: Letting go of the past to live in the moment. Chicago: Contemporary Books.

Ward, E. (1995). Good grief: Exploring feelings of loss and death with under elevens. London: Jessica Kingsley.

Yalom, I.D. (1995). The theory and practice of group psychotherapy. New York: Basic Books.

Yin, R. K. (1994). Case study research: Design and methods. London: Sage Publications.

Zunin, L., \& Zunin H.S. (1991). The art of condolence: What to write, what to say, what to do at a time of loss. New York: HarperCollins. 
APPENDIX A: A Model for the Learning Process

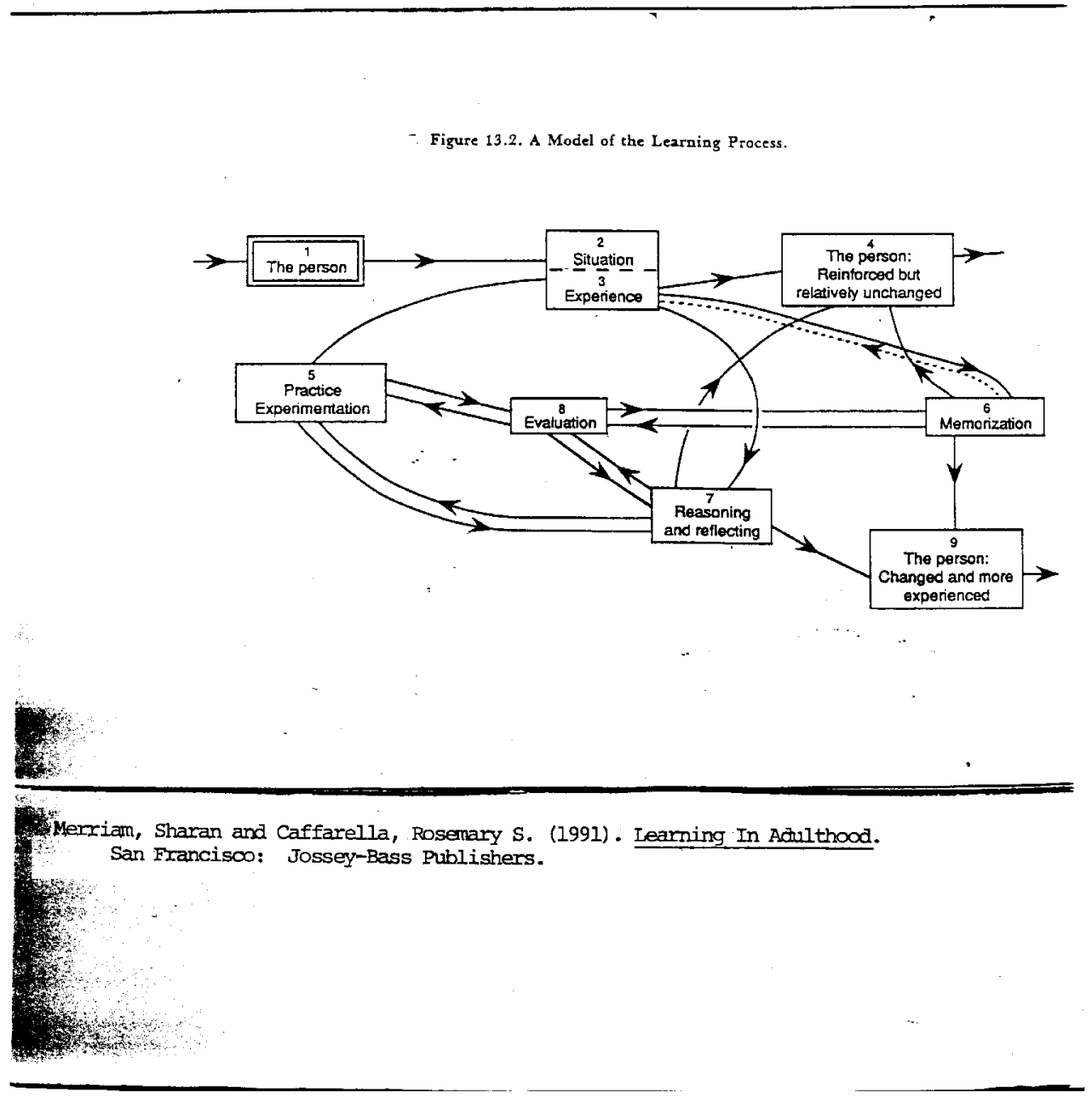




\section{APPENDIX B \\ The Eight Principles of Study Circles}

1. The principle of equality and democracy.

2. The principle of liberation.

3. The principle of cooperation and companionship.

4. The principle of the freedom of the Study Circle and its right to set its objective.

5. The principle of continuity and planning.

6. The principle of participation.

7. The principle of printed study material.

8. The principle of change and action.

\section{Four approaches for Study Circles}

1. The thematic circle approach.

2. The course circle approach.

3. The debate circle approach.

4. The research circle approach.

Henry Blid. Education By The People--Study Circles, Tryckeri AB Primo, Oskarsh 


\section{APPENDIX C \\ LETTER OF INVITATION FOR PARTICIPANTS}

Dear Participant,

I would like to invite you to participate in my dissertation research project entitled USING STUDY CIRCLES IN THE WORKPLACE AS A METHOD OF FACILITATING A READJUSTMENT AFTER A TRAUMATIC LIFE EXPERIENCE. I hope I can count on you to continue the conversation we started a few months ago.

I have long been professionally interested in creating positive workplace environments within organizations. My research project will focus on a unique and important workplace issue, namely how to effectively assimilate Traumatic Life Experience (TLE) employees who are returning to their jobs. Dealing with individuals returning to the workplace after having experienced a trauma poses a unique dilemma to organizations and, in particular, to the managers who must assist the TLE employees make the transition as smoothly, effectively and quickly as possible.

As I mentioned to you, Study Circles will be used in my research project. Study Circles have been used successfully in education for over 100 years. In as Study Circle, about 10-12 people meet several times to discuss topics of interest relative to their social, political and cultural interests. Complex issues are broken down into manageable discussion points and controversial topics are discussed in depth.

I would appreciate your participation in a series of three Study Circle sessions on TLE employees. Each session will be two hours long with a mix of managers and employees in each group. I will discuss with each participant the scheduling of the Study Circles. It is important that you participate in all three Study Circle sessions. The schedule follows:

Group A

Theme Date $\quad \underline{\text { Time }}$

Establishing a Safety Net

Telling the Trauma Story

Reconnecting to the Workplace
Month, 1997

Month, 1997

Month, 1997
11:30 a.m. - 1:30 p.m.

11:30 a.m. - 1:30 p.m.

11:30 a.m. - 1:30 p.m. 
Group B

Theme Date $\quad \underline{\text { Time }}$

Establishing a Safety Net

Telling the Trauma Story

Reconnecting to the Workplace
Month, 1997 11:30 a.m. - 1:30 p.m.

Month, 1997 11:30 a.m. - 1:30 p.m.

Month, 1997 11:30 a.m. - 1:30 p.m.

We will meet in Room for all sessions.

One of the best aspects of Study Circles is that expertise on the topic under discussion is not necessary. Rather, Study Circles are a vehicle through which people like you and I can bring the experience of ordinary employees to bear on important workplace issues. All that you need is a willingness to participate in the discussions and to really want to hear what others have to say. I can promise you the discussions will be spirited, cordial, informative and -- best of all -- fun!!

I will contact you in a few days to talk to discuss any questions you may have and deliver materials for our first Study Circle session. If you have any questions, please call me on (202) 619-3677.

Sincerely,

Barbara Barski-Carrow

Adapted from a Study Circle program in Glen Ridge, New Jersey. 


\section{APPENDIX D \\ CONFIDENTIALITY AGREEMENT}

I, (Participant), as a condition of participating in the Study Circles being conducted by Barbara Barski-Carrow at (Location)

(Dates) and

1997, hereby agree that I will not, directly or indirectly, divulge or otherwise make known to any person or entity any information of any type disclosed by other participants during the course of the Study Circle.

I understand that any information disclosed by Participants in the Study Circles is personal and confidential in nature, and that any information that I may provide during the course of the Study Circles will be treated as such by all other participants each of whom will be required to sign a Confidentiality Statement identical to this one as a condition of their participation in the Study Circles.

Notwithstanding the foregoing, I understand that the Study Circles will be videotaped, and that approximately 15 minutes of each tape will be shown in the course of a doctoral defense for Barbara Barski-Carrow during 1998. I hereby consent to use of the above-referenced videotapes, but only for the limited purpose and to the limited audience contemplated by this paragraph. I also understand that Barbara Barski-Carrow will write case studies based on interviews and the Study Circles which will be presented to her dissertation committee at such defense. I hereby consent to such use of the above-referenced case studies, on the understanding that such studies will preserve the anonymity of all participants.

Researcher/Leader:

Participant:

Printed Name of Participant:
Date

Date 


\section{APPENDIX E \\ Pre-Study Circles Interview Questions}

1. Did you have a personal experience with trauma? If so, how did you handle it?

2. Did you ever supervise a person who returned to the workplace after having experienced a trauma? If so, how did you handle it?

3. Did you ever have a co-worker who experienced a trauma and returned back to the workplace? What did you say to that person upon their return?

4. If an employee was returning to the workplace after having experienced a trauma, how did you behave toward that person?

5. Would you ask the returning employee to tell their trauma story?

6. Have you ever observed an employee telling their trauma story to anyone upon their return to the workplace?

7. How comfortable do you feel approaching or talking to a person who has just returned to work after having experienced a trauma?

8. Do you know what to say to a returning TLE?

9. What approach would you use if you had to communicate your expectations to the person who is returning to the workplace after having experienced a trauma?

10. How would you go about explaining to your staff the importance of greeting and talking with the person who is returning to the workplace after their trauma?

11. How would you go about assisting the returning TLE participate in office activities?

12. What would you do if you had to set limits with a returning TLE when he/she returns to work (e.g. lateness/tardiness)?

13. How would you respond to a TLE who refuses to work and begins to have emotional outbursts?

14. How would you present work assignments and expectations of productivity to the returning TLE?

15. Do you think gender plays a role in dealing with a returning TLE? Do women behave differently than men when they return to the workplace? 


\section{APPENDIX F \\ THE STUDY CIRCLE AS AN EDUCATIONAL PROCESS EMPLOYEES RETURNING TO WORK AFTER A TRAUMATIC LIFE EXPERIENCE}

CURRENT SITUATION: Violence and trauma cost U.S. businesses over $\$ 4$ billion annually. Much is written on how to observe and report warning signals of potential outbursts, and most organizations provide or recommend some form of psychotherapy--personal counseling or Group work--for such trauma survivors. But what is not available is training for managers on how to deal with returning employees who have undergone a traumatic life experience (TLE), whether in the workplace or elsewhere. With the rise of violent incidents, more assistance is needed on how to manage such employees and ways to educate supervisors and managers to work with such traumatized employees.

PARTICIPANTS: Employees, Managers and Supervisors.

PURPOSE: To help managers and supervisors deal effectively with an employee returning to the work after having survived a TLE.

DEFINITION: A Traumatic Life Experience (TLE) refers to a single overwhelming traumatic incident, such as a suicide or sudden death of a loved one, rape, witnessing a murder, bombing, break-in, hold-up, robbery, serious accident, bypass or other major surgery, divorce, job demotion, major financial loss, etc.

A TLE is in contrast with a Chronic Traumatic Condition, whether of self or of a loved one, such as continual abuse, alcoholism, drug addiction, terminal illness, etc. This Study Circle is not designed for helping employees in chronic traumatic conditions.

OBJECTIVES: After this Study Circle, participants will be able to:

o recognize a TLE and its effects. 0 identify stages of the trauma healing process. o communicate helpfully with a returning TLE employee. o coach co-workers in creating an appropriate workplace atmosphere to foster the healing process. 
NOTE: $\quad$ This Study Circle is not a psychological process but an educational one, teaching managers how to cooperate with the TLE employee's psychotherapeutic process. It is not teaching managers to be psychologists, but simply how to talk and act with a TLE employee in such a way that their healing process is helped, not hindered.

STUDY CIRCLE PROCESS: Participants achieve the objectives of the Study

Circle by studying appropriate texts, sharing personal experiences in the group and discussing in depth questions posed by the leader.

\section{STAGES OF THE HEALING PROCESS FOLLOWING A TRAUMATIC LIFE EXPERIENCE (TLE)}

According to Judith Lewis Herman in her book Trauma and Recovery (1992), recovery happens best and most effectively for trauma survivors when they can return to their jobs and begin to work and elate normally and effectively. Their path to recovery and healing can best be achieved if managers can contribute to the following three stages of the healing process:

1. Establish a safety net for the individual who suffered the TLE.

2. Allow them to reconstruct and retell their trauma story.

3. Restore the connection between the survivor and their community, namely their co-workers.

\section{Characteristics of Returning TLE Employees}

When TLEs return to the workplace they express an inability to concentrate on work because of the trauma they have experienced. Often, they prefer to be alone and work alone. In general, men tend to lose themselves in their work and repress their feelings; while women are more aware of how they were wounded by the experience and are able to talk about their feelings.

\section{Tasks of Returning TLE Employees}

When TLE employees are returning to the workplace, they must first of all reacquaint themselves with their workplace as if it were a new environment. Second, because they have experienced a trauma, they must accept that their energy level for work productivity maybe lower than that of the normal employee. Third, TLE employees will likely be in professional counseling trying to cope with their loss and may feel unable to truly function in a "normal manner."

\section{Treatment From Others of Returning TLE Employees.}


Managers often find it difficult to cope with a returning TLE . Managers say they do not know what to say or do when the individual returns to the workplace. Even though most managers try to talk to the returning TLE employee, their organizations usually do not offer preparation, training, guidance or in-house support for such managers.

Workplaces are likely to go into a turmoil when hearing of the TLE's trauma. Managers, unprepared themselves, find it difficult coaching co-workers when the TLE returns to the workplace. Managers may want to create a trusting environment for the TLE, but for many this is a new and confusing experience.

\section{Tasks For Others Regarding Returning TLE Employees}

Each of the three Study Circle Sessions will focus on one of the three healing stages, as outlined by Herman. The purpose of each session will be to recognize the dynamics of that stage and how managers and co-workers can best facilitate the healing process related to that stage.

\section{STAGE ONE \\ ESTABLISH A SAFETY NET}

According to Dr. Herman's approach, the first stage in fostering the recovery process of the TLE employee would be for the manager and co-workers establish a safety net in the workplace for the individual returning to work after a traumatic life experience.

Usually when TLEs return to the workplace, they are anxious and ambivalent about how they will be seen and treated by their co-workers. Consequently, they may not want to socialize with fellow employees and feel they don't belong to the organization. Outside work, they are usually seeing a social worker or therapist for depression, may be taking some medication.

TLEs are not sure how to behave in situations where they previously had been confident. Because they have difficulty sleeping and concentrating, these effects are seen in the workplace as an inability to complete tasks they could easily do before the trauma. They feel unsafe everywhere and they tend to have little control over their emotions and reactions. After a trauma, some may want to go into seclusion. Their old reality seems broken and nothing feels solid anymore.

Usually, there is little or no support from organizations when TLE employees return to the workplace. Managers and co-workers are confused and uncomfortable relating to the returning TLE.

\section{DISCUSSION QUESTIONS:}

1. What would it mean to you to establish a safety net in your workplace environment for the returning TLE employee? What would constitute a safety net? How would you act to establish a safety net? How would you encourage co-workers to act? What would you 
tell them to do? Not to do?

2. What would it look like in your workplace if it was emotionally "unsafe" for returning TLE employees? How might you expect co-workers to speak and act to make it "unsafe" for a returning TLE survivor?

3. In your workplace, what are the current typical reactions of co-workers to returning TLE employees? What are your typical reactions to such returning employees? Are you or the co-workers especially nervous or uncomfortable in adjusting to the returning TLE employee?

4. What kinds of questions might you ask the returning employee to find out what would make them feel safe? Do you think the following questions to the TLE employee would help? Why or why not? If not, how might you change or restate the question?

o Are you especially nervous or uncomfortable in readjusting to the workplace?

o Are you consulting a therapist or mental health worker in dealing with your emotions and self-esteem?

o What can I do to make your return to the workplace comfortable?

$o$ What can your co-workers do to assist you?

o Is the work schedule we have arranged for you flexible enough?

o Do you have any special requests of me or the organization?

o Are you aware of the resources in the organization that can assist your return to the workplace? (Employee Assistance Program etc.)

\section{STAGE TWO \\ RETELL THE TRAUMA STORY}

According to Dr. Herman's approach, the second stage in fostering the recovery process of the TLE employee would be that the manager and co-workers allow the survivor to reconstruct and retell their trauma story.

TLEs find it difficult to reconstruct the trauma after it has occurred. Even though it would be psychologically helpful for them to talk about their trauma, they are reluctant to do so and do find themselves avoiding people who would encourage them to talk. Some may be tempted to turn to drinking or brooding, blaming themselves for the traumatic incident. Depending on the trauma, survivors may feel degraded, shamed, humiliated, helpless, isolated, pain, fear, rage, etc. There is much emotional turbulence.

\section{DISCUSSION QUESTIONS:}


1. What would it mean to you to "allow" the returning TLE employee to tell his or her trauma story? What would you do if the TLE employee said he or she wanted to be left alone?

2. Are there ways you could, verbally or nonverbally, "not allow" the employees to tell the trauma story? How could you hinder or stop this process? Do you sometimes feel you would rather not hear the trauma story?

3. Are there ways you could allow the employee to tell the trauma story that would not be helpful in the employee's healing? What if you didn't empathize with the employee but just wanted to hear the gory details? What if in telling the story, you denied the employee's expressed feelings, or told him what he should have done, or disapproved of his behavior during or after the trauma?

4. Do you know how to exhibit "active listening skills" with a TLE employee?

\section{STAGE THREE RESTORE THE CONNECTION}

According to Dr. Herman's approach, the third stage in fostering the recovery process of the TLE employee would invite the manager and co-workers to restore the connection with the survivor.

Survivors feel disorganized, disoriented and disconnected. Their sense of trust is severely weakened, their sense of control over things is shaken, their connection to others is infected with mistrust. For some, their life meaning falls apart and they question their fundamental beliefs.

Usually co-workers are unable to understand the unusual behavior of a TLE and show very little support toward him/her. Co-workers do not know how to treat the TLE. They expect the TLE to have gone for counseling and to have gotten "straightened out" before returning to the job. Just as TLEs themselves have difficulty reconnecting with the organization, co-workers are not sure what to do, how to relate to them or suggest where they can go for assistance.

\section{DISCUSSION QUESTIONS:}

1. What are some of the kinds of "connections" that exist between managers and workers and between workers and co-workers? Can you list some of these "connections"?

2. How do people in the workplace re-establish such "connections: after they have been broken? How do people re-establish trust and confidence?

3. What kinds of questions might you ask the returning employee to help re-establish 
connections? Do you think the following suggestions to a manager would be appropriate and helpful? If not, how might you change or restate the suggestions?

o Demonstrate to the TLE employee that their status has not changed because of the trauma.

o Don't overload the TLE employee with work. Give no more than normal work assignments.

o Prepare a flexible work schedule for the returning TLE employee, and discuss their schedule and other needs with them.

$o$ Watch for signs of stress from the TLE employee.

4. Here are some questions that have been suggested for managers to ask co-workers in Re-establishing connections. Do you think they are helpful? Do you have any other suggestions for managers to ask co-workers?

o Is the employee participating in conversations with other co-workers?

o Is the employee socializing with others, e.g., going to lunch with them?

o Is the employee argumentative with others?

$o$ Is the employee having difficulty communicating with other, managers or co-workers? 


\section{APPENDIX G \\ EVALUATION FORM OF GROUP A STUDY CIRCLE SESSIONS}

Please take a few minutes to read and answer the following questions as honestly as possible. You do not need to sign your name to this form. Thank you for your time.

1. How has the Study Circle affected your attitudes and beliefs about traumatic life experiences?

2. How has the Study Circle affected your ability to communicate with and manage employees returning to work after a traumatic life experience?

3. After participating in the Study Circle, what ideas or approaches would you take back to the workplace?

4. What parts of the Study Circle did you consider most significant or helpful to you personally and/or professionally?

5. What is the most important quality a manager should have to assist a returning TLE?

6. Name one resource the workplace needs to assist a returning TLE employee?

7. List in order of importance (1-3) which of the three Study Circle themes you considered most significant. (1) lowest (3) highest.

(_) Establishing a safety net for the Re-entry person.

(_) Telling the trauma story.

(_) Reconnecting to the workplace.

8. Did the Pre-Study Circle interview assist you in participating in the Study Circle? Is so, how?

9. Which age group are you in?

_Under 18

10. What is your

Male

Female 18-29 $30-44$ $45-64$ 65- and over

11. What is your job title? How long have your worked for the Department of Health and Human Services?

12. Manager Question: Approximately how many TLE employees have you had to supervise in your role as a manager?

13. What would you change to improve the effectiveness of the Study Circle? 
14. Additional Comments:

The foregoing information will be be used for research purposes.

Names will not be used.

Thank you for your cooperation. 


\section{APPENDIX H \\ Evaluation Form of Pilot Study}

Please take a few minutes to read and answer the following questions as honestly as possible. You do not need to sign your name to this form.

Thank you for your time.

1. How has the Study Circle affected your attitudes and beliefs about traumatic life experiences?

2. How has the Study Circle affected your ability to communicate with and manage employees returning to the work after a traumatic life experience?

3. After participating in the Study Circle, what ideas or approaches would you take back to the workplace?

4. What parts of the Study Circle did you consider most significant or helpful to you personally and/or professionally?

5. List in order of important (1-3) which of the three Study Circle themes you considered most significant. (1) lowest (3) highest.

(__ Establishing a safety net for the re-entry person.

(_ Telling the trauma story.

(_ Reconnecting to the workplace.

6. Name up to three thoughts or ideas that you recall from the Study Circle interviews that assisted you in contributing to the group during the Study Circle sessions.

(1).

(2).

(3)

7. Which age group are you in?

Under 18

$18-29$

$30-44$

45-64

$65 \&$ over

8. What is your sex?

What is your grade level?

_male female

SES

GS14/15

9. How long have you worked in the Department of Health and Human Service? What is your 
job title?

10. Manager Question: Approximately how many TLE employees have you had to manage in your role as a manager?

11. What would you change to improve the effectiveness of the Study Circle?

12. Additional Comments:

The foregoing information will be used

for research purposes. Names will not be used.

Thank you for your feedback. 


\section{APPENDIX I \\ STUDY CIRCLE HANDOUTS}

\section{The Role of the Participant}

The participants in a Study Circle are the most important element of a Study Circle. Their commitment, eagerness and interest help make the Study Circle a success.

An important remember to know about the Study Circle is that textual material does not have to be memorized and participants do not have to learn a lot of facts. Rather encourage participants to focus on the interaction with each other and thereby gain a deep understanding of the topic through listening to their experience. The process -- an open democratic dialogue with colleagues -- is an important part of this experience.

The following points adapted from The Study Circle Handbook (1993) will assist those participating in a Study Circle:

1. Make a commitment to attend all Study Circle sessions. Each Study Circle creates its own culture and getting to know the people with whom who you will spend this time is part of the ongoing learning experience of a Study Circle.

2. Communicate your thoughts and feelings to others. Share your perceptions and suggestions with the group and ask for clarification of others' experiences when issues are not clear. Even though you may feel alone in your experience, you may be helping the group by sharing it.

3. Keep the discussion focused. Try not to bring in other ideas or topics that have no relevance to what is being discussed in your Study Circle. But don't hesitate to bring in relevant points for discussion.

4. Speak to the group. When addressing your remarks, address the entire group, not just the leader/facilitator. Feel free to engage directly in dialogue with other participants; everyone learns from interactions among the group members.

5. Listen to others. Give everyone a chance to speak and be heard. If you have a question for a group member, don't hesitate to ask the person to elaborate on a specific point. Also, be aware that some people may not be as assertive as others and may need time to come forward with their thoughts.

6. Speak up. Don't hesitate to engage in the Study Circle discussion; however, be sensitive that you do not monopolize the discussion. Encourage others to participate and express their points of view. 
7. Don't withdraw from the group. Each person in the Study Circle brings unique skills and experiences to the topic. It's important to draw on these experiences during the Study Circle sessions. Not participating keeps the whole group from learning what you know.

8. Friendly disagreement. Conflict among participants is not discouraged. We all learn when people disagree and share their opinions with the group. Ideas can be challenged and individuals can be the catalyst in the group for bringing up new ideas. However, it is important that group emotions not get out of hand.

9. Humor. Your personality is key is the group participation. If humor can be used to lighten up a session, it is encouraged. Be aware of your body language and the body language of others.

10. Keep an open mind. Your participation is appreciated when you come to each Study Circle with an open mind to learning and engaging others. Don't hesitate to engage others in a dialogue about points that may need clarification or an idea that you may want to discuss.

11. Evaluate critical faculties. Think about what is being said in the sessions. It's important for you to keep a critical eye on statements made by authors of readings, the leader/facilitator, or other participants. Don't allow yourself to be intimidated by false assertions.

12. Understand the people who you may disagree with you. Its important to understand another person's point of view, before outwardly criticizing that individual. They usually have a very good reason why they do not see a situation the same way you do. If you show empathy and understanding, many times your point of view will be heard with a different ear.

Adapted from The Study Circle Handbook: A manual for Study Circle discussion leaders, organizers and participants. Topsfield Foundation, Inc., (1993) 


\section{APPE NDIX J}

\section{HOW HAS THE STUDY CIRCLE AFFECTED YOUR ATTITUDES AND BELIEFS ABOUT TRAUMATIC LIFE EXPERIENCES?}

MANAGERS:

1. Yes.

2. Heighten my awareness that I should pay particular attention to employees that have or are going through some traumatic life experience. It also gave me some ideas as to how I should deal with various situations.

3. Better aware of the needs of people returning to normalcy

4. It has confirmed my belief that these experiences must be acknowledged and addressed.

5. It has enhanced my sensitivity toward TLEs.

6. Very beneficial - increased my understanding and provided me with some new and useful insights.

7. It reinforced my beliefs that it is a manger's responsibility to acknowledge that a traumatic life experience has occurred and help is appropriate, or work with the employee to seek appropriate help. This will help the employee to transition back to work.

8. Generally improved my awareness of it as a specific issue because we recognize it.

\section{EMPLOYESS:}

9. It has made me understand that I am not alone and that there are people who are worse off than I am.

10. Traumas take many forms. In dealing with a TLE, use common sense; treat a person like you would like to be treated.

11. It has shown me that there are many types of trauma but there seems to be a common tread, a sense of mourning is needed. A time to heal and rebuild. 


\section{HOW HAS THE STUDY CIRCLE AFFECTED YOUR ABILITY TO COMMUNICATE WITH AND MANAGE EMPLOYEES RETURNING TO WORK AFTER A TRAUMATIC LIFE EXPERIENCE?}

\section{MANAGERS:}

1. Will go out of my way to lend a sympathetic ear and listen, if nothing more.

2. Y es, I feel free to approach employees and let them know I am available to them.

3. "A bility" requires experience. Practice may provide ability and skill.I hope not to have to experience too much.

4. It has given me some concrete examples of what would be helpful and appropriate.

5. Y es, it has assisted in formulating a plan to interact with TLEs.

6. I would expect that the next time it occurred, I will be better equipped to respond.

7. I have already used this information to advise others who are involved with employees who have had a recent traumatic experience.

8. I hope that this will help me to deal with these situations forthrightly and directly (along with compassion).

\section{EMPLOYEES:}

9. It gave me several options. It made me understand that each person handles trauma in their own way. However, it made me think about how one person's trauma can change the atmosphere and attitudes of the team.

10. Be super-sensitive for TLE and realize that each situation is different.

11. It has given me some ideas and guidelines. It has validated my belief that there is a real need for managers to be able to recognize employees undergoing trauma and knowing how to handle/approach it. 


\section{AFTER PARTICIPATING IN THE STUDY CIRCLE, WHAT IDEAS OR APPROACHES WOULD YOU TAKE BACK TO THE WORKPLACE?}

\section{MANAGERS:}

1. Must balance drive for productivity with sensitivity of the trauma on an individual in the workplace.

2. Share this information with other managers and suggest that this issue be discussed in our manager meetings.

3. (left blank)

4. (1) acknowledge the trauma (2) communicate concern and availability (3) allow TLE space to discuss the trauma don't push and don't let this become disruptive (4) have a staff meeting and bring TLE up-to-date (5) be willing to negotiate with the TLE with respect to his/her assignments and (6) get clear understanding and agreement of expectations, e.g., time and attendance work and degree of flexibility.

5. Look for guidelines and other assistance programs to which the TLE could be referred.

6. M ost important is the need for supervisors to prepare themselves and their staff (individual co-workers) for the return of a TLE employee.

7. (1) discuss or offer to discuss (when an employee wants to talk is important) (2) there are different approaches for helping employees (3) a manager needs to know what resources are available.

8. Simply greater awareness and attentiveness.

\section{EMPLOYEES:}

9. (1) plan must be in effect before the person returns to work (2) plan must be flexible

(3) the entire team must be informed, via classes, on how to handle the situation.

10. Trauma cannot be ignored. A gain, each situation is different. Empathize with the TLE to the extent possible. Put yourself in that person's shoes. What would you want from employees and management in a similar situation?

11. A greater sensitivity to TLE employees. 


\section{WHAT PARTS OF THE STUDY CIRCLE DID YOU CONSIDER MOST SIGNIFICANT OR HELPFUL TO YOU PERSONALLY AND/OR PROFESSIONALLY?}

\section{MANAGERS:}

1. Concrete human experience of those who suffered a trauma, and the diversity of manager's response.

2. The discussion among the various attendees, sharing their experiences and how they dealt with the situations. Additionally, I thought the feedback you presented from the previous session was helpful.

3. To realize that others know as little as and need instruction too.

4. The entire exercise was helpful and instructive. I found reconnecting to the workplace and the "staff meeting" idea to be the most concrete discussions.

5. The group interaction.

6. For me, it was simply the sharing of actual traumas and individual responses to them.

7. Professionally, I thought that the discussion of balancing the employee's needs with the pressure to get the work done was valuable. Personally, listening to how others dealt with the traumas was helpful.

8. The interaction with a fine group of real live people - doing the best they can.

\section{EMPLOYEES:}

9. The telling of the trauma story by the people participating in the Study Circle.

Hearing their stores, how they handled it and what worked/did not work for them.

10. All of it was helpful, especially the last part of the third session when several people "opened up" and shared their experiences.

11. Telling the trauma stories. 
List, in order of importance (1-3) which of the three Study C ircle themes you considered most significant. (1) lowest (3) highest

ESTABLISHING A SAFETY NET FOR THE REENTRY PERSON - $\underline{\text { Score: } 21}$

MANAGERS:

$\underline{\text { EMPLOYEES }}$

1. J. 2

9. $\quad$ I. 3

2. C. 2

3. S. 3

10. J. 2

4. M. 1

11. R. 2

5. M. 1

6. A. 1

7. C. 1

8. M. 3

TELLING THE TRAUMA STORY - Score: 21

MANAGERS:

1. J. 1

2. C. 1

3. S. 1

4. M. 3

5. M. 2

6. A. 3

7. C. 3

8. M. 2

9. I. 1

10. J. 3

11. R. 1

RECONNECTING TO THE WORKPLACE - Score: 25

MANAGERS:

1. J 3

2. C. 3

3. S. 2

4. M. 2

EM PLOYEES;

$9 . \quad 1.2$

10. J. 1

5. M. 3

11. R. 3

6. A. 2

7. C. 2

8. M. 2 


\section{NAME UP TO THREE THOUGHTS OR IDEAS THAT YOU CAN RECALL FROM YOUR PRE-STUDY CIRCLE INTERVIEWS THAT ASSISTED YOU IN CONTRIBUTING TO THE GROUP DURING THE STUDY CIRCLE SESSIONS.}

MANAGERS:

1. J. -Remembering my experience with TLE's -L ooking back on my response to TLE employees

-L earning about the purpose of the study

2. C. -Sharing experiences -Having this Study Circle -Having this as part of management training

3. S. -Culture

-Gender difference -(left blank)

4. M. -What about the TLE who is very private?

-How did I cope with my own trauma?

-How could this benefit managers and employees?

5. M. -Experience with a Reentry person.

-M isconception about what should happen when dealing with a returning TLE -Group sessions in understanding other people's trauma.

6. A. -Recollection of details and sequence of events -F ocus on my response

-R eviewing responses of other individuals

7. C. -E mployees react to trauma differently

- $M$ anagers need to talk to employees about the trauma to the extent that the employee needs/wants to talk.

- I have experienced a trauma myself and have managed an employee who experienced traumas.

8. M. -Experience with life trauma

-A bility to talk about my trauma with strangers -(left blank) 


\section{EMPLOYEES:}

9. I. It made me begin to think about trauma in general terms -It made me remember the trauma of others -It made me begin to ask myself, "W hat would I do"?

10. J. -The importance of telling the trauma story -Probing questions about agency responses -(left blank)

11. R. -Goals for the Study -Probing questions about agency responses -(left blank)

\section{WHICH AGE GROUP ARE YOU IN?}

MANAGERS:

1. J.

2. C.

3. S.

4. M.

5. $M$.

6. A.

7. C.

8. M.
EMPLOYEES:
45-64
45-64
45-64
45-64
45-64
45-64
45-64
30-44

9. $45-64$

10. $45-64$

11. $45-64$

\section{WHAT IS YOUR SEX?}

\section{MANAGERS:}

1. J.

2. C.

3. S.

4. M.

5. M.

6. A.

7. C.

8. M.
$M$ ale

$M$ ale

$M$ ale

Female

$M$ ale

$M$ ale

Female

Female
EMPLOYEES:

9. I. Female

10. J. Male

11. R. Male 


\section{HOW LONG HAVE YOU WORKED FOR THE DEPARTMENT OF HEALTH AND HUMAN SERVICES?}

MANAGERS:

1. J. 25 Y ears - Director

2. C. $27 \mathrm{Y}$ ears - Director

3. $\quad$ S. $6 \mathrm{Y}$ ears - Executive Office to General Counsel

4. $\quad$ M. 20 Y ears - Supervisory Trial A ttorney

5. $\quad$ M. $8 Y$ ears - Director

6. A. 6 Y ears - Deputy Director

7. C. $8 Y$ ears - Financial $M$ anagement Specialist

8. $\quad$ M. 9 Y ears - Director

EMPLOYEES:

9. I. 2 years - A ssociate Director

10. J 16 years - Accountant

11. R. 17 years - $M$ anagement $A$ nalyst

\section{APPROXIMATELY HOW MANY TLE EMPLOYEES HAVE YOU HAD TO MANAGE IN YOUR YEARS AS A MANAGER?}

\section{MANAGERS}

1. J. 6

2. C. 4

3. S. 0

4. M. 3

5. M. 1

6. A. M ore than 5 in the early years (we did not recognize it as such)

7. C. 3 that I can recall and I was involved with a group of individuals with traumatic experiences

8. M. 0

\section{EMPLOYEES:}

9. I. $\quad 2$ (a fire destroyed her home - final stages of terminal illness)

10. J. (left blank)

11. R. (left blank) 


\section{WHAT WOULD YOU CHANGE TO IMPROVE THE EFFECTIVENESS OF THE STUDY CIRCLE?}

\section{MANAGERS;}

1. J. Nothing, I found the Study Circle excellent.

2. C. Add more employees to see how they feel about their managers so that managers can see prospective of employees.

3. S. (left blank)

4. M. I would like to know about the individual participants. To know are they a manager of an employee and have experience with or supervised a person with a trauma.

5. M. Maybe make individual assignments to individuals in the group within the Circle to encourage participation.

6. A. Nothing

7. C. More discussion of the symptoms and possible behaviors of employees who are the traumatized (from a professional prospective). M ore discussion of how the trauma affects not only the employee but others and possible solutions.

8. M. More flexibility on time. Sometimes we need more sometimes less.

\section{EMPLOYEES:}

9. I. Extend the number of meetings from 3 to 5 . It takes time to feel at ease with people with whom you are sharing a traumatic experience.

10. J. Nothing

11. R. Tell the stories in the first session so we know where each person is coming from. 


\section{ADDITIONAL COMMENTS:}

\section{MANAGERS}

1. J. I think your study will be useful to the managers of DHHS.

2. C. What do you do for an employee/manager who is dealing with an on-going trauma?

3. S. I found the people have the same difficulties and are race/ethnic neutral.

4. M. I enjoyed the exchange of ideas. I hope that this topic is covered in future supervisory courses.

5. M. Good idea - more group type approaches are needed.

6. A. Great job!!

7. C. This is a valuable offset -- the results should be provided to managers and organizations for their use.

8. M. I enjoyed the experience. Thanks for including me.

\section{EMPLOYEES:}

9. I. This is a very informative topic. Thank you for including me. I learned a lot.

10. J. It might be a better idea for the facilitator to bring everyone to the discussion for the second session; i.e., in regards to telling the trauma story. Several people did not tell theirs until late in the third sessions, and although those telling provoked positive discussions, I'm not certain, they told their stories.

11. R. (left blank) 


\section{APPENDIX K}

\section{WHAT IS THE MOST IMPORTANT QUALITY A MANAGER SHOULD HAVE TO ASSIST A RETURNING TLE?}

When a trauma occurs with a TLE, work is not the first thing that comes to mind, a recognition of the trauma would make for a better manager--a more sensitive and understanding manager.

Patience--do not expect too much too soon.

Knowing how important communication (including listening skills) are to the returning TLE.

Ability to communicate.

Observe, listen be aware that the person returning to the workplace has had a trauma in their life.

Understanding and communication.

Sensitivity to the needs of the employee and the ability to balance this with productive work.

Be willing to listen to the TLE and help the TLE help himself/herself.

Understanding and flexibility.

Truly caring for the returning TLE employee.

Empathy and good listening skills.

Sensitivity.

Ability to listen with empathy.

\section{NAME ONE RESOURCE THAT THE WORKPLACE NEEDS TO ASSIST A RETURNING TLE EMPLOYEE?}

(left blank)

Family Work Center at HHS.

Communication skills.

Employee Counseling Service.

Flexibility.

A resource for managers/supervisors.

Employee Assistance Program or something similar to assist supervisors and employees (TLEs) and co-workers.

Employee Assistance Program.

A place supervisors or employees can call to discuss their concerns.

A place the returning TLE can trust.

(left blank)

Employee Assistance Program.

Sensitive supervisors. 


\section{APPENDIX L}

Notes From Study Circle Discussion

\section{Retelling the Trauma Story}

Each person (TLE) has his/her own way of dealing with their trauma when they return to the workplace. Some individuals do not talk about their trauma while others "share" their trauma with everyone.

\section{Personality and Culture}

It is important to understand the personality and the culture of an individual when a TLE returns to the workplace after having experienced a trauma. For example, some individuals may have been brought up not to talk to anyone outside of the family. Both managers and co-workers should be sensitive to that employee and honor that for the returning TLE.

\section{Personality Type: Extroversion and Introversion}

We may find that some returning TLEs want to share their stories while others may not--what does a manager do to assist the returning employee?

-Acknowledge their presence when they come back to work.

-Suggestions to the employee would be--"I am glad your back to work, what can I do to help you?

-Have a "listening ear"--show the returning TLE that you are interested by practicing active listening skills.

-Body language plays a part here--watch for cues from the employee.

-If a person does not want to talk to you--suggest that they talk to a colleague or someone.

\section{Manager's Dilemma}

If an employee consistently talks about their trauma, what do you do? -If a person is taking up a lot of their co-workers time, the managers must intercede. Suggestions can be to see someone in the Employee Assistance Program (EAP) for counseling.

-Try to get the TLE back on track. Focus on the task that needs to be accomplished in a gentle way with some diplomacy and tact. 
-Give the employee options when he/she returns--try to understand that there are different types of trauma and the recovery process may be longer for a specific type of trauma.

-Timing is important. When the person returns to work how and when the manager approaches the TLE is important.

\section{What Organizations Need to Do}

-Guidelines/guideposts to assist managers in this area.

-Some type of structured program to carry this message.

-Managers have different types of personalities (i.e., some are outgoing, aloof and cool). Managers may need to understand themselves.

\section{Other Comments from the Group}

- "My trauma changed me"--we can use the wound and help someone else in their pain.

-Those managers who have experienced a trauma themselves state they felt they have a good understanding of what a TLE is experiencing when they return to the workplace. 


\section{VITA}

Barbara Barski-Carrow was born in Northeastern Pennsylvania (Mocanaqua). She received her formative schooling in Conyngham Township and graduated from Newport High School. She received an associate degree from the Wilkes-Barre Business College, and her Bachelor of Arts degree from Wilkes University, Wilkes Barre, Pennsylvania.

Upon moving to Washington, DC in 1973 she obtained a position with the Department of Interior (Office of Coal Research) which later merged with the Energy Research \& Development Administration (ERDA), which then formed the Department of Energy (DOE).

At DOE she worked in a number of management, administrative and technical positions.

In 1983, she received a Master of Arts degree from Georgetown University Liberal Studies Program focusing on Organizational Behavior and Management. Upon completion of this program she formed her own consulting practice in personnel, management and career counseling. She has designed, conducted and presented training programs, workshops and seminars for business organizations, professional associations, and government agencies.

She has served as an adjunct faculty member at Northern Virginia Community College (NOVA), Alexandria, Virginia Campus and Mount Vernon College in Washington, DC. She has been affiliated with The Women's Center, Vienna, Virginia as a Career Consultant and Instructor, and has been a guest lecturer at Georgetown University.

In 1987 she assumed a position in the Department of Health and Human Services (HHS) and was responsible for designing the Sexual Harassment Prevention Training for managers and employees in the Office of the Secretary. She has trained more than 1200 employees in headquarters and regional offices. In her current position as Equal Employment Specialist she is a senior consultant specializing in overall human resource issues and Equal Employment Opportunity conflict cases.

As part of her outreach in HHS she is a certified Instructor in Zenger Miller Frontline Leadership and a certified Myers-Briggs Instructor and Technologies for Creating Instructor.

As a result of her extensive research on trauma and grief, she serves as a consultant to managers in HHS on these issues.

Her professional affiliations include the Association for Death Education and 
Counseling(ADEC), and the Middle Atlantic Career and Counselors Association (MACCA). 